Helgoländer wiss. Meeresunters. 23, 485-534 (1972)

\title{
Vergleichende Untersuchungen zur Atmungsphysiologie euryhaliner Gammariden unter besonderer Berücksichtigung der Salzgehaltsanpassung
}

\author{
H.-P. Bulnheim \\ Biologische Anstalt Helgoland (Zentrale); \\ Hamburg 50, Bundesrepublik Deutschland
}

\begin{abstract}
Comparative investigations on the respiratory physiology of euryhaline gammarids with special reference to salinity adaptation. Metabolic rates were measured of the euryhaline amphipods Gammarus locusta (L.), G. oceanicus Segerstråle, G. salinus SpooNER, G. zaddachi SeXton, and $G$. duebeni LnLjeBorg at $15^{\circ} \mathrm{C}$ by means of flow-through polarographic respirometry. The relationships between oxygen consumption $(y)$ and body weight $(x)$, expressed by the equation $y=a \cdot x^{b}$, under the influence of two salinities (10\%o and $30 \%$ ) were investigated. The regression coefficients $(b)$, which describe the slopes of the regression lines, reveal significant differences for the salinities tested. Except for $G$. duebeni, higher values were obtained in $30 \%$ than in $10 \%$. In the five species, metabolism as a function of size is characterized by regression coefficients ranging from 1 to 0.6 . An interspecific comparison of the parameter $a$, representing the intercept on the $y$ axis, exhibits a decrease in oxygen requirements in the order G. locusta, G. oceanicus, G. salinus, G. zaddachi, G. duebeni. The respective values for $0.1 \mathrm{~g}$ (fresh weight) animals range from 17.1 to $7.1 \mathrm{~mm}^{3} \mathrm{O}_{2} / \mathrm{h}(30 \%$ ). Experiments on the alterations in metabolic rates following osmotic stress were designed to provide information on time course and capacity of adaptation to salinity. Depending on the salinity tolerances of the species, the responses after abrupt transfers from 10 to $30 \%$, 30 to $45 \%, 30$ to $10 \%$ and 10 to $3 \%$ were recorded. Changes from more concentrated to more dilute media induce less extensive alterations in respiratory rates and lead to faster adaptation to new salinity levels than transfers in the opposite direction. A new steady state of metabolic rate following salinity stress may be reached after 3 to about 30 hours. G. duebeni exhibits higher capabilities for compensatory adjustments than the other species. G. locusta was shown to be least capable of compensating for salinity changes. Oxygen consumption declines during starvation and attains a fairly constant level, reduced by ca. $15 \%, 20$ to 24 hours after the beginning of fast, as demonstrated in $G$. oceanicus by long-term experiments over 6 days. In adult individuals, activity metabolism exceeds standard rates by about $2^{1 / 2}$ to 3 times. Under basal conditions, distinct respiratory ventilation rhythms of pleopod beating may occur. In addition, the time course of respiratory alterations during moulting was measured. At exuviation, oxygen uptake increases the mean respiratory rates 2.2 to 3.9 times. Some physiological and ecological aspects are discussed, mainly with respect to salinity adaptation and the processes of osmotic and ionic regulation involved. Metabolic rates of gammarid species are compared and related to environmental requirements. The similarity in the functional responses of the sibling species G. zaddachi and G. salinus is emphasized.
\end{abstract}




\section{EINLEITUNG}

Im Bereich der Nord- und Ostsee treten mehrere sehr nahe miteinander verwandte Arten der Gattung Gammarus auf, die zum Teil auch Astuare und andere angrenzende brackige Gewässer besiedeln. $\mathrm{Zu}$ den an den deutschen Meeresküsten verbreiteten Species gehören Gammarus locusta (L.), G. oceanicus Segerstråle, G. salinus Srooner, G. zaddachi SeXton und G. duebeni LILJJEBORG. Obgleich morphologisch durch nur sehr wenige Merkmale getrennt, erweisen sich diese Flohkrebs-Arten in ökologischer Hinsicht zum Teil als deutlich voneinander differenziert. Diese Unterschiede dokumentieren sich besonders in der Toleranz und der Präferenz gegenüber dem Salzgehalt des Außenmediums, aber auch in einigen anderen Merkmalen.

Wegen der geringen strukturellen Unterschiede ist eine zweifelsfreie systematische Abgrenzung bei einigen der angeführten Arten lange Zeit in Frage gestellt gewesen. Abgesehen von $G$. duebeni, dessen taxonomische Eigenständigkeit unbestritten blieb, sind G. zaddachi, G. salinus und G. oceanicus zunächst als eine einzige Art unter der Bezeichnung G. zaddachi (SEXToN 1912), später als drei Unterarten - G. zaddachi zaddachi, G. zaddachi salinus und G. zaddachi oceanicus - geführt worden (SPOONER 1947, 1951, Segerstråle 1947). Durd Kinne (1954) sind die genannten Subspecies schließlich in den Rang echter Arten erhoben worden, nachdem eindeutige Kriterien für ihre genetische Selbständigkeit gefunden worden waren. Die Trennung dieser drei als Geschwisterarten anzusprechenden Formen ist nicht nur durch ihre morphologische Ahnlichkeit erschwert worden, sondern auch durch die Tatsache, daß sich ihre Lebensräume teilweise überlappen.

Auf Grund einer taxonomischen Revision der G. locusta-Gruppe ist inzwischen durch STOCK (1967) die Existenz weiterer Geschwisterarten festgestellt worden. So konnten neben $G$. locusta, der früher mit den vorstehend genannten Formen häufig verwechselt wurde, noch vier bislang nicht erkannte Species diagnostiziert werden, die in verschiedenen europäischen Meeresgebieten auftreten, darunter auch der in der Ostsee neuerdings nachgewiesene G. inaequicauda STOck (JAżDżEwsKr 1970).

Angesichts der Tatsache, daß es sich bei den angeführten Vertretern der Familie Gammaridae um verwandtschaflich sehr eng verbundene Artengruppen handelt, stellte sich die Frage, inwieweit sie sich auch durch physiologische Merkmale unterscheiden. Die Erkenntnis, daß die mehr oder weniger deutliche ökologische Differenzierung, die zwischen den einzelnen Gammarus-Species besteht, mit stoffwechselphysiologischen Unterschieden korreliert ist, lieferten bereits eine Reihe von Arbeiten über das osmound ionenregulatorische Leistungsvermögen (BeAdLE \& CRAGG 1940, KINNE 1952, WerNTZ 1963, Lock WOOD 1961, 1964, 1965, 1970, Sutcliffe 1967a, b, 1968, 1971a, b, SUTCLIFFE \& SHAW 1967, 1968 u. a.) sowie einige durch vergleichende Untersuchungen gewonnene Angaben über den Sauerstoffbedarf (Löwenstein 1935, SuomalaineN 1958, Roux \& Roux 1967, Roux 1972) bei verschiedenen Repräsentanten dieser Gattung aus marinen, brackigen und limnischen Lebensräumen.

Die vorliegenden vergleichenden atmungsphysiologischen Untersuchungen an den fünf euryhalinen Arten Gammarus locusta, G. oceanicus, G. salinus, G. zaddachi und $G$. duebeni stellen einen experimentellen Beitrag zur weiteren Klärung dieses Problemkreises dar. Angesichts der produktionsbiologischen Bedeutung, welche diesen Amphi- 
poden innerhalb des marinen Litorals auf Grund ihres Individuenreichtums zukommt, ist es darüber hinaus von Interesse, Kenntnisse über ihre Atmungsintensität zu erlangen, um ihre Rolle im Stoff- und Energiekreislauf besser abschätzen zu können.

Die im Rahmen dieser Untersuchung durchgeführten Respirationsmessungen befaßten sich mit den Beziehungen zwischen Sauerstoffverbrauch und Körpergröße in Abhängigkeit von der Salinität. Sie verfolgten weiterhin das Ziel, die Veränderungen der Stoffwechselintensität nach einem sprunghaften Wechsel des Salzgehaltes im Außenmedium zu ermitteln und den zeitlichen Verlauf des Anpassungsvorganges zu erfassen. Da diè Untersuchungen auf polarographischem Weg in einer kontinuierlich durchströmten Versuchsanlage vorgenommen wurden und die angewandte Methode fortlaufende Registrierungen über längere Zeiträume gestattete, konnten zudem Vergleiche zwischen Ruhe- und Aktivitätsstoffwechsel angestellt und die Änderungen des Sauerstoffverbrauchs während des Häutungsvorganges gemessen werden.

\section{MATERIAL UND METHODE}

\section{Versuchsobjekte}

Als Versuchsobjekte dienten die vorstehend genannten fünf Arten, die alle im Labor gezüchtet werden konnten. Die Ausgangspopulation von Gammarus duebeni stammte aus dem Elbe-Ästuar bei Müggendorf, die von G. zaddachi aus dem Weserund Elbe-Mündungsgebiet. G, salinus wurde im Felslitoral bei Helgoland (NordostWatt), G. oceanicus in der Kieler Förde (im Bereich der Schwentine-Mündung) und G. locusta im Wattengebiet bei List (Sylt) sowie im Außenhafen Helgolands gefangen. Weder bei $G$. locusta noch bei $G$. zaddachi konnten populationsbedingte Unterschiede hinsichtlich des $\mathrm{O}_{2}$-Bedarfs festgestellt werden; die entsprechenden Meßwerte werden daher nicht gesondert aufgeführt. Die Determination der einzelnen Species erfolgte nach den Bestimmungsschlüsseln von KINNE (1954) und STOck (1967).

Von allen Gammarus-Arten wurden in großen gekachelten Becken mit einem Wasservolumen von ca. 100-115 1 oder in kleineren Aquarien mit Bodenfilter Zuchten angelegt, die mit den vorher determinierten Individuen aus den Frischfängen besetzt wurden. G. duebeni und $G$. salinus erwiesen sich bei geringen Mortalitätsraten als relativ leicht züchtbar, während die anderen drei Arten eine höhere Sterblichkeit zeigten und auch nicht kontinuierlich zur Vermehrung gebracht werden konnten. Die Kulturmethode entsprach weitgehend dem Verfahren, das zur Zucht von G. duebeni angewendet und in anderem Zusammenhang bereits beschrieben worden ist (vgl. BuLNHEIM 1969, 1972). Als Nahrung wurden den Krebsen Algen (Enteromorpba, Ulva), Enchyträen und gekochtes Miesmuschelfleisch (Mantel-, Mitteldarmdrüsen- und Gonadengewebe) angeboten. Das Wasser wurde ständig belüftet und von Zeit zu Zeit teilweise oder vollständig erneuert. Die Zuchttemperatur betrug $15 \pm 2^{\circ} \mathrm{C}$. Größere Abweichungen von der Solltemperatur $\left(15^{\circ} \mathrm{C}\right)$ ergaben sich im allgemeinen nur kurzfristig bei extremen Außentemperaturen im Winter und im Hochsommer.

Die Individuen, die für die Respirationsversuche benutzt wurden, entstammten in der Regel den Folgegenerationen der aus dem Freiland eingefangenen Individuen (ab- 
gesehen von einigen Messungen an $G$. zaddachi und $G$. oceanicus). Um über einen langen Zeitraum gleichartig vorbehandelte Versuchstiere zur Verfügung zu haben, wurden die einzelnen Gammarus-Arten von vornherein in zwei Salzgehaltsstufen $(10 \%$ und $30 \%$ ) aufgezogen. Im Gegensatz zu G. locusta, G. salinus, G. oceanicus und $G$. duebeni war die Kultur von $G$. zaddachi in Medien von $30 \%$ wenig erfolgreich, so daß in dieser Salzgehaltsstufe keine kontinuierlichen Zuchten aufgebaut werden konnten.

Nach Durchführung der Respirationsmessungen wurden die Krebse in 0,1prozentiger Lösung von MS-222 (Firma Sandoz, Nürnberg) betäubt, um die Geschlechtszugehörigkeit zu bestimmen sowie das Frischgewicht zu ermitteln. Vor den Wägungen wurden die Gammari durch Betupfen mit Filtrierpapier von anhaftendem Wasser befreit, insbesondere wurde die zwischen den Beinen und Kiemen zurückbleibende Flüssigkeit aufgesogen. In allen angegebenen Fällen sind die $\mathrm{O}_{2}$-Verbrauchswerte auf das Feuchtgewicht bezogen worden. Wie durch Vergleichswägungen lebender und getrockneter Tiere ermittelt wurde, beträgt der Wassergehalt $78 \%$ (G. duebeni) bis $80 \%$ $(G$. locusta). Diese Angaben ermöglichen annäherungsweise eine nachträgliche Umrechnung der Meßdaten auf das Trockengewicht. Schließlich ist noch zu bemerken, daß unter den $\nmid$ 오 nur solche Exemplare als Versuchstiere ausgewählt worden sind, deren Marsupium weder Eier noch Embryonen enthielt.

Die Herstellung der einzelnen Salzgehaltskonzentrationen geschah durch Verdinnen von Seewasser mit Leitungswasser (Alkalität: p-Wert 0,35-0,40, m-Wert 3,8-4,3 mval/1) bzw. durch Zusatz von käuflichem Seesalz. Die Salinitätsbestimmungen erfolgten auf aräometrischem bzw. osmometrischem Wege.

\section{Methodik}

Wie bereits eingangs angedeutet, wurde der $p \mathrm{O}_{2}$ nach dem polarographischen Prinzip mit Hilfe von Platin-Silber-Elektroden gemessen. Das elektrochemische Verfahren der $\mathrm{O}_{2}$-Messung hat in neuerer Zeit zunehmende Bedeutung erlangt, da es sich gegenüber anderen konventionellen Methoden ( $z$. B. Manometrie, $\mathrm{O}_{2}$-Bestimmung nach WINKLER, Methode nach ScholandER) durch einen geringeren Arbeitsaufwand, gute Reproduzierbarkeit der Meßwerte und den Vorzug eines kontinuierlichen Meßvorganges bei langdauernden Versuchen auszeichnet.

Für die vorliegenden Untersuchungen wurde eine stabilisierte membranüberzogene Ganzglas-Platin-Elektrode (nach GleichmanN \& LüBbERs 1960) in der Modifikation als Kugelschliffelektrode (LüBBERs \& WINDISCH 1963) benutzt. Diese nach dem CLARKschen Prinzip konstruierte, jedoch wesentlich verbesserte Elektrode ist durch eine wasserundurchlässige, hingegen sauerstoffpermeable, $25 \mu \mathrm{m}$ starke Teflonmembran vom Meßmedium getrennt. Sie besteht aus einer Platindrahtkathode (Meßelektrode) und einer Silberanode (Bezugselektrode), die zur Erhöhung der Meßstabilität mit Silberchlorid überzogen wurde (vgl. Ring et al. 1969).

Die Kathode, ein $200 \mu \mathrm{m}$ starker, in Glas luftblasenfrei eingeschmolzener Platindraht, liegt im distalen kugelförmig ausgebildeten Teil der Elektrode, welcher in das ebenfalls aus Glas bestehende Elektrodenmantelgefäß eingepaßt und dort befestigt ist. 
Mit der unterhalb des Elektrodenkopfes liegenden Anode ist die Kathode durch eine Elektrolytlösung $(0,5 \mathrm{~m} \mathrm{KCl}$ bei chlorierter Anode) leitend verbunden. Zwischen Kathode und Teflonmembran befindet sich als stabilisierende $Z_{\text {wischenschicht eine }}$ dünne Cellophanfolie ( $12 \mu \mathrm{m})$, so daß eine konstante, unveränderliche Diffusionsstrecke gegeben ist. An der Basis der Elektrode liegt der Analysenraum, eine Erweiterung des Glaskapillarsystems. Er enthält einen kleinen Rührstab aus Glas, in das ein Eisenplättchen eingeschmolzen ist. Ein unterhalb der Elektrode angebrachter Magnetrührer versetzt das Rührstäbchen in rotierende Bewegung $(370 \mathrm{U} / \mathrm{min})$. Die dadurch entstehende Turbulenz gewährleistet eine gleichmäßige Diffusion des $\mathrm{O}_{2}$ aus der Meßlösung zur Platinoberfläche.

Die physikalisch-chemischen Vorgänge, die sich beim Anlegen einer Spannung an die Kathode abspielen, sind u. a. von Gleichmann \& LübBERS (1960) beschrieben worden. Der an die Platinoberfläche diffundierende molekulare Sauerstoff wird mit Elektronen beladen; dabei reagiert der reduzierte Sauerstoff in mehreren Teilschritten unter Bildung von Hydroxylionen mit den Wasserstoffionen des Wassers.

Der bei der kathodischen Sauerstoffreduktion fließende Strom ist abhängig von der Anzahl der diffundierenden Sauerstoffmoleküle. Ist die an der Elektrode angelegte Spannung groß genug, um alle Sauerstoffmoleküle sofort zu reduzieren, so ist der Reduktionsstrom dem Sauerstoffdruck in der Lösung proportional. Ausschlaggebend für die gasanalytische Messung ist der Verlauf der Stromspannungskurve (Polarogramm). Mit steigender Spannung nimmt der Reduktionsstrom zunächst zu, und zwar bis zu einem Bereich (etwa 600-900 mV), in dem bei weiterer Erhöhung der Spannung die Größe des fließenden Stromes gleichbleibt. Da in diesem sogenannten Diffusionsgrenzstromgebiet der Stromfluß eine Funktion der $\mathrm{O}_{2}$-Konzentration ist, wird dieser als Arbeitsbereich gewählt. Bei Verwendung von Elektroden, deren Anode einen Überzug von Silberchlorid aufweist, hat es sich als günstig erwiesen, die Messungen bei einer Polarisationsspannung von $800-900 \mathrm{mV}$ durchzuführen.

Die für die vorliegende Fragestellung benutzte Meßanordnung bestand aus einem Analysenteil mit 1 bzw. 2 Frittengefäßen zur Aquilibrierung des Mediums mit Luftsauerstoff, einer Respirationskammer und einem Kapillarsystem, das die Verbindung $z$ wischen Frittenflaschen, Atemkammer und Elektrode herstellte und aus einem Meßteil. Der Analysenteil befand sich in einem thermostatisierten Wasserbad, das auf die Versuchstemperatur von $15 \pm 0,05^{\circ} \mathrm{C}$ einreguliert wurde. Mit Hilfe einer sehr präzise arbeitenden Pumpe (Dauerinfusionsapparatur Unita IIb, Firma Braun, Melsungen) wurde das zu messende Medium aus den Frittenflaschen mit konstanter Geschwindigkeit an der Elektrode vorbeigeleitet, entweder auf direktem Weg zur Aufnahme des Leerwertes oder über die Atemkammer, wenn diese mit einem Versuchstier besetzt war. Wie Abbildung 1 verdeutlicht, konnte durch mehrere in dem Kapillarsystem angebrachte Dreiwegehähne die Richtung des Wasserstromes innerhalb der Durchflußapparatur verändert werden. Durch Einsatz einer zweiten Pumpe, welche an dem hinter der Atemkammer liegenden Dreiwegehahn angeschlossen wurde, ließ sich bei langdauernden Messungen nach Umschalten der Dreiwegehähne auch intermittierend der Leerwert aufnehmen, ohne daß die Notwendigkeit bestand, das Versuchstier aus der Atemkammer herauszunehmen. Je nach Individuengröße wurden Respirationskammern verschiedener Volumina benutzt. In die Atemkammer wurde zur Dämpfung 
der lokomotorischen Aktivität ein Streifen Kunststoffgaze eingelegt; da sich die Verm suchstiere auf Grund ihres stark thigmotaktischen Verhaltens daran ansetzten, kamen sie in der Regel nach einiger Zeit weitgehend zur Ruhe.

Die Elektrode wurde nach ihrer Herrichtung (Bespannung, Elektrolytfüllung, Abdichtung etc.) und Funktionsprüfung an das Meßgerät (Combi-Analysator der Firma

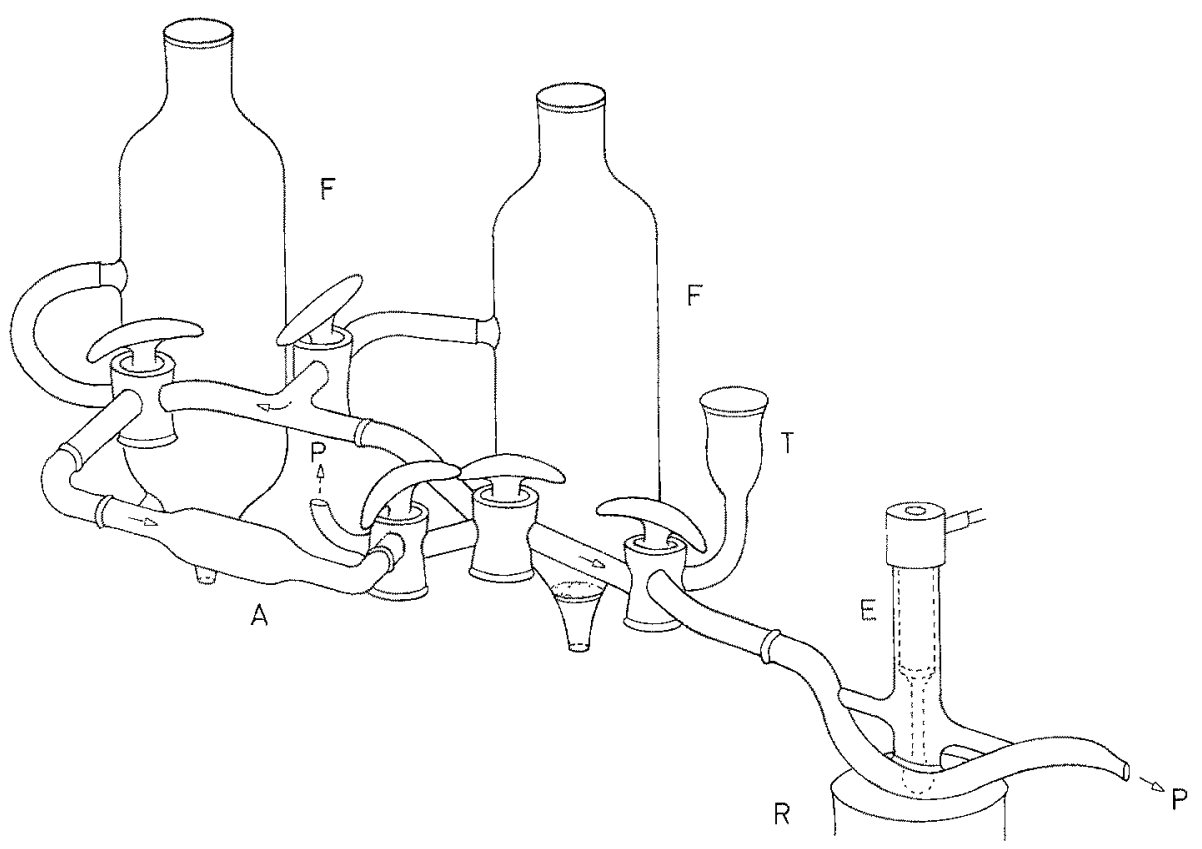

Abb. 1: Schema der Durchflußapparatur mit Atemkammer $(A), p \mathrm{O}_{2}$-Elektrode $(E)$, Magnetrührer $(R)$, zwei Frittenflaschen $(F)$ zur Aquilibrierung des Versuchsmediums mit Luftsauerstoff und Einfülltrichter $(T)$ zur Aufnahme sauerstoffreien Wassers für die Eichung. Die Pfeile geben die Strömungsrichtung des durch Pumpen $(P)$ geförderten Versuchsmediums an. Durch Kugelschliffe sind die einzelnen Elemente des aus Glas bestehenden Durchflußsystems gelenkig miteinander verbunden. Die zur Befestigung verwendeten Metallklammern und sonstige Halterungseinrichtungen sind nicht eingezeichnet worden

Eschweiler \& Co., Kiel) angeschlossen. Dieses liefert die Polarisationsspannung, verstärkt den durch den Meßkreis fließenden Strom und gestattet die Ablesung der Meßwerte, die kontinuierlich mittels eines Kompensations-Linienschreibers (Modell „Servogor", Firma Metrawatt, Nürnberg) aufgezeichnet wurden. Letzterer war über ein Gerät zur Nullpunktunterdrückung an den Combi-Analysator angeschlossen.

Bei der Eichung der Elektrode wurde auf den Einsatz von Gasgemischen mit definiertem $\mathrm{O}_{2}$-Gehalt bzw. von wasserdampfgesättigter atmosphärischer Luft verzichtet, da oft kleinere Gasbläschen nach dem späteren Durchleiten von Flüssigkeit an der Elektrodenmembran festhaften, deren Entfernen mitunter erst nach längerem Bemühen gelingt. Die Einstellung des Nullpunktes erfolgte mit Hilfe einer frisch angesetzten Natriumdithionit-Lösung. Durch Zugabe von Natriumdithionit wird der im Wasser gelöste $\mathrm{O}_{2}$ chemisch gebunden. Die Lösung wurde in einen vor der Elektrode angebrach- 
ten Trichter gefüllt, der über einen Dreiwegehahn mit dem Kapillarsystem in Verbindung stand. Da die Eichkurve bei konstanter Temperatur einen linearen Verlauf aufweist, genügt die Ermittlung eines zweiten Eichpunktes. Dieser wurde mit temperiertem, luftgesättigten Wasser bestimmt, das anschließend bei gleichbleibendem Durchfluß an der Elektrode vorbeigeleitet wurde.

Die verwendete stabilisierte Ganzglas-Platin-Elektrode (Hersteller: Firma Eschweiler \& Co., Kiel) zeichnet sich durch eine große Empfindlichkeit, gute Reproduzierbarkeit und rasche Einstellzeit (ca. 20-30 sec) aus. Der mittlere Fehler der Einzelmessung beträgt $\pm 0,5 \%$ (GleichMANN \& LüBBERS 1960); die minimale Ablesegenauigkeit auf dem Schreiber liegt bei ca. 0,3 Torr. Eine befriedigende Meßstabilität der Elektrode konnte bei einem ununterbrochenen Einsatz in der Durchflußapparatur im allgemeinen über eine Dauer von 2-3 Wochen, ausnahmsweise auch bis zu etwa 4 Wochen verzeichnet werden, bevor eine neue Bespannung mit den zuvor erwähnten Folien und eine neue Elektrolytfüllung vorgenommen werden mußte. Neben anderen Faktoren hängt die Qualität einer Elektrode in erster Linie von der Sorgfalt ab, die bei der manuellen Herrichtung aufgewendet wird. Als Beispiel einer besonders guten Stabilität sei eine Meßreihe angeführt, bei der innerhalb von 4 Tagen die Abweichung vom Sollwert nur $-0,2 \%$ und innerhalb von 6 Tagen $-0,5 \%$ unter Beridksichtigung der Luftdruckänderungen betrug. Einer Elektrodendrift läßt sich zumeist durch eine geringfïgige Veränderung der Polarisationsspannung entgegenwirken.

Das Versuchsmedium wurde vor Gebrauch filtriert, mittels einer UV-Lampe sterilisiert und in eine Vorratsflasche abgefüllt. Diese stand mit einer Niveauflasche in Verbindung, durch welche der Wasserstand in der Frittenflasche auf konstanter Höhe gehalten werden konnte. Bei den Versuchen über den Einfluß einer sprunghaften Anderung des Salzgehaltes wurden zwei Frittenflaschen mit Medien unterschiedlicher Salinität eingesetzt, aus denen je nach Stellung der Verschlußhähne luftgesättigtes Wasser der einen oder der anderen Salzgehaltskonzentration durch das Kapillarsystem gepumpt wurde (vgl. Abb. 1).

Die Versuchstiere wurden im allgemeinen nach einer eintägigen Hungerperiode in die Atemkammer gesetzt, wo sie je nach Fragestellung unterschiedlich lange Zeit, mindestens jedoch drei Stunden, bis zum Erreichen konstanter Werte verblieben. Vor und nach einer Messung, bei langdauernden Versuchen auch intermittierend, wurde zur Kontrolle der Leerwert aufgenommen.

Die Auswertung der auf dem Kompensationsschreiber kontinuierlich registrierten Meßdaten erfolgte für Zeitintervalle von jeweils 20, 40 oder 60 Minuten. Sofern die Atmungskurven größere Schwingungen aufwiesen, wurde von graphisch ermittelten Durchschnittswerten ausgegangen.

Mit Hilfe eines Barographen wurde der aktuelle Luftdruck fortlaufend aufgezeichnet, der bei der Eichung zu berücksichtigen ist.

\section{Berechnungen}

Für die Eichung und für die Umrechnung der gemessenen Änderungen des $p \mathrm{O}_{2}$ in Volumeneinheiten gelten die im folgenden dargestellten Bezichungen, denen die Gesetze über die Löslichkeit von Gasen in Flïssigkeiten zugrunde liegen. 
Die Löslichkeit eines Gases in einem Lösungsmittel ist proportional seinem Druck bzw. seinem Partialdruck und umgekehrt proportional der Temperatur sowie dem Gehalt an gelösten Stoffen. Die Sauerstoffspannung in Wasser, das mit atmosphärischer Luft gesättigt ist, entspricht somit dem Partialdruck des $\mathrm{O}_{2}$ in der Außenluft. Unter Berücksichtigung des Dampfdrucks des Wassers, durch den die proportionalen Anteile der atmosphärischen Gase in Abhängigkeit von der Temperatur verändert werden, ergibt sich für die Berechnung der Sauerstoffspannung $\left(p \mathrm{O}_{3}\right)$ :

$$
p \mathrm{O}_{2}=0,2094\left(p_{a}-p_{w}\right)
$$

$\left(0,2094=\mathrm{O}_{2}\right.$-Partialdruck trockener Luft bezogen auf $1 \mathrm{Atm} ; p_{a}=$ aktueller Luftdruck; $p_{w}=$ Wasserdampfpartialdruck bei Versuchstemperatur.)

Die Werte über den Dampfdruck des Wassers in Abhängigkeit von der Temperatur sind bei OpITz \& Bartels (1955) tabellarisch zusammengefaßt. Die $\mathrm{O}_{2}$-Spannung in äquilibriertem Wasser wird durch den aktuellen Luftdruck und Dampfdruck, nicht jedoch durch die Konzentration gelöster Stoffe bestimmt. Wasser unterschiedlicher Salinität weist daher unter sonst identischen physikalischen Bedingungen die gleiche $\mathrm{O}_{2}$-Spannung auf; die Volumina sind jedoch auf Grund der Abhängigkeit von der Konzentration gelöster Stoffe verschieden.

Bei der Umrechnung der gemessenen $p \mathrm{O}_{2}$-Unterschiede in Volumeneinheiten ist der Bunsensche Absorptionskoeffizient ( $\alpha$ ) des Sauerstoffs zu berücksichtigen. Dieser stellt das auf $0^{\circ} \mathrm{C}$ und 1 Atm Druck bezogene Volumen eines Gases dar, das von $1 \mathrm{~cm}^{3}$ Flüssigkeit bei einer bestimmten Temperatur und einem bestimmten Druck gelöst wird. Für den Bunsenschen Absorptionskoeffizienten ergibt sich folgende Beziehung (vgl. EuCKEN \& WICKE 1958):

$$
\alpha=\frac{L \cdot 273,15}{273,15+t}
$$

$\left(L=\right.$ OswaLDscher Löslichkeitskoeffizient; $t=$ Versuchstemperatur in $\left.{ }^{\circ} \mathrm{C}\right)$.

Der OswaLDsche Löslichkeitskoeffizient ist definiert durch das Konzentrationsverhältnis (c) des in der Flüssigkeit und des in dem darüberstehenden Gasgemisch enthaltenen Gases. Im vorliegenden Fall gilt:

$$
L=\frac{\mathrm{CO}_{2} \text { (Wasser) }}{\mathrm{CO}_{2} \text { (Luft) }}
$$

Für die Löslichkeit von $\mathrm{O}_{2}$ in Wasser verschiedenen Salzgehalts wurden die Angaben von Green \& CarritT (1967) zugrunde gelegt. An Hand des Absorptionskoeffizienten läßt sich die $\mathrm{O}_{2}$-Konzentration $\left(\mathrm{VO}_{2}\right)$ in Abhängigkeit vom $\mathrm{O}_{2}$-Partialdruck $\left(\not \mathrm{O}_{2}\right)$ und des Gesamtdruckes des Gasgemisches (Normalbedingungen für Luft $P=760$ Torr) wie folgt errechnen:

$$
V_{\mathrm{O}_{2}}=\frac{\alpha \cdot p \mathrm{O}_{2}}{P}
$$

Zur Umrechnung der gemessenen Änderungen der Sauerstoffspannung in Volumeneinheiten $\left(\mathrm{cm}^{3} \mathrm{O}_{2}\right)$ ergibt sich daher unter Berücksichtigung des geförderten Wasservolumens (in $\mathrm{cm}^{3}$ pro Zeiteinheit) für den $\mathrm{O}_{2}$-Verbrauch:

$$
V_{\mathrm{O}_{2}}=\frac{\alpha \cdot \Delta \text { Torr } \cdot v}{P}
$$


$\left(v=\right.$ gefördertes Flüssigkeitsvolumen; $\triangle$ Torr $=$ gemessene Änderung der $\mathrm{O}_{2}$-Spannung).

Der $\mathrm{O}_{2}$-Verbrauch kann dann auf Gewichtseinheiten (bezogen auf das Frischoder Trockengewicht der Versuchsobjekte) umgerechnet werden.

\section{ERGEBNISSE}

Der respiratorische Stoffwechsel umfaßt die im Organismus ablaufenden oxidativen Prozesse, die der Energiegewinnung für die Aufrechterhaltung der Lebensvorgänge und dem Aufbau körpereigener Stoffe dienen. Der Sauerstoffverbrauch als ein indirektes Maß für die Stoff- und Energiewechselleistung ist von zahlreichen, zum Teil in Wechselwirkung stehenden Faktoren exogener und endogener Natur abhängig. Die Analyse der Wirkung aller Einzelfaktoren sowie die Aufhellung ihres komplexen $\mathrm{Zu}$ sammenspiels stellt daher eine außerordentlich umfangreiche und nur in zahlreichen Einzelschritten zu lösende Aufgabe dar, zu der die vorliegenden, in erster Linie auf einen interspezifischen Vergleich ausgerichteten Untersuchungen ebenfalls einen Beitrag liefern sollen.

\section{Abhängigkeit von Größe und Salinität}

Den ersten Kernpunkt der Untersuchungen bildete das Problem der Größenabhängigkeit der Atmungsintensität bei den einzelnen Gammarus-Arten. Zahlreiche Untersuchungen an Vertretern verschiedener poikilothermer Tiergruppen, so auch an Crustaceen (vgl. Wolvekamp \& Waterman 1960), haben zu der Erkenntnis geführt, daß der $\mathrm{O}_{2}$-Verbrauch eine Größe darstellt, die zumeist im Bereich zwischen Oberflächen- und Gewichtsproportionalität liegt.

Eine eindeutige mathematische Beschreibung der Beziehungen zwischen Körpergewicht und Stoffwechselgröße bietet die Anwendung der allometrischen Funktion:

$$
y=a \cdot x^{b}
$$

In dieser Formel ist $y=$ die Stoffwechselgröße, $x=$ das Tiergewicht, während $a$ und $b$ Koeffizienten darstellen. In logarithmierter Form ist die allometrische Funktion die Gleichung einer Geraden:

$$
\log y=\log a+b \cdot \log x
$$

Bei graphischer Darstellung der Grundumsatzgrößen als Funktion des Gewichts in einem doppel-logarithmischen Koordinatensystem erhält man eine Gerade, auf der bzw. in deren Nähe die Meßwerte liegen. Der Tangens des Anstiegswinkels dieser Regressionsgeraden wird durch den Exponenten $b$, den Regressionskoeffizienten, bestimmt. Dessen Wert kennzeichnet somit die Abhängigkeit der Atmungsintensität von der Körpergröße. Er schwankt zumeist zwischen 0,66 (Oberlächenproportionalität) und 1,0 (Gewichtsproportionalität). Der Parameter a stellt die Stoffwechselgröße der gewählten Gewichtseinheit (im vorliegenden Fall $1 \mathrm{~g}$ ) dar und gibt den Schnittpunkt der Regressionsgeraden mit der Ordinatenachse an. Er bildet zusammen mit dem Re- 
gressionskoeffizienten ein geeignetes Maß für art- oder gruppenspezifische Vergleiche. Durch die Ermittlung dieser beiden Parameter ist die Möglichkeit gegeben, die Atmungsgrößen beliebiger anderer Gewichtsklassen zu berechnen.

Für eine möglichst exakte Bestimmung beider Werte ist es erforderlich, eine breite Gewichtsspanne zu berücksichtigen. Diesem Gesichtspunkt wurde bei der Auswahl der Versuchstiere weitgehend Rechnung getragen. Die Gewichtsverhältnisse zwischen den kleinsten und größten Versuchstieren, auf denen die Messungen basierten, lagen zwischen 1:22 und 1:50 (vgl. Abb. 2-6). Sehr junge Individuen bis zu einer Körperlänge von 4-5 mm konnten keine Berücksichtigung finden, da diese auf Grund ihrer geringen Größe aus der Respirationskammer in das Kapillarsystem der Durchflußapparatur gelangen und dadurch den Meßvorgang stören konnten. Uberdies schien es auch wegen der sehr niedrigen Durchflußgeschwindigkeiten, die für Untersuchungen an derart kleinen Tieren erforderlich gewesen wären und wegen der damit verbundenen größeren Ungenauigkeit der Messungen sinnvoll, auf diese Größengruppe zu verzichten.

$\mathrm{Da}$ es für intra- und interspezifische Vergleiche angezeigt war, von einer größeren Differenz der zu vergleichenden Salinitäten auszugehen, erfolgten die Messungen in zwei Konzentrationen, $10 \%$ und 30\%. Beide Salzgehaltsstufen umfassen einen Bereich, in welchem diese fünf Species auch im Freiland, wenngleich zum Teil nur temporär, vorkommen. Zumindest ist mit der 30\%-Stufe die ungefähre obere Grenze der natürlichen Verbreitung von G. duebeni und G. zaddachi erreicht. Auf Einzelheiten der Salzgehaltsansprüche dieser Arten wird an späterer Stelle noch ausführlich eingegangen werden.

Die Respirationsmessungen, die stets an langfristig adaptierten Einzeltieren vorgenommen wurden, dauerten in der Regel mehrere Stunden, bis sich konstante Stoffwechselwerte einstellten. An Hand des Verlaufs der Atmungskurven konnte abgeschätzt werden, wann annähernd Grundumsatzbedingungen erreicht waren. Allerdings ist einschränkend festzustellen, daß eine völlige Ruhestellung der Versuchstiere praktisch nicht gegeben war. Sofern die Messungen nicht an betäubten Flohkrebsen vorgenommen werden, wie es Fox \& SrMmonds (1933) sowie LöwensteIn (1935) getan haben, wobei freilich bestimmte Effekte des Narkotikums auf den Stoffwechsel nicht ausgeschlossen werden können, muß eine gewisse Spontanaktivität in Kauf genommen werden. Daraus erklärt sich auch die nicht unerhebliche Schwankungsbreite der Meßdaten, die in den Abbildungen 2-6 wiedergegeben sind. In diese graphischen Darstellungen sind die für beide Salinitäten berechneten Regressionsgeraden eingezeichnet worden. Für die Regressionsanalyse wurden die $\mathrm{O}_{g}$-Verbrauchswerte für die $q Q q$ und ô $\hat{O}$ sowie für die sexuell noch nicht differenzierten Jungtiere zusammengefaßt, da keine geschlechtsspezifischen Unterschiede nachgewiesen werden konnten. Die aus der Gesamtheit der Meßdaten berechneten allometrischen Parameter $a$ und $b$ mit ihren Standardabweichungen $s_{a}$ und $s_{b}$, dem Standardschätzfebler $s_{y \cdot x}$ als Maß der Streuung um die Regressionsgerade und dem Korrelationskoeffizienten $r$ sind in Tabelle $1 \mathrm{zu}$ sammengestellt. Diese Angaben gestatten es, die entsprechenden Konfidenzintervalle für eine gewählte Vertrauenswahrscheinlichkeit zu ermitteln (vgl. SAcHs 1972) und andere statistische Berechnungen anzustellen.

Vergleicht man die Regressionskoeffizienten auf intra- und interspezifischer Ebene, so wird deutlich, daß in der $30 \%$-Stufe bei allen Arten mit Ausnahme von G. duebeni 
Tabelle 1

Parameter der allometrischen Beziehung $y=a \cdot x^{b}$ zwischen Körpergewicht (Frischgewicht) und Sauerstoffverbrauch $\left(\mathrm{mm}^{3} \mathrm{O}_{2} / \mathrm{g} / \mathrm{h}\right)$ bei fünf euryhalinen Gammarus-Arten in Abhängigkeit vom Salzgehalt $\left(15^{\circ} \mathrm{C}\right), a=$ Ordinatenabschnitt; $s_{a}=$ Standardabweichung des Ordinatenabschnittes $a ; b=$ Regressionskoeffizient; $s=$ Standardabweichung des Regressionskoeffizienten $b ; s_{y} \cdot x=$ Standardfehler der Regressionsgeraden; $r=$ Korrelationskoeffizient; $n=$ Anzahl der Wertepaare

\begin{tabular}{|c|c|c|c|c|c|c|c|c|}
\hline Species & $\begin{array}{c}\text { Salinität } \\
\left(\% 0_{0}\right)\end{array}$ & $a$ & $s_{a}$ & $b$ & $s_{b}$ & $s_{y} \cdot x$ & $r$ & $n$ \\
\hline G. locusta & $\begin{array}{l}30 \\
10\end{array}$ & $\begin{array}{l}180,33 \\
113,71\end{array}$ & $\begin{array}{l}13,37 \\
13,27\end{array}$ & $\begin{array}{l}1,024 \\
0,868\end{array}$ & $\begin{array}{l}0,035 \\
0,035\end{array}$ & $\begin{array}{l}1,327 \\
1,234\end{array}$ & $\begin{array}{l}0,956 \\
0,954\end{array}$ & $\begin{array}{l}84 \\
64\end{array}$ \\
\hline G. oceanicus & $\begin{array}{l}30 \\
10\end{array}$ & $\begin{array}{l}76,58 \\
54,25\end{array}$ & $\begin{array}{l}12,85 \\
12,50\end{array}$ & $\begin{array}{l}0,896 \\
0,702\end{array}$ & $\begin{array}{l}0,032 \\
0,024\end{array}$ & $\begin{array}{l}1,295 \\
1,281\end{array}$ & $\begin{array}{l}0,956 \\
0,947\end{array}$ & $\begin{array}{l}75 \\
97\end{array}$ \\
\hline G. salinus & $\begin{array}{l}30 \\
10\end{array}$ & $\begin{array}{l}48,96 \\
37,57\end{array}$ & $\begin{array}{l}13,03 \\
13,27\end{array}$ & $\begin{array}{l}0,699 \\
0,632\end{array}$ & $\begin{array}{l}0,032 \\
0,033\end{array}$ & $\begin{array}{l}1,269 \\
1,206\end{array}$ & $\begin{array}{l}0,930 \\
0,920\end{array}$ & $\begin{array}{l}79 \\
69\end{array}$ \\
\hline G. zaddachi & $\begin{array}{l}30 \\
10\end{array}$ & $\begin{array}{l}40,55 \\
31,77\end{array}$ & $\begin{array}{l}15,10 \\
13,87\end{array}$ & $\begin{array}{l}0,672 \\
0,609\end{array}$ & $\begin{array}{l}0,035 \\
0,036\end{array}$ & $\begin{array}{l}1,357 \\
1,380\end{array}$ & $\begin{array}{l}0,931 \\
0,887\end{array}$ & $\begin{array}{l}59 \\
80\end{array}$ \\
\hline G. duebeni & $\begin{array}{l}30 \\
10\end{array}$ & $\begin{array}{l}26,92 \\
29,99\end{array}$ & $\begin{array}{l}12,08 \\
12,59\end{array}$ & $\begin{array}{l}0,582 \\
0,608\end{array}$ & $\begin{array}{l}0,025 \\
0,031\end{array}$ & $\begin{array}{l}1,231 \\
1,308\end{array}$ & $\begin{array}{l}0,934 \\
0,907\end{array}$ & $\begin{array}{l}80 \\
86\end{array}$ \\
\hline $\begin{array}{l}\text { G. duebeni } \\
\text { (juv. }+Q Q \text { ) }\end{array}$ & 10 & 30,63 & 16,63 & 0,607 & 0,054 & 1,316 & 0,888 & 36 \\
\hline $\begin{array}{l}\text { G. duebeni } \\
\text { (Thelohania- } \\
\text { infizierte juv. }\end{array}$ & $\begin{array}{l}10 \\
99)\end{array}$ & 24,35 & 18,62 & 0,570 & 0,062 & 1,257 & 0,896 & 23 \\
\hline
\end{tabular}

höhere Werte als in der 10\%-Stufe zu verzeichnen sind. Dies bedeutet, daß der Anstieg der Regressionsgeraden in der höheren Salinität bei G. locusta, G. oceanicus, $G$. salinus und $G$, zaddachi steiler ist als in der niedrigeren Konzentrationsstufe, während bei $G$. duebeni in beiden Versuchsreihen annähernd identische Verhältnisse in bezug auf die Steigung der Geraden vorliegen. Bei einem intraspezifisch ausgerichteten statistischen Vergleich der Regressionskoeffizienten $z$ wischen den jeweiligen $30 \%$ and 10\%-Versuchsreihen ergeben sich für alle fünf Arten hochsignifikante Unterschiede bei einer Irrtumswahrscheinlichkeit von $0,1 \%$.

Bemerkenswert ist fernerhin, daß eine beträchtliche Variabiliät der Regressionskoeffizienten vorliegt. Diese reicht von Werten um 1 bei $G$, locusta in $30 \%$ bis zu Werten um 0,6 , die bei $G$. salinus und $G$. zaddachi in $10 \%$ und bei $G$. duebeni in beiden Salzgehaltsbereichen errechnet worden sind. Aus diesen Ergebnissen wird ersichtlich, daß die Stoffwechselgröße von einer Gewichtsproportionalität bis zu einer Oberflächenproportionalität reicht; in einigen Fällen ist sogar eine unterhalb einer Oberflächenproportionalität liegende Relation festzustellen. Derart niedrige Regressionskoeffizienten sind vereinzelt auch von anderen Crustaceen bekannt geworden, wie aus einer Zusammenstellung von WolvekAMP \& WATERMaN (1960, p. 45) hervorgeht. Da die Versuchstiere ziemlich breite Gewichtsspannen umfaßten, dürfte eine hinreichend genaue Ermittlung der Regressionskoeffizienten gewährleistet sein.

Betrachtet man die Größe des Sauerstoffyerbrauchs zunächst auf der Basis eines zwischenartlichen Vergleiches, so ergibt sich, daß in den meisten Fällen keine feststehenden Relationen abgeleitet werden können, ohne das Körpergewicht zu berücksich- 


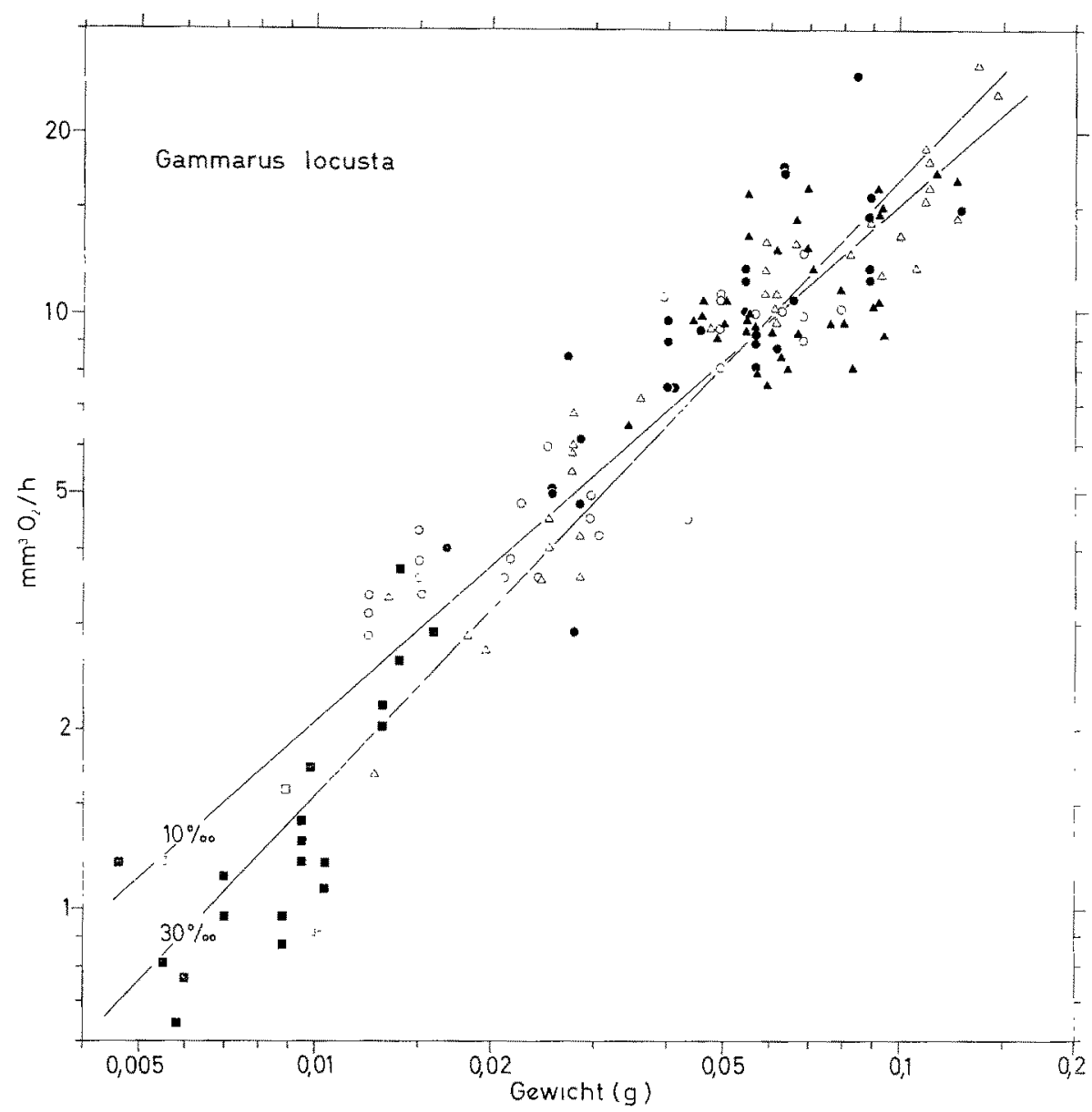

Abb. 2: Gammarus locusta. Abhängigkeit des $\mathrm{O}_{2}$-Verbrauchs vom Körpergewicht (Frischgewicht) bei $30 \%$ und und $10 \%\left(15^{\circ} \mathrm{C}\right)$ in doppel-logarithmischer Darstellung. Die aus den Meßdaten errechneten Regressionsgeraden sind für beide Salinitäten eingezeichnet worden. Symbole der 30\%-Stufe: geschlechtlich noch nicht differenzierte Jungtiere, $90, \boldsymbol{A}$ o $\hat{\delta}$; Symbole der $10 \%$-Stufe: $\square$ geschlechtlich noch nicht differenzierte Jungtiere, $\bigcirc \%$

tigen. Da die Regressionsgeraden mehr oder weniger unterschiedliche Steigungen aufweisen, sind die Differenzen zwischen beiden Salzgehaltsstufen in bezug auf die mittlere Stoffwechselrate von den Größenverhältnissen abhängig (Abb. 2-6). So ist für $G$. locusta und $G$. oceanicus im Gewichtsbereich unterhalb von $0,06 \mathrm{~g}$ bzw. $0,2 \mathrm{~g}$ in $10 \%$ ein durchschnittlich höherer Sauerstoffbedarf zu verzeichnen als in 30\%, wobei die Unterschiede mit abnehmender Größe zunehmend markanter hervortreten. Da sich die Regressionsgeraden von $G$. locusta bei einem Körpergewicht von etwa $0,06 \mathrm{~g}$ schneiden, beginnt sich dieses Verhältnis oberhalb der genannten Gewichtsstufe umzukehren. Bei G. oceanicus liegt indessen der Schnittpunkt der Geraden fast außerhalb des geprüften Gewichtsbereiches. Die anderen drei Arten zeigen eine weitaus geringere Abhängigkeit der Atmungsintensität vom Salzgehalt. Bei G. salinus und G. zaddachi nehmen 


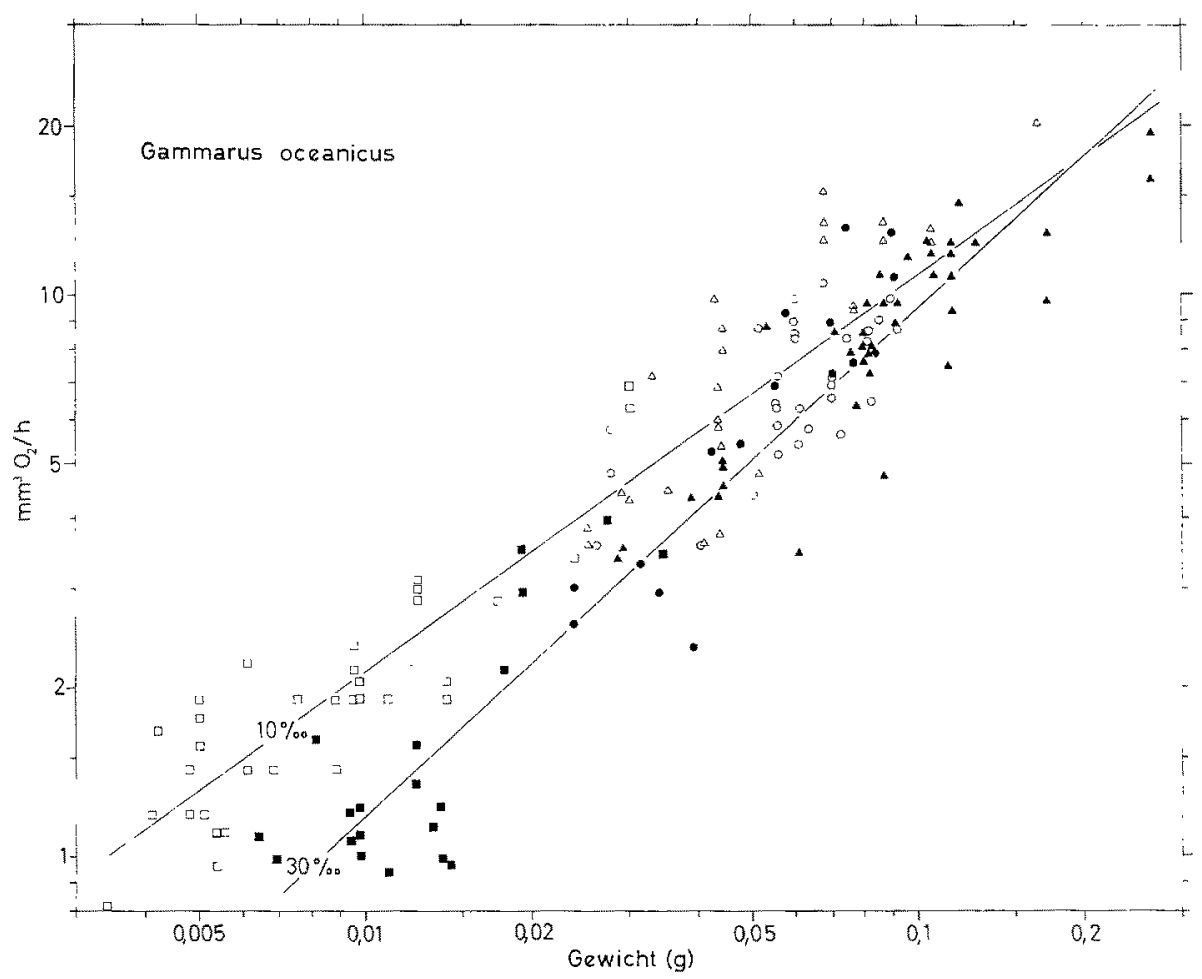

Abb. 3: Gammarus oceanicus. Abhängigkeit des $\mathrm{O}_{2}$-Verbrauchs vom Körpergewicht bei $30 \%$ und $10 \%$ und $15^{\circ} \mathrm{C}$. (Vgl. Erläuterungen $\mathrm{zu} \mathrm{Abb} .2$ )

die Unterschiede mit steigendem Körpergewicht geringfügig $\mathrm{zu}$, wobei der $\mathrm{O}_{2}$-Bedarf in der salzreicheren Stufe etwas höher ist als in dem salzärmeren Medium.

Bezieht man den $\mathrm{O}_{2}$-Verbrauch auf ein Lebendgewicht von $0,1 \mathrm{~g}$, so ergibt sich bei einem interspezifischen Vergleich eine von G. duebeni über G. zaddachi, G. salinus, $G$. oceanicus bis zu G. locusta reichende Tendenz einer zunehmend höheren Atmungsintensität in beiden Salzgehaltsstufen. G. zaddachi und G. salinus zeigen in bezug auf ihre Stoffwechselgröße die geringsten Unterschiede. G. locusta hingegen hebt sich von den anderen Arten durch einen relativ hohen Sauerstoffbedarf deutlich $a b$, wobei das Verhältnis des mittleren $Q_{02}$ zwischen $G$. duebeni und $G$. locusta mehr als 1:2 beträgt. Wie aus den Daten der Tabelle 1 errechnet werden kann, reicht dieses von 7,1 bis $17,1 \mathrm{~mm}^{3} \mathrm{O}_{2} / 0,1 \mathrm{~g} / \mathrm{h}\left(30 \%\right.$ on) bzw. von 7,4 bis $15,4 \mathrm{~mm}^{3} \mathrm{O}_{2} / 0,1 \mathrm{~g} / \mathrm{h}(10 \%)$.

Schließlich sei noch auf die relativ hohen Werte für die Korrelationskoeffizienten hingewiesen (vgl. Tab. 1), durch welche die enge Beziehung zwischen Sauerstoffverbrauch und Körpergröße ihren zahlenmäßigen Ausdruck findet.

In Ergänzung zu den bisher geschilderten Versuchen über die Größenabhängigkeit der Atmungsintensität wurde noch eine besondere parasitologische Fragestellung in die Stoffwechselanalyse einbezogen. Dabei handelt es sich um einen Vergleich der Atmungsgrößen von Individuen, die mit bestimmten Mikrosporidien infiziert sind, und jener von nichtbefallenen Tieren. 


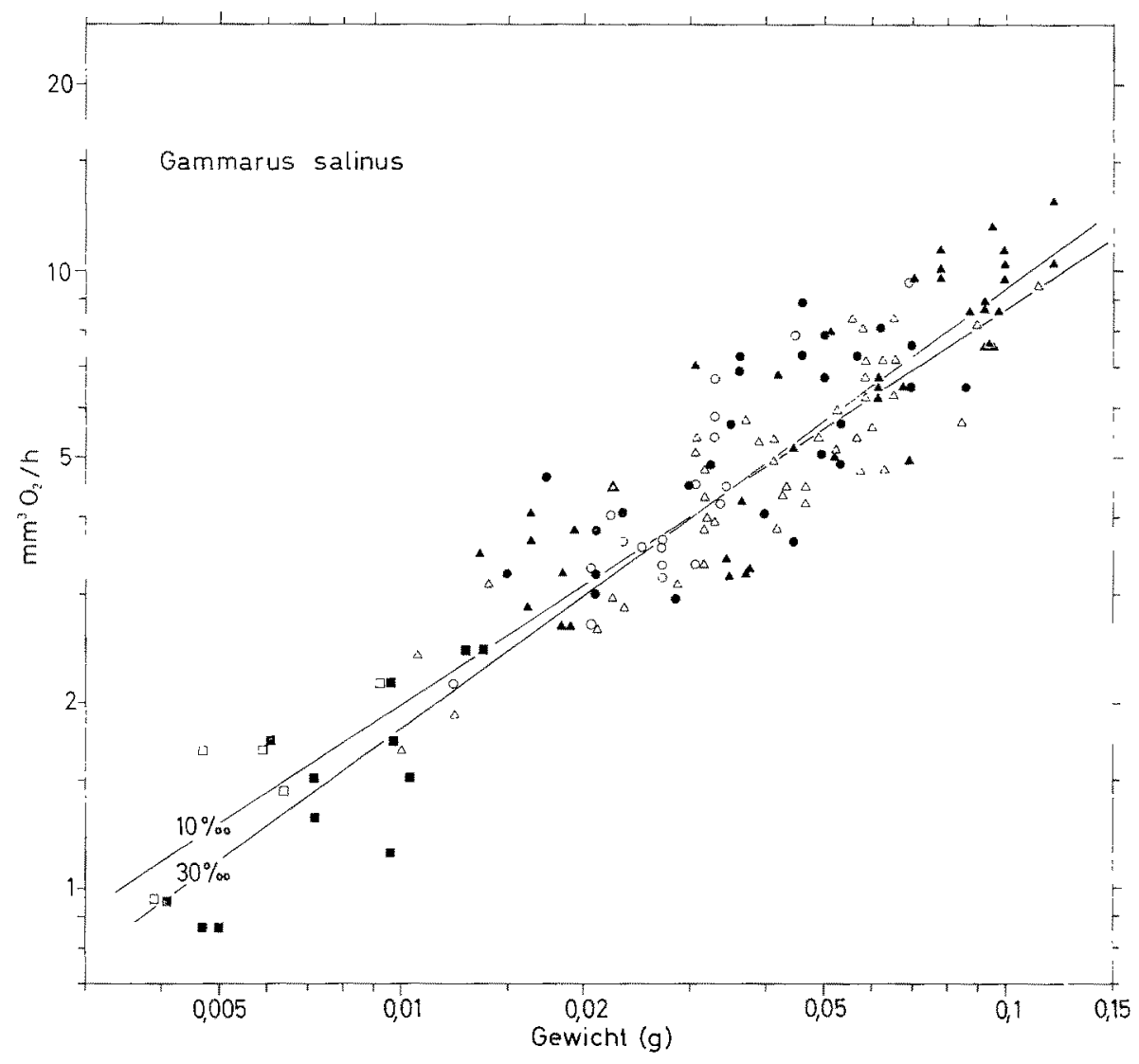

Abb. 4: Gammarus salinus. Abhängigkeit des $\mathrm{O}_{2}$-Verbrauchs vom Körpergewicht bei $30 \%$ und $10 \%$ und $15^{\circ} \mathrm{C}$. (Vgl. Erläuterungen zu Abb. 2)

Im Rahmen ausgedehnter Studien über die Geschlechtsbestimmung bei G. duebeni wurde das Vorkommen von zwei Mikrosporidienarten, Octosporea effeminans und Thelobania herediteria, festgestellt, die einen geschlechtsdeterminierenden Einfluß ausüben. Sie werden über die Eier auf die Nachkommen übertragen und bewirken, daß sich alle befallenen Jungtiere zu 우오, ausnahmsweise auch zu Intersexen entwickeln (vgl. Bulnherm 1969, 1972). Beide Arten besiedeln das Ovar, Thelobania herediteria parasitiert darüber hinaus in der gesamten Körpermuskulatur. Um eine Aussage treffen zu können, ob durch eine Mikrosporidieninfektion auch der respiratorische Stoff wechsel beeinflußt wird, wurden bei $G$. duebeni Parallelmessungen zwischen nichtbefallenen und Thelohania-infizierten Individuen, die - wie alle anderen Versuchstiere - auch aus Laborzuchten stammten, durchgeführt. Die Ergebnisse dieser Untersuchungen sind ebenfalls in Tabelle 1 sowie in Abbildung 6 aufgeführt.

Eine Signifikanzprüfung der Regressionskoeffizienten zwischen nichtbefallenen und befallenen 우 einschließlich sexuell noch nicht differenzierter Jungtiere ergab keine gesicherten Unterschiede bei einer Irrtumswahrscheinlichkeit von $>2 \%$. Die 


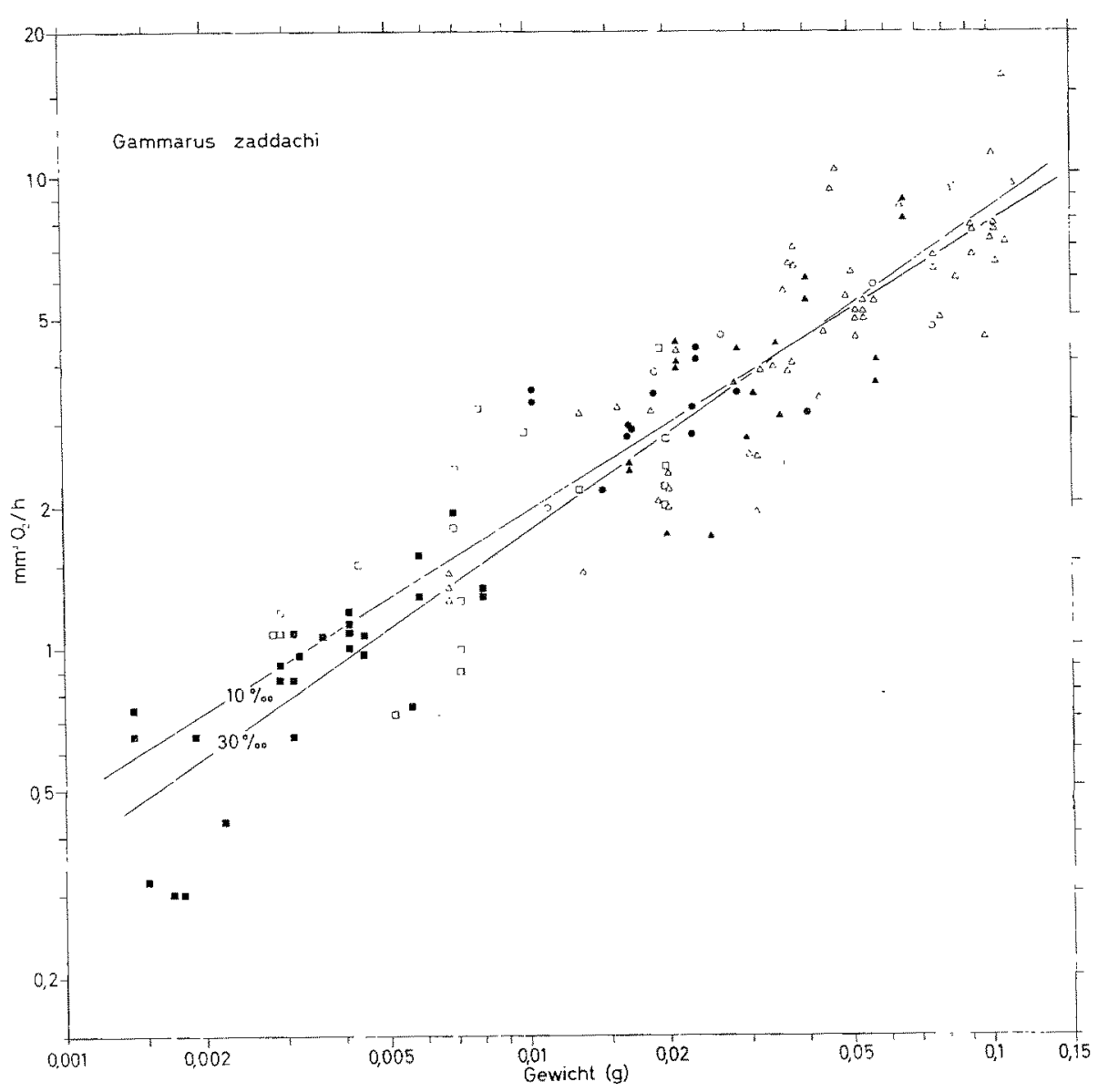

Abb. 5: Gammarus zaddachi. Abhängigkeit des $\mathrm{O}_{2}$-Verbrauchs vom Körpergewicht bei $30 \%$ und $10 \%$ und $15^{\circ} \mathrm{C}$. (Vgl. Erläuterungen zu Abb. 2)

Atmungsintensität der Flohkrebse erfährt trotz der recht starken Parasitierung keine ins Gewicht fallende Veränderungen, wodurch die insgesamt geringe pathogene Wirkung dieser Mikrosporidien unterstrichen wird (BULNHEIM 1971).

Aus der Gegenüberstellung der kaum voneinander abweichenden Werte der allometrischen Parameter für die 우 und Jungtiere einerseits sowie für Individuen beiderlei Geschlechts andererseits (Tab. 1) wird ferner deutlich, daß keine geschlechtsspezifischen Unterschiede vorliegen.

\section{Einfluß eines sprunghaften Wechsels des Salzgehalts}

Organismen, die Brackwasserbiotope besiedeln, sind meist stark wechselnden Salinitätsbedingungen ausgesetzt. In Flußmündungsgebieten, den Ubergangszonen zwi- 


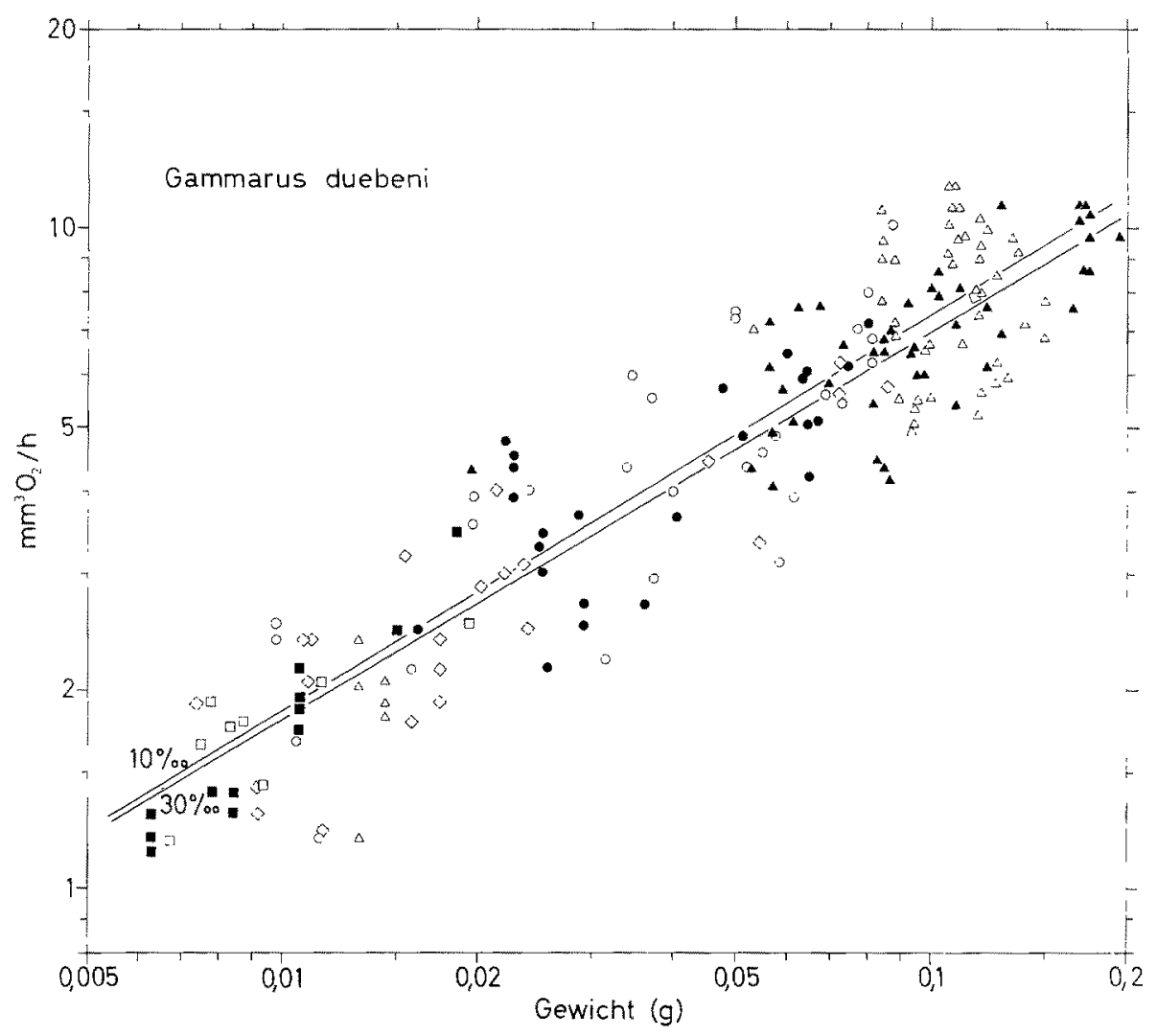

Abb. 6: Gammarus duebeni. Abhängigkeit des O2-Verbrauchs vom Körpergewicht bei $30 \%$ und $10 \%$ und $15^{\circ} \mathrm{C} . \diamond$ Meßdaten der mit Thelohania berediteria befallenen Jungtiere und $9 Q$. (Vgl. Erläuterungen zu Abb. 2)

schen limnischen und marinen Lebensräumen, treten besonders drastische Fluktuationen des Salzgehalts auf, die kurzfristiger. (gezeitenrhythmischer) wie auch langfristiger (jahreszeitlicher) Natur sein können. Bedingt durch diese und andere sich ständig verändernde Umweltgegebenheiten werden Astuarbewohner in ihren physiologischen und ökologischen Reaktionen. besonders stark beansprucht. Sie verfügen daher über bestimmte Kompensationsmöglichkeiten, wie z. B. ausgeprägte osmoregulatorische Fähigkeiten, um den wechselnden Außenbedingungen widerstehen zu können.

Da die untersuchten Gammarus-Arten größtenteils auch Ästuarien besiedeln und durch die dort herrschenden Salzgehaltsschwankungen einem ständigen osmotischen Streß ausgesetzt sind, wurde im Anschluß an das Problem der Größenabhängigkeit des respiratorischen Stoffwechsels geprït, wie sich ein plötzlicher Wechsel der Salinität auf die Atmungsintensität auswirkt. Im Zusammenhang mit den damit verbundenen osmoregulatorischen Vorgängen interessierte vor allem die Frage nach dem zeitlichen Verlauf der Umadaptation, der Neueinstellung der Stoffwechsellage vom Ausgangsniveau auf einen neuen Gleichgewichtszustand. Diese Versuche verfolgen daher das Ziel, das 
Ausmaß der physiologischen Anpassungsfähigkeit an Salinitätsänderungen unter dem Gesichtspunkt eines zwischenartlichen Vergleichs zu beleuchten.

Wie Untersuchungen von BeAdle \& Cragg (1940), Kinne (1952) und WernTZ (1963) gezeigt haben, sind Gammariden als hyperosmotische Regulierer einzustufen. Marine Arten vermögen die osmotische Konzentration des Blutes stärker als Brackwasserformen zu regulieren, während Süßwasserarten über die geringste Regulations" kapazität verfügen. Diese Fähigkeit dokumentiert sich darin, daß erstere iber weitaus größere Salinitätsbereiche einen bestimmten osmotischen Konzentrationsgradienten zwischen Innen- und Außenmedium aufrechtzuerhalten in der Lage sind als letztere.

Bei der Durchführung der Versuche über die Wirkung einer sprunghaften Anderung des Salzgehaltes galt es, die Salinitätstoleranzen der einzelnen Arten zu berücksichtigen. Die unteren Toleranzgrenzen, die das natürliche Vorkommen in brackigen Gewässern limitieren, weisen für die untersuchten Gammarus-Species gewisse Unterschiede auf, wie aus zahlreichen ökologischen Befunden über thre Verbreitung geschlossen werden kann. G. locusta toleriert in der Ostsee noch Salzgehalte von 5-6\%, während das Vorkommen von $G$. oceanicus sowie von G. salinus durch Salinitäten von 2-3\% \%egrenzt wird (SEGERSTRÅLE 1947, 1959). Alle drei Arten treten aber auch im rein marinen Bereich auf. Für G. zaddacbi wurde ein Vorkommen in Salinitäten zwischen 0,1 und 33,4\% im Bereich eines Flußmündungssystems festgestellt (STOCK et al. 1966). G. duebeni ist ebenso wie $G$. zaddachi eine typische Brackwasserform. Sie treten vorzugsweise in meso- und oligohalinen Gewässern auf; beide Arten vermögen sogar bis in Süßwasserbiotope vorzudringen (vgl. u. a. Hynes 1954, Sutcliffe 1967, PrNKSTER et al. 1970). Darüber hinaus ist $G$. duebeni auch in Gewässern mit einem Salzgehalt bis zu $30 \%$, vereinzelt sogar in noch höheren Konzentrationen (45\%) gefunden worden (ForSMAN 1951).

Ausgehend vom euhalinen bzw. mesohalinen Salinitätsbereich und dem Wechsel von einer Stufe zur anderen, gehörte zu dem Versuchsprogramm auch der sprunghafte Übergang zu oligohalinen und polyhalinen Stufen. Um die Flohkrebse nicht allzu starken physiologischen Belastungen zu unterwerfen, betrug die Differenz der einzelnen Salzgehaltskonzentrationen, denen sie ausgesetzt wurden, maximal $20 \%$. Im einzelnen wurden folgende Testserien durchgeführt: Sprunghafter Wechsel von 10\% in 30\% und umgekehrt, von $30 \%$ in $45 \%$ sowie von $10 \%$ in $3 \%$.

Alle Messungen erfolgten an adulten Individuen, die langfristig an 10\% oder $30 \%$ und gleichbleibende Laborbedingungen adaptiert waren. In diesen Salzgehaltsstufen wurden zunächst über mehrere $(>8)$ Stunden sich erstreckende Respirationsmessungen durchgeführt. Dann erst folgte ein abrupter Salinitätswechsel unter kontinuierlicher Weiterführung der Registrierungen. Da deutlich wurde, daß sich entscheidende Veränderungen der Stoffwechselintensität im allgemeinen innerhalb eines Tages, meist jedoch unmittelbar nach dem Salzgehaltssprung vollziehen, wurde der Meßvorgang in der Regel nicht über 35-40 Stunden ausgedehnt. Die Abbildungen 7 bis 23 veranschaulichen, welche Veränderungen der respiratorische Stoffwechsel in den verschiedenen Testserien erfahren hat.

Wie im vorangegangenen Kapitel ausgeführt wurde, besteht zwischen Körpergröße und Atmungsintensitär - abgesehen von G. locusta in der 30\%-Stufe - keine Proportionalität, sondern eine mehr oder weniger oberflächenbezogene Relation. Aus 
diesem Grund unterblieb ein Bezug der Stoffwechselwerte auf eine bestimmte Gewichtseinheit. Da ferner nicht für alle Arten und für alle Testserien gewichtsgleiche Versuchstiere zur Verfügung standen, erfolgte eine Umrechnung der Meßdaten auf Relativwerte, die zudem eine bessere Vergleichbarkeit der Ergebnisse gestatten. Dies geschah nach folgendem Prinzip: Die in der ersten Salzgehaltsstufe erhaltenen Atmungsgrößen dienten als Bezugswerte für alle später gemessenen Anderungen. Stets wurden jene Meßdaten $\left(\mathrm{O}_{2}\right.$-Verbrauch pro Stunde) zugrunde gelegt, die über einen Zeitraum von 5-6 Stunden vor dem Salinitätswechsel registriert worden waren. Diese wurden für jedes einzelne Versuchstier gemittelt und gleich $100 \%$ gesetzt. Durch starke lokomotorische Aktivität bedingte höhere Stoffwechselwerte blieben unberücksichtigt. Ein Salinitätswechsel erfolgte erst dann, wenn eine gleichbleibende Atmungsintensität verzeichnet werden konnte. Die in der 2. Salzgehaltsstufe registrierten Meßdaten wurden dementsprechend ebenfalls als Relativwerte ausgedrückt, d. h. als prozentuale Abweichungen gegenüber den Ausgangswerten der 1. Salinitätsstufe. Die für jedes Versuchstier pro Stunde erhaltenen Relativwerte wurden addiert und die Mittelwerte, mittleren Fehler des Mittelwerts und Standardabweichungen berechnet. Pro Versuchsreihe wurden im Durchschnitt mindestens 5-6 Flohkrebse getestet. Da keine geschlechtsbedingten Abweichungen auftraten, konnten die Meßdaten für weibliche und männliche Individuen zusammengefaßt werden; in zahlreichen Fällen wurden die Experimente allerdings ausschließlich an Individuen eines Geschlechts durchgeführt. Bei den Arten, die sich durch größere Unterschiede der Regressionskoeffizienten auszeichnen, wurde darauf geachtet, daß die pro Versuchsserie eingesetzten Individuen aus annähernd gleichen Gewichtsklassen entstammten.

Im zeitlichen Ablauf des Adaptationsprozesses, der durch den Einfluß plötzlicher Veränderungen der Intensität bestimmter Umweltfaktoren ausgelöst wird, kann eine aus drei Phasen bestehende Reaktion zutage treten (vgl. Prosser 1958, KINNE 1964): Sie beginnt im typischen Fall mit einer nur kurze Zeit währenden Schockreaktion, die in Gestalt eines „Overshoots" ihren Ausdruck findet. Darauf folgt die Stabilisierungsphase, die mehrere Minuten, Stunden oder Tage andauert. Diese geht schließlich in die Phase eines neuen stationären Zustands über, womit die Adaptation an den veränderten Umweltfaktor vollzogen ist. Wie die Abbildungen 7-23 veranschaulichen, heben sich diese einzelnen Phasen, soweit die Veränderungen der Atmungsintensität den Prozeß der Salzgehaltsanpassung widerspiegeln, mehr oder weniger deutlich voneinander ab. Allerdings treten in einigen Fällen die Schockreaktion und die Phase des neuen stationären Zustandes nicht so deutlich abgegrenzt hervor.

Zunächst werden die Resultate vorgestellt, die sich bei der Uberführung der Gammariden aus einem verdünnten in ein konzentrierteres Medium ergeben haben.

Bei dem Salinitätssprung von 10\% in $30 \%$ ist generell festzustellen, daß sich die Einstellung auf ein neues Stoffwechselniveau ziemlich rasch vollzieht; nach etwa 3 bis 5 Stunden sind bereits annähernd gleichbleibende $\mathrm{O}_{2}$-Verbrauchswerte erreicht (Abb. 7-9). Dabei kommt es bei den getesteten Größenklassen von G. locusta und G. oceanicus zu einer geringfügigen Abnahme, bei G. zaddacbi zu einer leichten Erhöhung der Atmungsintensität, während sich bei $G$. salinus und $G$. duebeni (Individuen der gleichen Gewichtsgruppe) keine weiteren Veränderungen zeigen. Da der Kurvenverlauf für $G$. locusta und $G$. oceanicus einerseits sowie für $G$. duebeni und $G$, salinus andererseits 


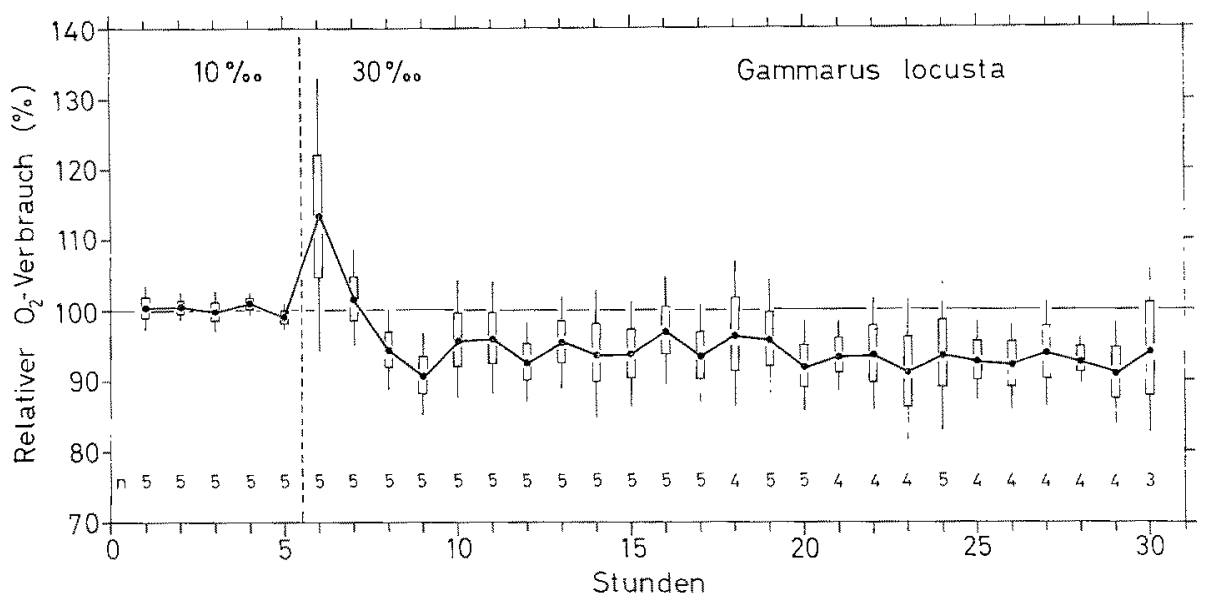

Abb. 7: Gammarus locusta $(\delta \delta, 0,04-0,06 \mathrm{~g})$. Relativer $\mathrm{O}_{2}$-Verbrauch (bei $15^{\circ} \mathrm{C}$ ) nad sprunghaftem Salinitätswechsel von $10 \%$ in $30 \%$ als Funktion der Zeit. Für die als Relativwerte wiedergegebenen Stoff wechseldaten (vgl. Text) wurden der mittlere Fehler des Mittelwertes (senkrechte Rechtecke) und die Standardabweichung (senkrechte Striche) errechnet. $\mathrm{n}=$ Anzahl der Versuchstiere

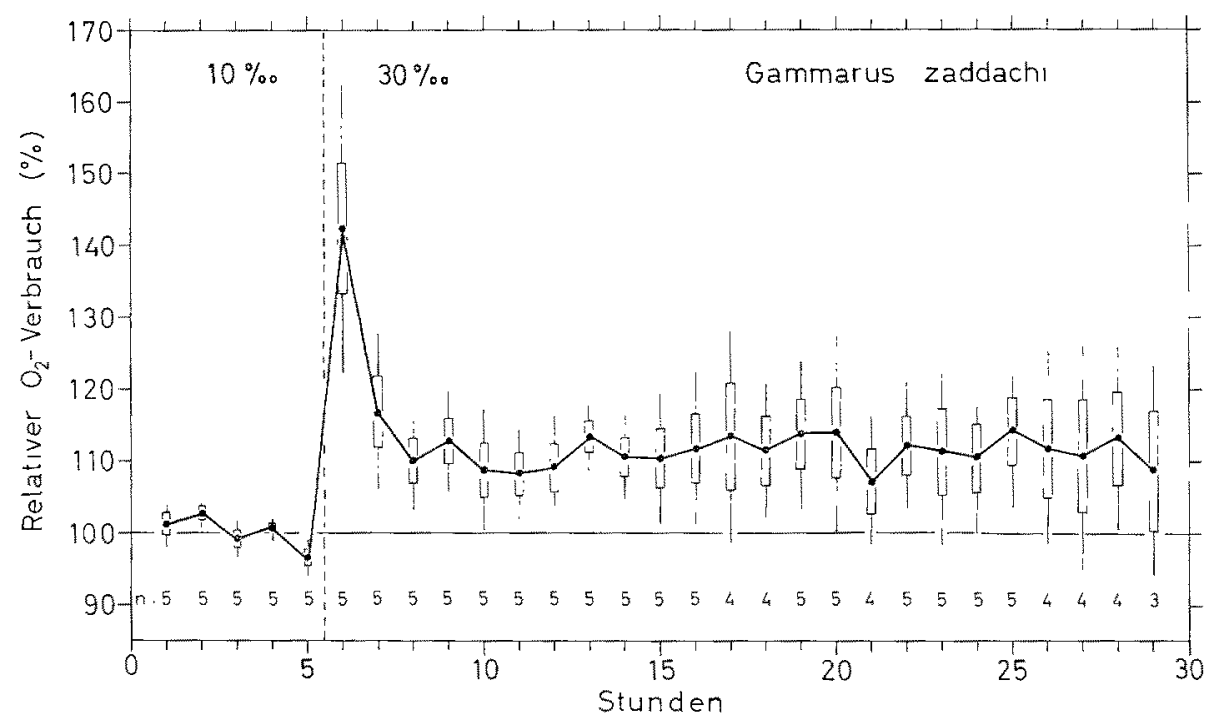

Abb. 8: Gammarus zaddachi ( $\hat{\partial}, 0,02-0,05 \mathrm{~g})$. Relativer $\mathrm{O}_{2}$-Verbrauch (bei $\left.15^{\circ} \mathrm{C}\right)$ nach sprunghaftem Salinitätswechsel von $10 \%$ in $30 \%$. (Vgl. Erläuterungen zu Abb. 7)

sich als recht ähnlich erwies, sind die Ergebnisse für jeweils nur einen Vertreter dieser Arten dargestellt worden.

Der mehr oder weniger starke Anstieg des respiratorischen Stoffwechsels, der in dieser und in den anderen Versuchsserien unmittelbar nach dem Salinitätswechsel zu- 
tage treten kann, ist zum Teil auf eine Erhöhung der lokomotorischen Aktivität zurückzuführen. Durch die Konzentrationsänderung im Außenmedium kommt es anfangs vielfach zu Fluchtreaktionen, die sich in stärkerer motorischer Aktivität niederschlagen. Derartige, im allgemeinen nur kurzzeitige Aktivitätsphasen können auch während des weiteren Verlaufs des Anpassungsgeschehens auftreten. Sie blieben jedoch bei der Auswertung unberücksichtigt. Daraus erklärt sich, weshalb sich die pro Stunde angegebenen Mittelwerte nicht durchgängig auf die gleiche Anzahl von Versudsstieren beziehen.

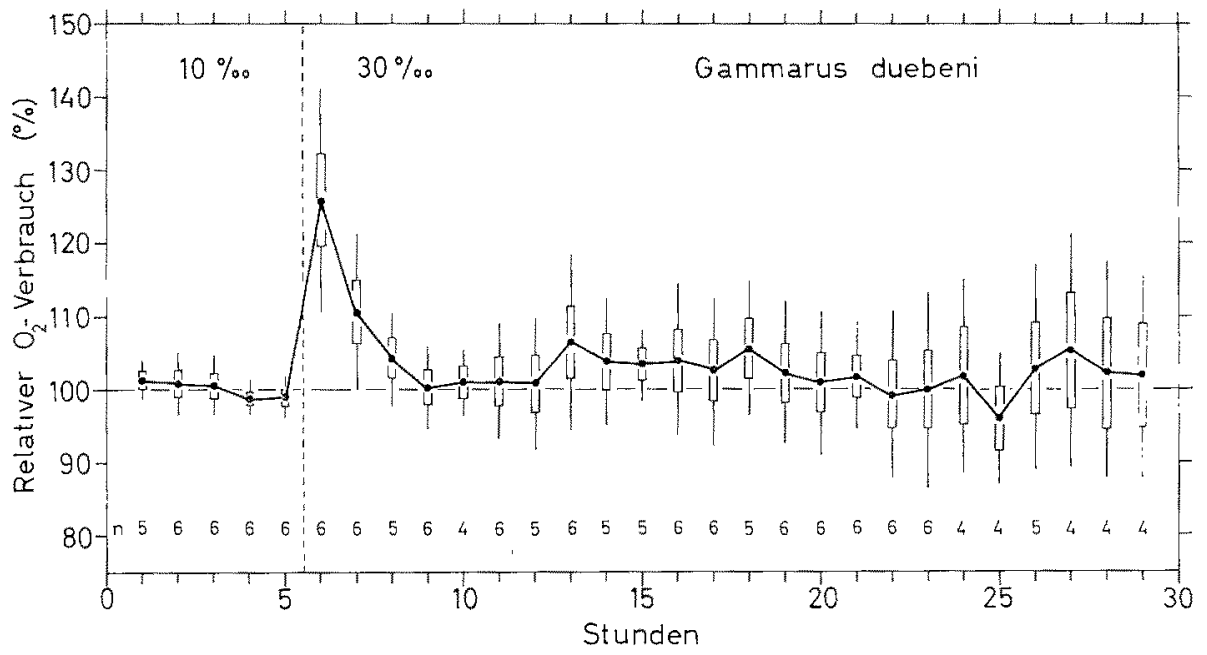

Abb. 9: Gammarus duebeni $\left(\hat{\partial} \hat{\delta}+q Q, 0,06-0,09 \mathrm{~g}\right.$ ). Relativer $\mathrm{O}_{2}$-Verbraudh (bei $15^{\circ} \mathrm{C}$ ) nach sprunghaftem Salinitätswechsel von $10 \%$ in $30 \%$. (Vgl. Erläuterungen zu Abb. 7)

Die nicht unerhebliche Streubreite der Messungen ist in erster Linie auf individuelle Unterschiede zurückzuführen, die in bezug auf die Reaktionen der Versuchstiere zutage tritt, in geringerem Maße aber auch auf eine etwas erhöhte Spontanaktivität, die jedoch im allgemeinen rasch abklingt. Es sei daher betont, daß angesichts des von Art zu Art recht unterschiedlichen Kurvenverlaufs keine Veranlassung besteht, die beobachteten Veränderungen des Atmungsstoffwechsels generell auf eine gesteigerte lokomotorische Aktivität zurückzuführen.

Die nächste Versuchsreihe umfaßte einen sprunghaften Wechsel von $30 \%$ in $45 \%$. Während sich bei $G$. locusta ein etwas verringerter Sauerstoffbedarf einstellt, kommt es bei $G$. oceanicus und $G$. salinus zu einem stärkeren, bei $G$. duebeni zu einem geringeren Stoffwechselanstieg (Abb. 10-13). Nach ungefähr 4-7 Stunden werden annähernd konstant bleibende mittlere Werte erreicht. Der Anpassungsvorgang vollzieht sich also ebenfalls ziemlich rasch. Die Reaktionen yon $G$, zaddacbi wurden nicht getestet, da die Toleranz dieser Species gegenüber polyhalinen Medien relativ gering ist. Die anderen Arten überstanden eine Uberführung von $30 \%$ in $45 \%$ besser, wie einige ergänzende Kontrollserien zeigten. So lag die Sterblichkeit in meinem Medium von $45 \%$ bei $G$. locusta, G. oceanicus und $G$. salinus innerhalb eines Zeitraumes von 12 Tagen $z$ wischen 20 und $30 \%$; bei $G$. duebeni betrug diese nur $5 \%$. 


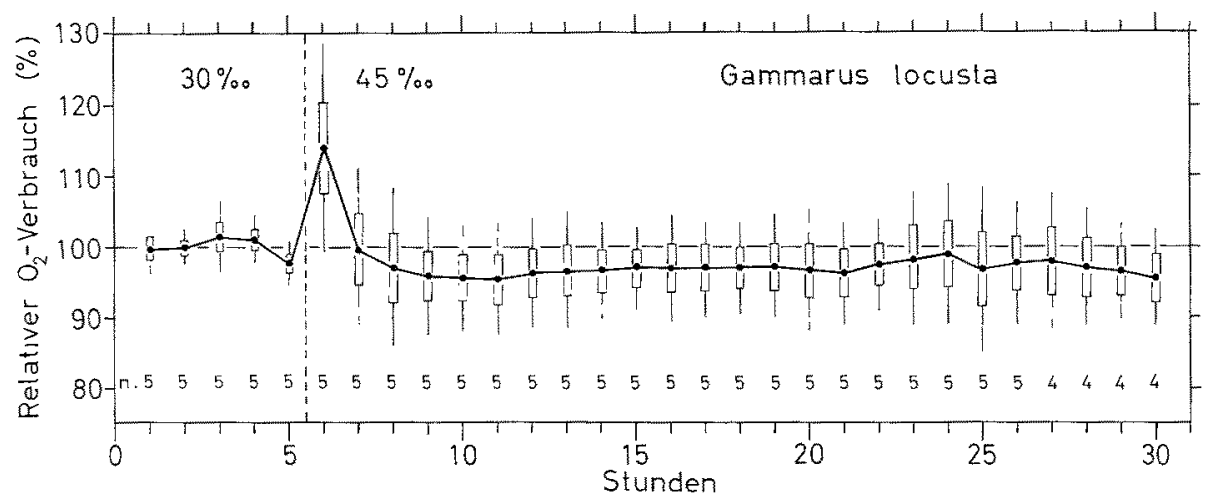

Abb. 10: Gammanus locusta $(\hat{\delta})+q 9,0,06-0,07 \mathrm{~g})$. Relativer O2-Verbrauch (bei $15^{\circ} \mathrm{C}$ ) nach sprunghaftem Salinitätswechsel von $30 \%$ in $45 \%$. (Vgl. Erläuterungen zu Abb. 7)

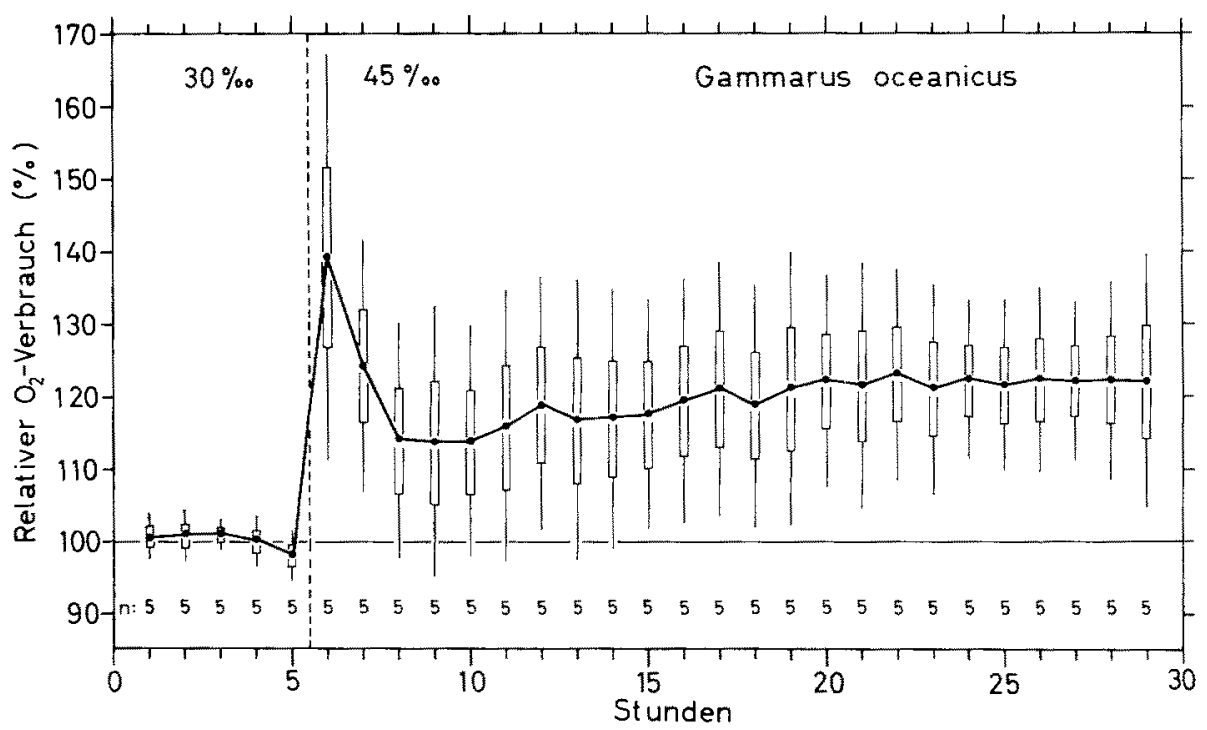

Abb. 11: Gammarus oceanicus ( $\partial \mathrm{o}+0,0,03-0,04 \mathrm{~g}$ ). Relativer Oz-Verbrauch (bei $15^{\circ} \mathrm{C}$ ) nach sprunghaftem Salinitätswechsel von $30 \%$ in $45 \%$. (Vgl. Erläuterungen zu Abb. 7 )

Zwei weitere Versuchsreihen galten schließlich der Frage nach der Art der Stoffw wechselreaktionen und ihres Zeitverlaufs bei einem Wechsel von höheren zu niederen Salinitäten. Der Salzgehaltssprung von 30\% in 10\% als Pendant zur ersten Testserie lieferte ein ganz anderes Bild (Abb. 14-19). Abgesehen von G. duebeni mit einem insgesamt gleichbleibenden Stoffwechselniveau, das nur durch eine Overshoot-Reaktion unterbrochen wird, erfährt die Atmungsintensität bei den anderen Arten eine mehr oder weniger drastische Steigerung. Diese ist bei G. locusta am größten mit einem anfänglichen Anstieg um ca. $70 \%$ über die Ausgangswerte. Den markanten Unterschied in der Reaktionsweise beider Arten veranschaulicht auch Abbildung 19, die das Resul- 


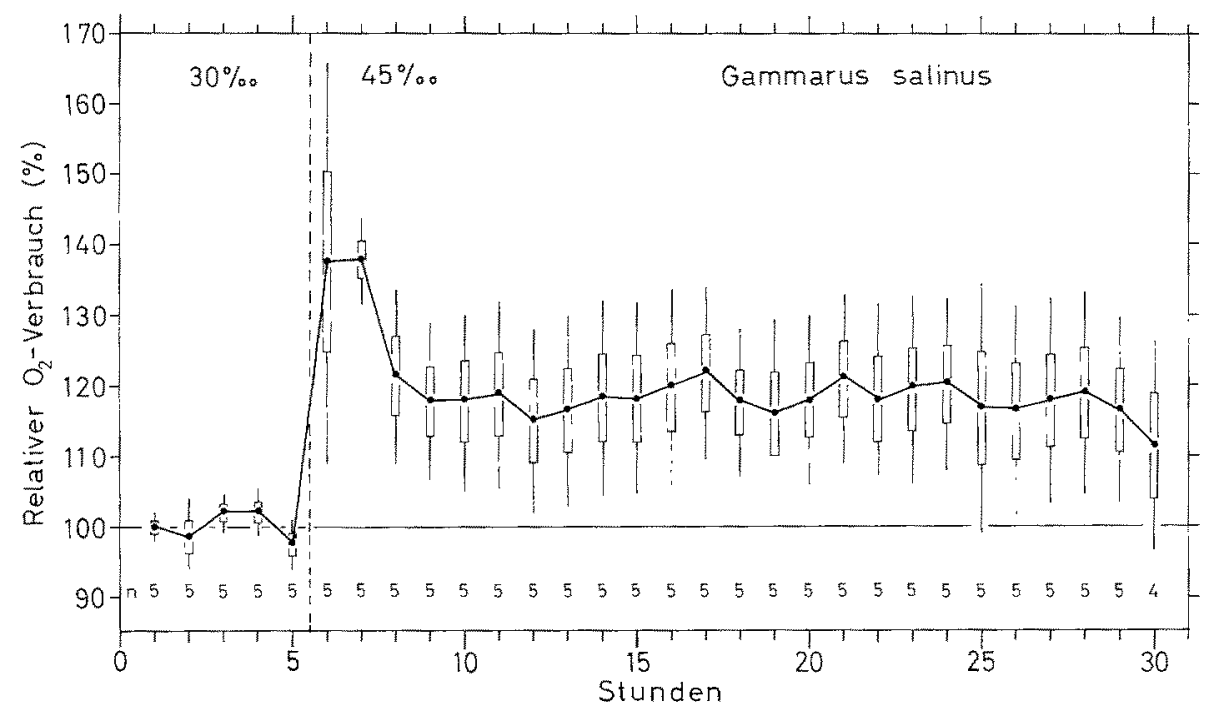

Abb. 12: Gammarus salinus $(\hat{\partial} \hat{\partial}, 0,03-0,04 \mathrm{~g})$. Relativer $\mathrm{O}$-Verbrauch (bei $15^{\circ} \mathrm{C}$ ) nach sprunghaftem Salinitätswechsel von $30 \%$ in $45 \%$. (Vgl. Erläuterungen zu Abb. 7 )

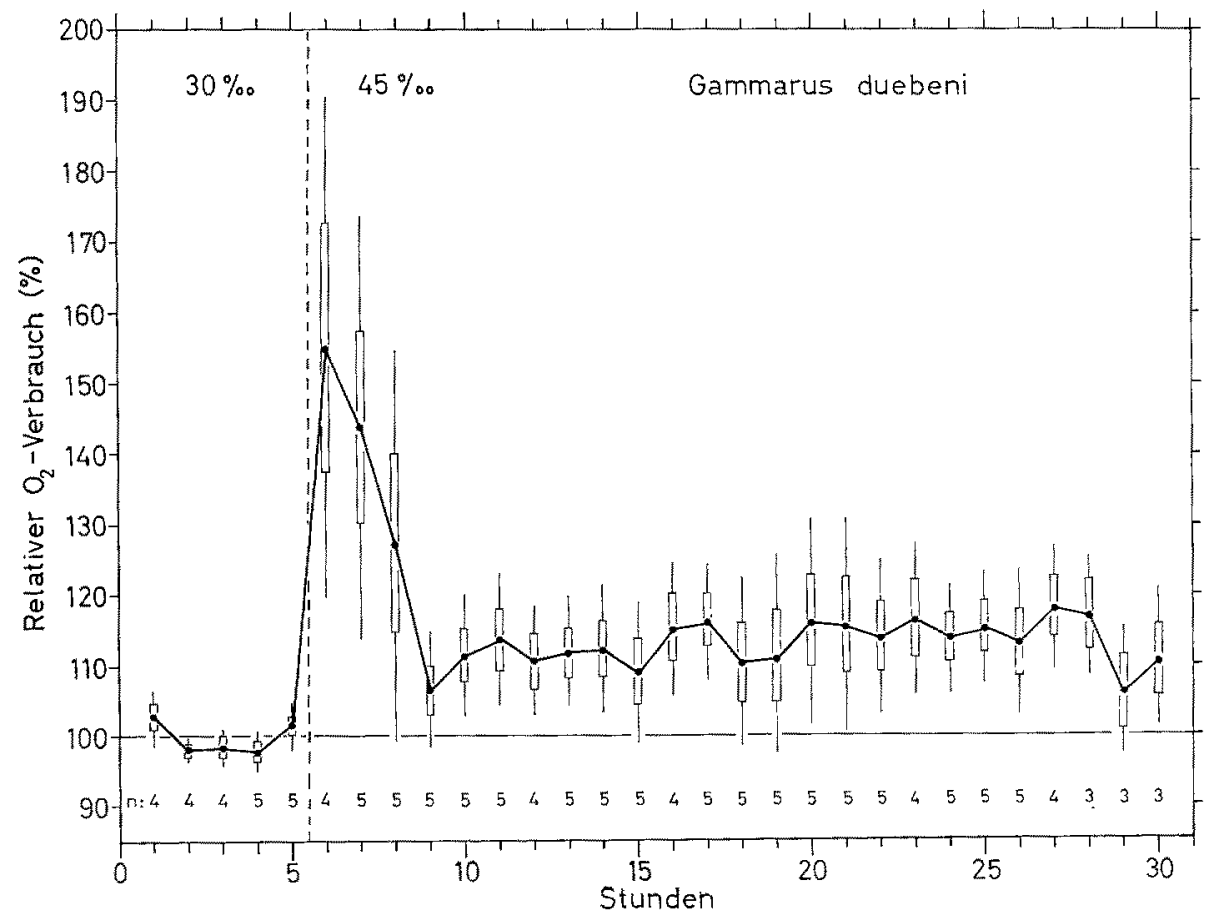

Abb. 13: Gammarus duebeni $\left(\hat{\partial} \hat{\delta}+00,0,04-0,08 \mathrm{~g}\right.$ ). Relativer $\mathrm{O}_{2}$-Verbrauch (bei $15^{\circ} \mathrm{C}$ ) nach sprunghaftem Salinitätswechsel von $30 \%$ in $45 \%$. (Vgl. Erläuterungen zu Abb. 7) 


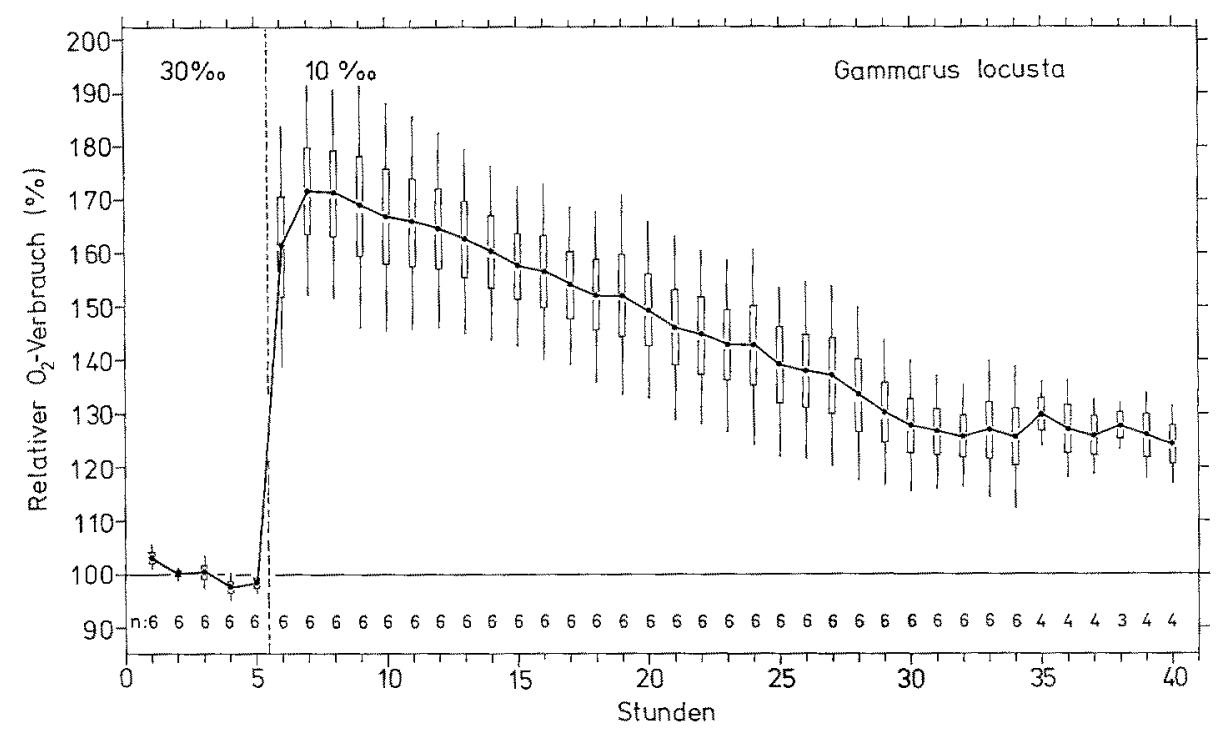

Abb. 14: Gammarus locusta ( $\hat{\partial} \hat{O}, 0,04-0,06 \mathrm{~g})$. Relativer $\mathrm{O}_{2}$-Verbrauch (bei $15^{\circ} \mathrm{C}$ ) nach sprunghaftem Salinitätswechsel von 30\% in 10\%. (Vgl. Erläuterungen zu Abb. 7)

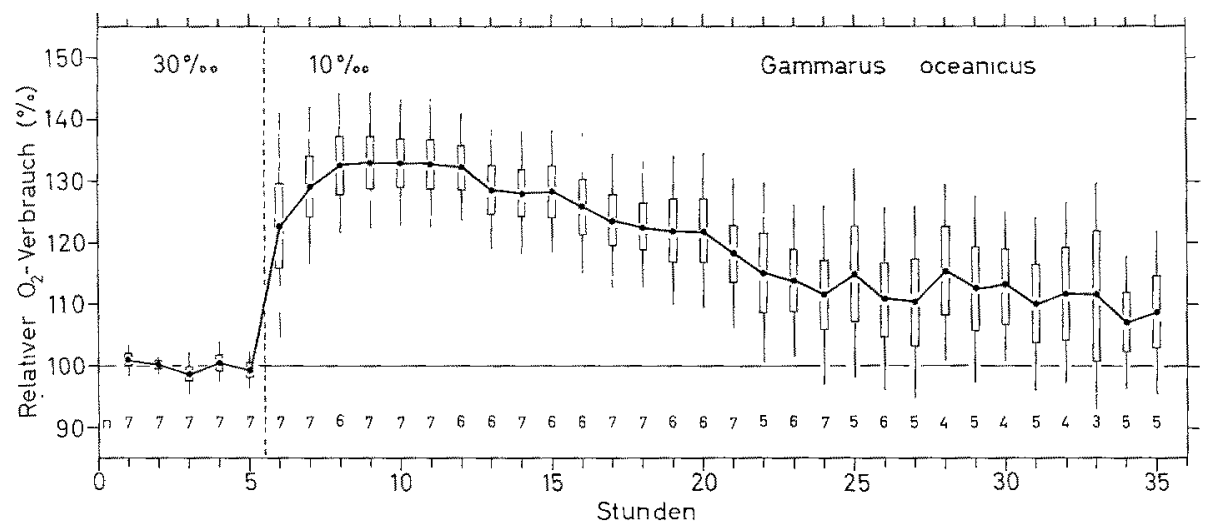

Abb. 15: Gammarus oceanicus $(\hat{\partial} \hat{\partial}+\phi 9,0,07-0,08 \mathrm{~g})$. Relativer $\mathrm{O}_{2}$-Verbrauch (bei $15^{\circ} \mathrm{C}$ ) nach sprunghaftem Salinitätswechsel von $30 \%$ in $10 \%$. (Vgl. Erläuterungen zu Abb. 7 )

tat eines mehrfachen Salinitätswechsels wiedergibt. Bei den anderen drei Arten, insbesondere bei G. zaddachi, erfährt der Atmungsanstieg ein nicht so beträchtliches Ausmaß. Die Änderungen des $\mathrm{Qo}_{2}$ während der Stabilisierungsphase zeigen einen viel langsameren Verlauf als bei den Uberführungen von einer niedrigeren in eine höhere Salzgehaltsstufe. Erst nach ungefähr 20-30 Stunden ist annähernd ein neuer ,steady state“ erreicht, wobei $G$. locusta und G. oceanicus erwartungsgemäß ein etwas höheres Niveau beibehalten als in der ersten Salzgehaltsstufe. Dies ist auch bei G. salinus der Fall; für die getestete Größenstufe liegen die beobachteten Endwerte im Mittel geringfügig höher 


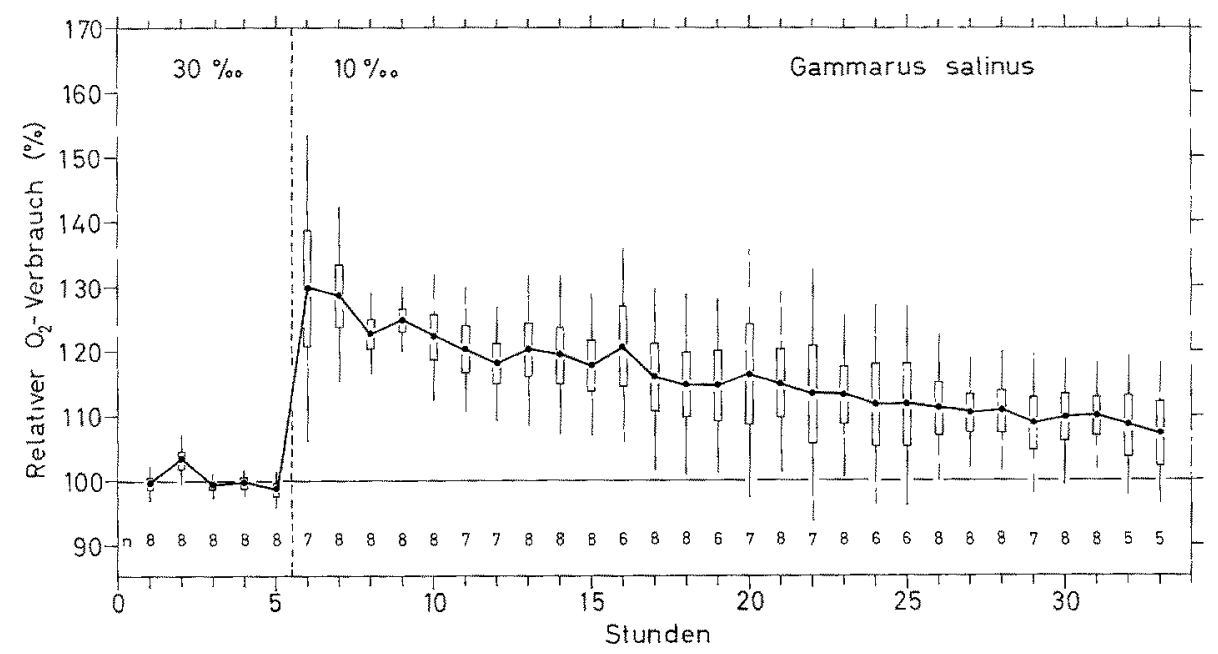

Abb. 16: Gammarus salinus ( $\delta \delta+q 9,0,03-0,05 \mathrm{~g}$ ). Relativer $\mathrm{O}_{2}$-Verbrauch (bei $15^{\circ} \mathrm{C}$ ) nach sprunghaftem Salinitätswechsel von $30 \%$ in $10 \%$. (Vgl. Erläuterungen zu Abb. 7)

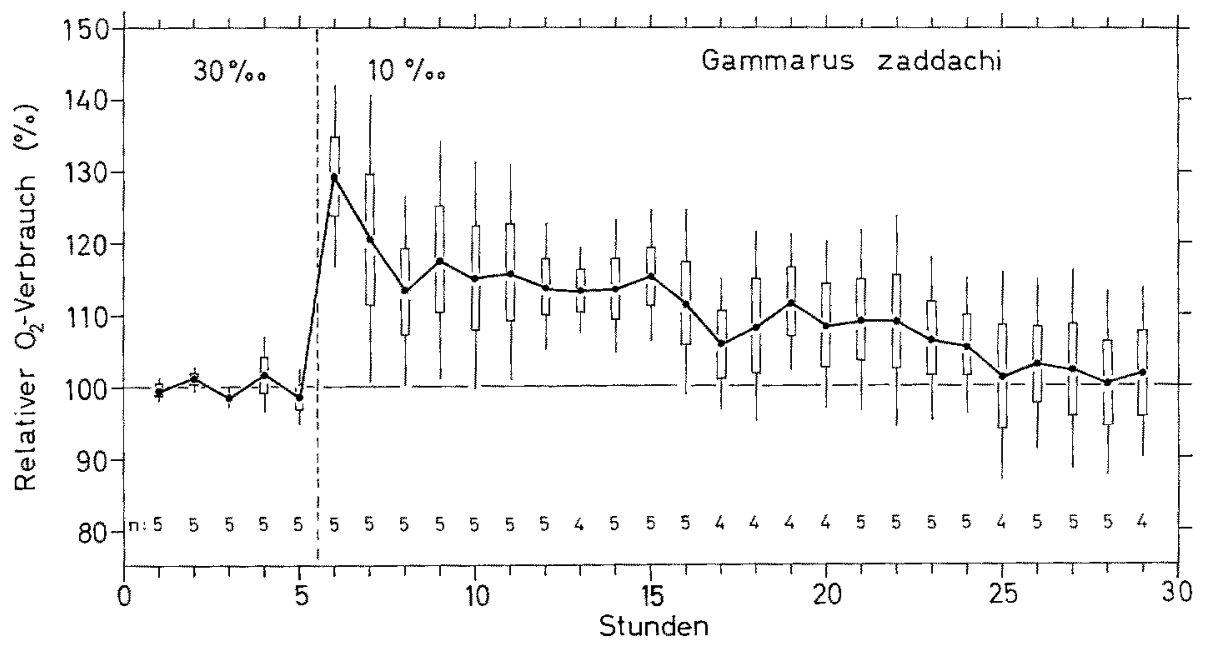

Abb. 17: Gammarus zaddachi ( $\delta, 0,03-0,04 \mathrm{~g}$ ). Relativer $\mathrm{O}_{2}$-Verbrauch (bei $15^{\circ} \mathrm{C}$ ) nach sprunghaftem Salinitätswechsel von $30 \%$ in $10 \%$. (Vgl. Erläuterungen zu Abb. 7 )

als bei den langfristig an 10\% adaptierten Individuen. Wenngleich es sich auch angesichts der relativ kleinen Zahl an Einzelmessungen um ein zufallsbedingtes Ergebnis handeln könnte, so deutet dieser Sachverhalt doch darauf hin, daß sich bei $G$. salinus die Endanpassung an einen neuen stationären Zustand innerhalb des Beobachtungszeitraumes möglicherweise noch nicht ganz vollzogen haben könnte. Diese Feststellung dürfte auch für $G$. locusta zutreffen. Einige Messungen, die sich bis zu 48 Stunden nach dem Salinitätssprung erstreckten, ließen erkennen, daß der $\mathrm{O}_{2}$-Ver- 


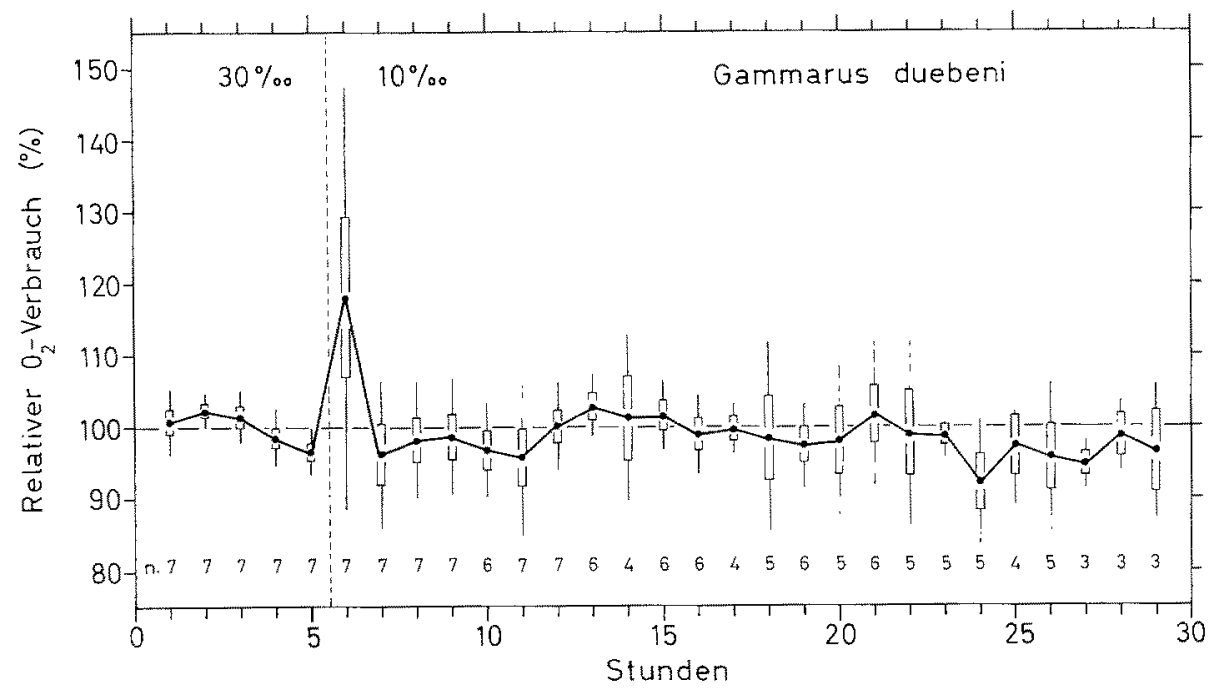

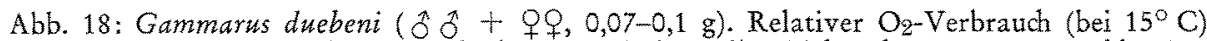
nach sprunghaftem Salinitätswechsel von $30 \%$ in $10 \%$. (Vgl. Erläuterungen zu Abb. 7)

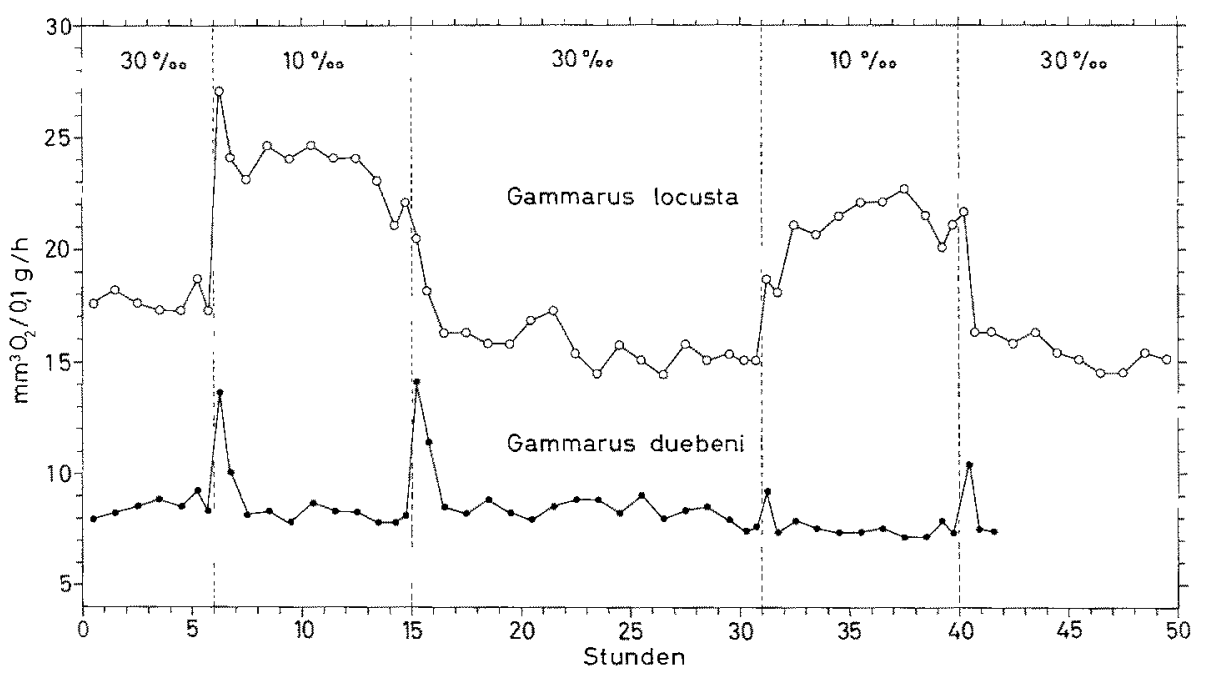

Abb. 19: $\mathrm{O}_{2}$-Verbrauch (bei $15^{\circ} \mathrm{C}$ ) eines $q$ von Gammarus locusta $(0,089 \mathrm{~g})$ und eines of von Gammarus duebeni $(0,091 \mathrm{~g})$ nach mehrfachem sprunghaftem Salinitätswechsel von $30 \%$ in $10 \%$ und zurück

brauch noch weiter absinken kann; allerdings zeichneten sich dabei nicht unerhebliche individuelle Unterschiede $a b$.

Außerdem ist $z u$ bemerken, daß nicht alle Individuen die plötzliche Uberführung von $30 \%$ in $10 \%$ überlebten. Daher wurden bei $G$. locusta wesentlich mehr Messungen als bei den anderen Arten durchgeführt. Bei der Auswertung fanden allerdings 


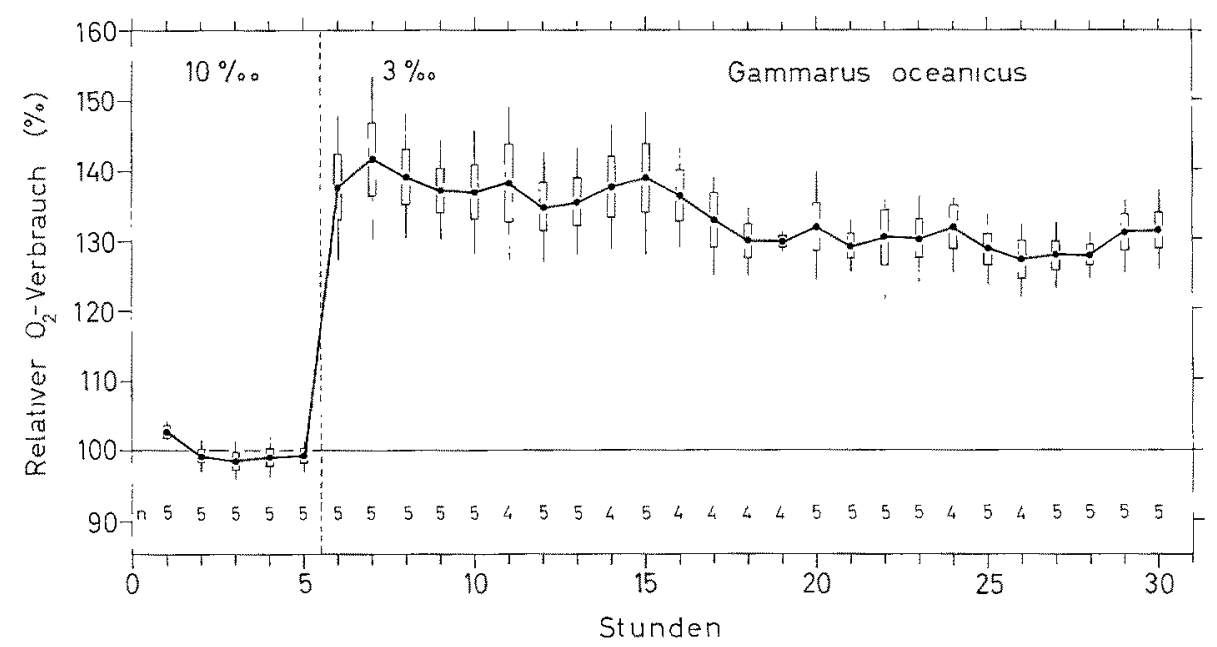

Abb. 20: Gammarus oceanicus ( $\left(9,0,06-0,08 \mathrm{~g}\right.$ ). Relativer $\mathrm{O}_{2}$-Verbraud (bei $15^{\circ} \mathrm{C}$ ) nach sprunghaftem Salinitätswechsel von $10 \%$ in $3 \%$. (Vgl. Erläuterungen zu Abb. 7)

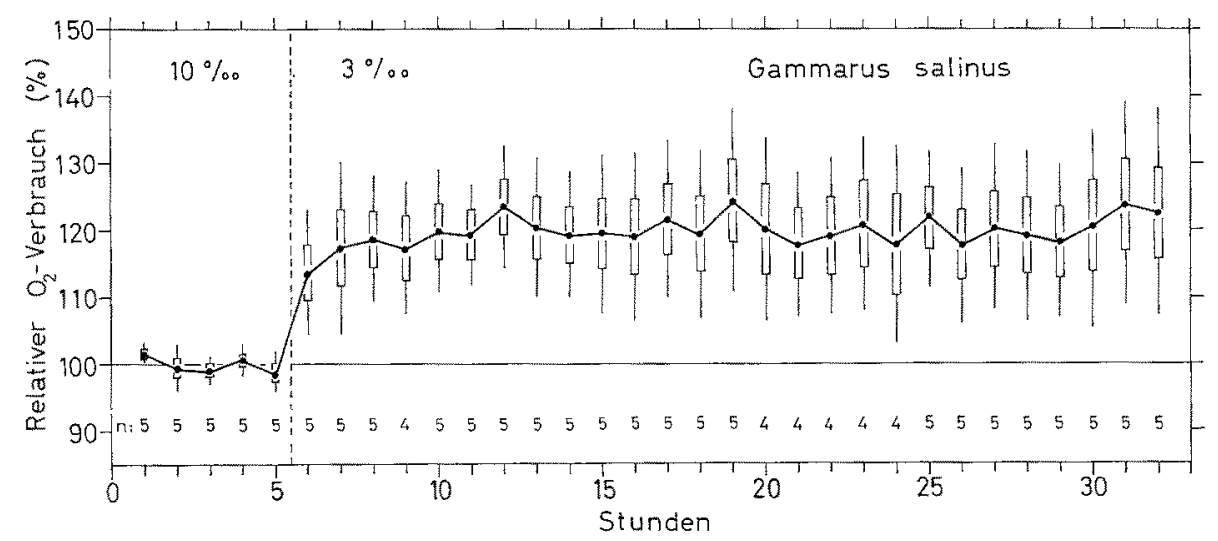

Abb. 21: Gammarus salinus $\left(\hat{\partial} \hat{\delta}+q 0,0,06-0,08 \mathrm{~g}\right.$ ). Relativer $\mathrm{O}_{2}$-Verbrauch (bei $15^{\circ} \mathrm{C}$ ) nach sprunghaftem Salinitätswechsel von $10 \%$ in $3 \%$. (Vgl. Erläuterungen zu Abb. 7)

nur die Tiere Berüdksichtigung, die den Salzgehaltswechsel ohne eine erkennbare Schädigung überstanden hatten.

Der Salinitätssprung von $10 \% \mathrm{zu} 3 \%$ repräsentiert $\mathrm{zwar}$ nur einen geringen Konzentrationsunterschied, doch bildet diese untere Salzgehaltsstufe bereits die Toleranzgrenze für $G$. oceanicus und $G$. salinus. Da sie bei $G$. locusta noch höher liegt, unterblieben entsprechende Versuche an dieser Art.

Wie die Abbildungen 20-23 belegen, tritt bei G. oceanicus unmittelbar nach dem Wechsel eine starke Zunahme des $\mathrm{O}_{2}$-Bedarfs auf, der dann wieder eine etwas rückläufige Tendenz aufweist und sich nach ca. 15 Stunden auf ein gleichbleibendes Niveau einpendelt. G. salinus erreicht mit einem langsameren Anstieg nach etwa 7 Stunden 


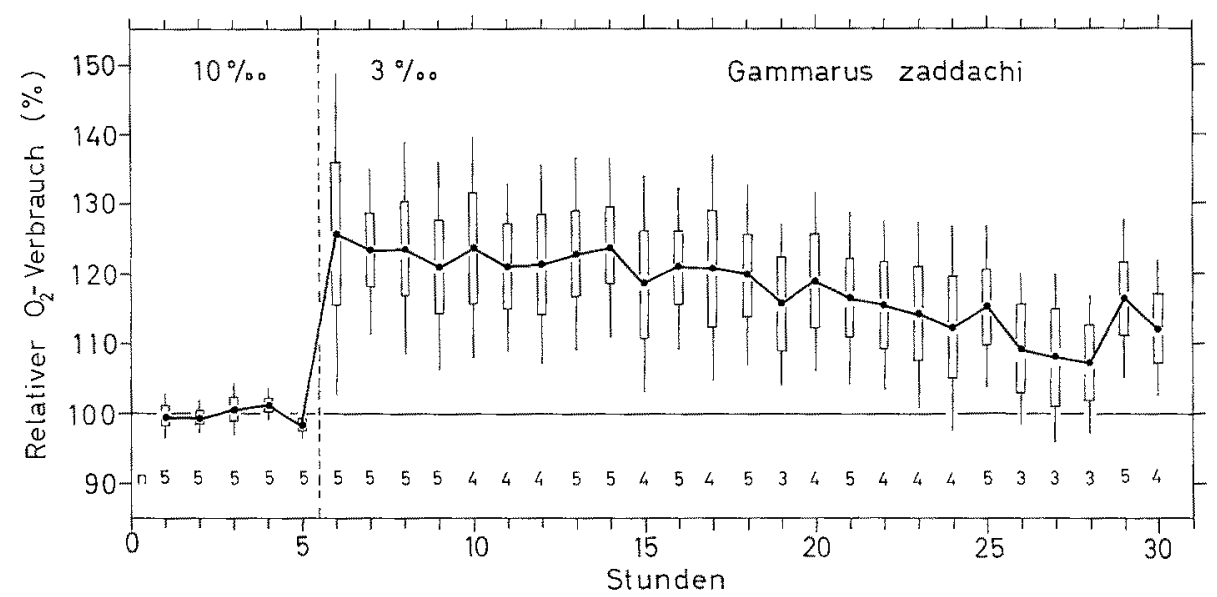

Abb. 22: Gammarus zaddachi $\left(\hat{\partial} \hat{O}, 0,1-0,11 \mathrm{~g}\right.$ ). Relativer $\mathrm{O}_{2}$-Verbrauch (bei $15^{\circ} \mathrm{C}$ ) nach sprunghaftem Salinitätswechsel von $10 \%$ in $3 \%$. (Vgl. Erläuterungen zu Abb. 7)

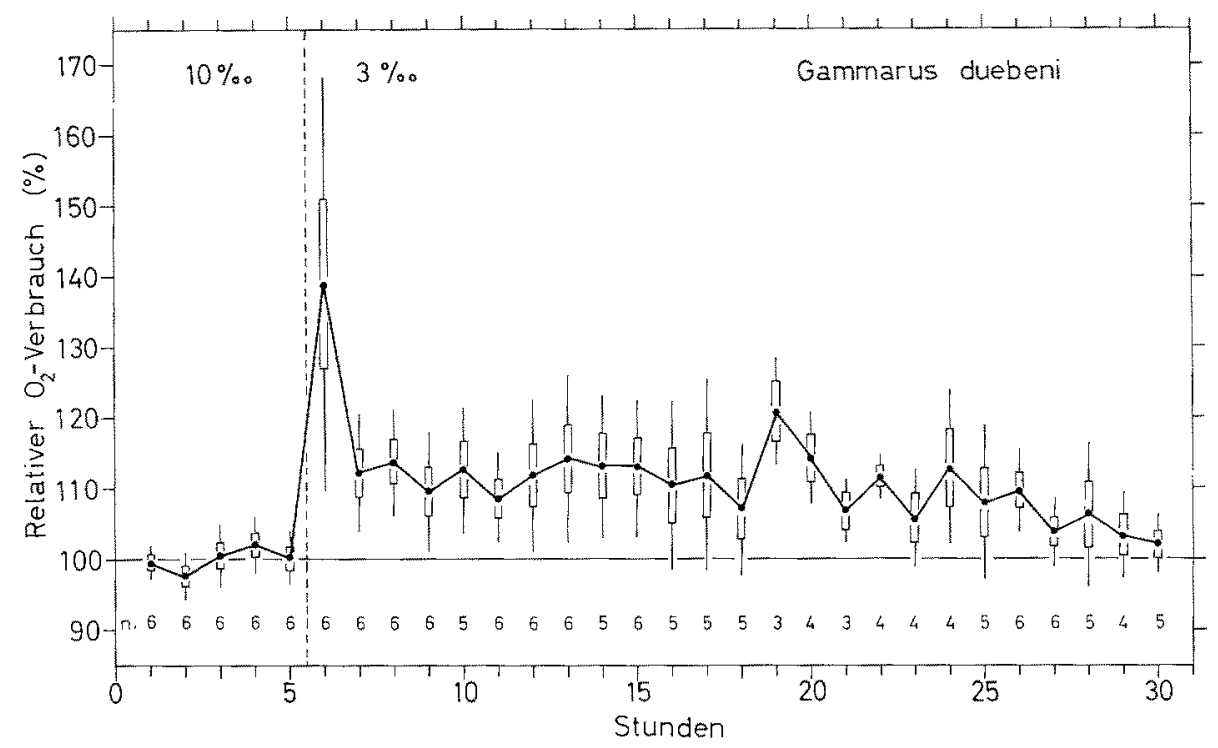

Abb. 23: Gammarus duebeni ( $\delta \partial, 0,09-0,11 \mathrm{~g})$. Relativer $\mathrm{O}_{2}$-Verbrauch (bei $15^{\circ} \mathrm{C}$ ) nach sprunghaftem Salinitätswechsel von $10 \%$ in $3 \%$. (Vgl. Erläuterungen zu Abb. 7)

einen neuen konstanten Wert. Gegenüber der Ausgangssituation ist in dieser neuen stationären Phase der Sauerstoffverbrauch noch um etwa $30 \%$ (G. oceanicus) bzw. $20 \%$ (G. salinus) erhöht. Bei G. zaddachi tritt ebenfalls ein Anstieg auf mit einem darauffolgenden Abfall, der offensichtlich nach 20-25 Stunden beendet ist. Ein gleiches Verhalten zeigt auch $G$. duebeni, wenngleich die Stoffwechselsteigerung wesentlich geringer ist und im Endstadium der Stabilisierungsphase die Ausgangswerte fast wieder erreicht werden. 
Zusammenfassend läßt sich feststellen, daß im allgemeinen der Anpassungsprozeß nach abrupten Anderungen des Salzgehaltes wesentlich langsamer vonstatten geht und mit stärkeren Anderungen der Atmungsintensität verbunden ist, wenn der Wechsel aus konzentrierteren in verdünntere Medien vorgenommen wird als bei Uberführungen in umgekehrte Richtung. Die Frage, inwieweit diese Stoffwechselreaktionen mit den sich dabei abspielenden osmoregulatorischen Vorgängen verknüpft sind, wird später noch zu erörtern sein.

\section{Einfluß eines längeren Nahrungsentzuges}

Daß die Stoffwechselintensität poikilothermer Tiere bei Nahrungsentzug abfällt, ist eine durch zahlreiche Untersuchungen belegte Tatsache. Weniger bekannt ist der zeitliche Verlauf dieser Stoffwechselreduktion. Versuche über den Einfluß eines langanhaltenden Hungerzustandes sollten daher klären, in welchem Maß der Sauerstoffverbrauch während eines größeren Zeitraumes absinkt. Von diesen Experimenten

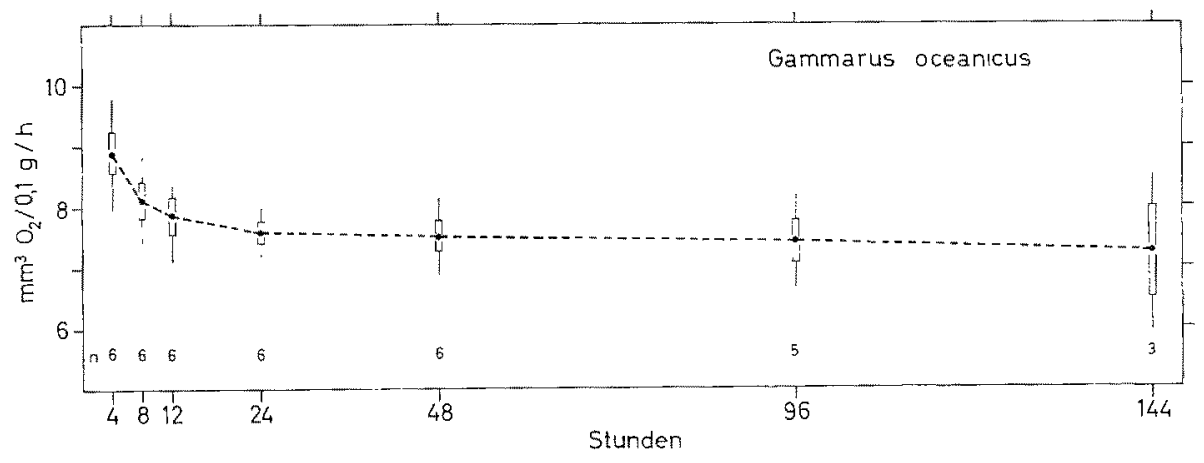

Abb. 24: Gammarus oceanicus $(\hat{\delta}, 0,07-0,09 \mathrm{~g})$. Veränderungen des $\mathrm{O}_{2}$-Verbrauchs $(30 \%$ $15^{\circ} \mathrm{C}$ ) im Verlauf eines 6 Tage währenden Nahrungsentzuges. (Vgl. Erläuterungen zu Abb. 7)

wurde zugleich ein Aufschluß dariber erwartet, inwieweit das Stoffwechselniveau bei den Versuchen über den Einfluß einer sprunghaften Anderung des Salzgehaltes, die sich ebenfalls über längere Zeit erstreckten, auf Grund des Hungerzustandes zusätzlich eine Veränderung erfahren haben könnte.

Abbildung 24 veranschaulicht die Veränderungen der Atmungsintensität von Gammarus oceanicus bei einem über 6 Tage währenden Nahrungsentzug. Wegen beträchtlicher anfänglicher Unregelmäßigkeiten begann die Auswertung der Messungen erst vier Stunden nach dem Einsetzen der Versuchstiere in die Respirationskammer. Die Flohkrebse waren zuvor ausreichend mit Nahrung versorgt worden. Wie aus dem Kurvenverlauf hervorgeht, ist innerhalb der ersten 12 Stunden eine relativ starke Stoffwechselreduktion $\mathrm{zu}$ verzeichnen. Nach ungefähr 20-24 Stunden werden annähernd gleichbleibende Werte erreicht, die etwa $15 \%$ unter dem Ausgangsniveau liegen; auch im weiteren Verlauf verringern sich diese in nur sehr geringfügigem Maße.

Parallelmessungen unter dem Einfluß eines längeren. Hungerzustandes an zwei 
Exemplaren von $G$. duebeni, die sich über eine Woche erstreckten, ergaben kein von den Verhältnissen bei $G$. oceanicus abweichendes Bild, so daß auch bei den anderen Arten mit einer ähnlichen Situation hinsichtlich der Stoff wechselreduktion im Hungerzustand gerechnet werden kann.

\section{Einfluß des Aktivitätszustandes und der Ventilationsthythmik}

Wie bei vielen in der Gezeitenzone beheimateten Tieren sind auch von Amphipoden Periodizitätserscheinungen bekanntgeworden, denen endogene Rhythmen zugrunde liegen. Bei verschiedenen Species - so auch bei Gammarus-Arten - wurde eine mit dem Tag-Nacht-Zyklus und dem Gezeitenzyklus gekoppelte Aktivitätsrhythmik nachgewiesen, über die zahlreiche Einzelarbeiten vorliegen. Eine erhöhte nächtliche Bewegungstätigkeit beobachteten JANSSON \& KäLLENDER (1968) an G. oceanicus sowie DenNert et al. (1969) an G. zaddachi. Eine mit den Gezeitenphasen korrelierte Aktivitätsperiodik stellten zudem HALCRow \& BoYd (1967) bei G. oceanicus sowie FinCHAM (1972) bei Marinogammarus marinus fest. HALCROW \& BoYd registrierten allerdings ein rasches Abklingen dieser Rhythmik unter zeitgeberfreien Laboratoriumsbedingungen.

Eine Analyse möglicher Einflüsse endogener Rhythmen auf das Stoffwechselniveau wurde nicht in den unmittelbaren Blickpunkt vorliegender Untersuchungen gestellt. Wie bereits ausgeführt wurde, stammten die Versuchstiere fast ausnahmslos aus Laboratoriumszuchten; sie boten somit keine Gewähr, daß im Freiland auftretende Periodizitätserscheinungen persistierten. So ließen insbesondere die Langzeitmessungen über mehrere Tage zur Ermittlung der Stoffwechselreduktion unter Hungerbedingungen ein deutliches Wirksamwerden derartiger Einflüsse nicht erkennen. Zwar wurde in einigen Fällen eine gewisse nächtliche Stoffwechselsteigerung, hervorgerufen durch erhöhte lokomotorische Aktivität, verzeichnet, doch traten zumeist tagesperiodische Schwankungen des Sauerstoffverbrauches unter den Bedingungen eines natürlichen Licht-Dunkel-Wechsels, wie sie im Labor während der Messungen herrschten, nicht hervor. Einige orientierende Versuche an Exemplaren von $G$. duebeni, die lange Zeit vor wie auch während der Messungen einem Licht-Dunkel-Wechsel von 12:12 Stunden ausgesetzt waren, ließen ebenfalls das Hervortreten einer Stoffwechselrhythmik nicht klar erkennen.

An Hand der kontinuierlich aufgezeichneten Meßwerte konnte der Aktivitätszustand der Versuchstiere recht genau beurteilt werden. Durch Beobachtung ihres Verhaltens in der Respirationkammer einerseits und Vergleich des registrierten Kurvenverlaufs andererseits konnte ein eindeutiges Bild darüber gewonnen werden, $\mathrm{b}$ die Flohkrebse im Ruhezustand verharrten oder Bewegungen ausführten. Ruhe- und Aktivitätsstoffwechsel ließen sich daher mit weitgehender Sicherheit auseinanderhalten und zueinander in Beziehung setzen. So konnte bei adulten Individuen im Zustand starker Bewegungstätigkeit ein Anstieg des Stoffwechselniveaus um das 2,5-3fache gegenüber den Ruhewerten gemessen werden; bei Exemplaren von G. duebeni ergab sich sogar eine Steigerung des Sauerstoffbedarfs von mehr als dem Dreifachen. Dabei ist zu be- 
rücksichtigen, daß die geringe Größe der Atemkammer keine kontinuierlichen Schwimmbewegungen, sondern nur ein Hin- und Herpendeln sowie ein Drehen um die eigene Körperachse zuließ. Die hier angegebenen Werte stimmen größenordnungsmäßig recht gut mit Daten von Halcrow \& Boyd (1967) überein. Diese Autoren führten bei G. oceanicus kombinierte Respirations" und Aktivitätsmessungen in Abhängigkeit von der Temperatur durch und ermittelten bei $15^{\circ} \mathrm{C}$ während Phasen einer Schwimmaktivität Steigerungen des Sauerstoffverbrauchs um das 2,5fache gegenüber dem Ruhezustand.

Es wurde bereits darauf hingewiesen, daß eine völlige Ruhestellung der Flohkrebse in der Respirationskammer über längere Zeit nicht gegeben war, sondern eine gewisse Spontanaktivität in Rechnung gestellt werden muß, die sich in gelegentlichen Bewegungen des Körpers und der Extremitäten sowie der Ventilationstätigkeit der Pleopoden äußert.

Durch die caudad gerichteten Schläge der Pleopoden wird ein Wasserstrom von vorn zum Hinterende getrieben, der eine ständige Erneuerung des Atemmediums entlang der Kiemenoberfläche und damit einen maximalen Konzentrationsgradienten für den Gasaustausch gewährleistet. Zur Frage des Regulationsmechanismus der Arembewegungen sind Untersuchungen über die Abhängigkeit der respiratorischen Pleopodenaktivität von der Sauerstoffspannung bei G. pulex, G. locusta (WäLSHE-MAETZ 1956) und Marinogammarus obtusatus (GAMBLE 1970) sowie an anderen Amphipoden angestellt worden. Sie ergaben, daß eine Reduktion der $\mathrm{O}_{2}$-Konzentration bis auf ca. $20 \%$ der Normalwerte zu einem starken Anstieg der Schlagfrequenz führt, während noch geringere Konzentrationen einen Abfall der Ventilationsaktivität bewirken. Bei Sauerstoffsättigung des Atemmediums beobachtete GAMBLE eine zwar nahezu kontinuierliche, jedoch mehr oder weniger irreguläre Pleopodenaktivität.

Auch bei den hier untersuchten Gammariden kommt es in Ruhestellung meistens zu keiner regelmäßigen Bewegungsfolge des Pleopodenschlages. Nach längerem, ungestörten Verweilen der Versuchstiere in der Atemkammer unter Grundumsatzbedingungen kann jedoch dieser respiratorische Ventilationsmechanismus eine mehr oder weniger ausgeprägte Rhythmik annehmen. Wie die Registrierbeispiele der Abbildung 25 verdeutlichen, spiegeln sich derartige periodische Ventilationsbewegungen in den ziemlich regelmäßigen Schwingungen der Atmungskurven wider. In mehr oder weniger rhythmischer Bewegungsfolge alternieren dann Phasen des Pleopodenschlages mit Phasen der Pleopodeninaktivität, so daß der Kurvenverlauf ein gezacktes Aussehen erhält. Während der Ventilationsbewegungen steigt der Sauerstoffverbrauch, um zum Zeitpunkt der Ruhestellung der Pleopoden wieder abzufallen. Die Amplitudengröße der Schwingungen, wie sie auf dem Kompensationsschreiber aufgezeichnet wurde, erwies

Abb. 25: Registrierbeispiele von verschiedenen Versuchstieren mit zum Teil deutlich ausgeprägter Ventilationsthythmik. a Gammarus locusta $(0,30 \% 0) ; b$ G. oceanicus $(\hat{\delta}, 30 \% 0)$; $c G$. salinus $(Q, 30 \%) ; d G$. duebeni $(9,10 \%)$; e $G$. duebeni (Jungtier, $30 \% 0$ ). Die Regelmäßigkeit des Kurvenverlaufs wird in einigen Fällen $(b, c, e)$ durch kurzzeitige Aktivitätsphasen unterbrochen, dic eine erhöhte Og-Aufnahme bedingen. Die Linien oberhalb der Atmungskurver geben die O2-Spannung luftgesättigten Wassers in Abhängigkeit von dem aktuellen Luftdruds wieder 


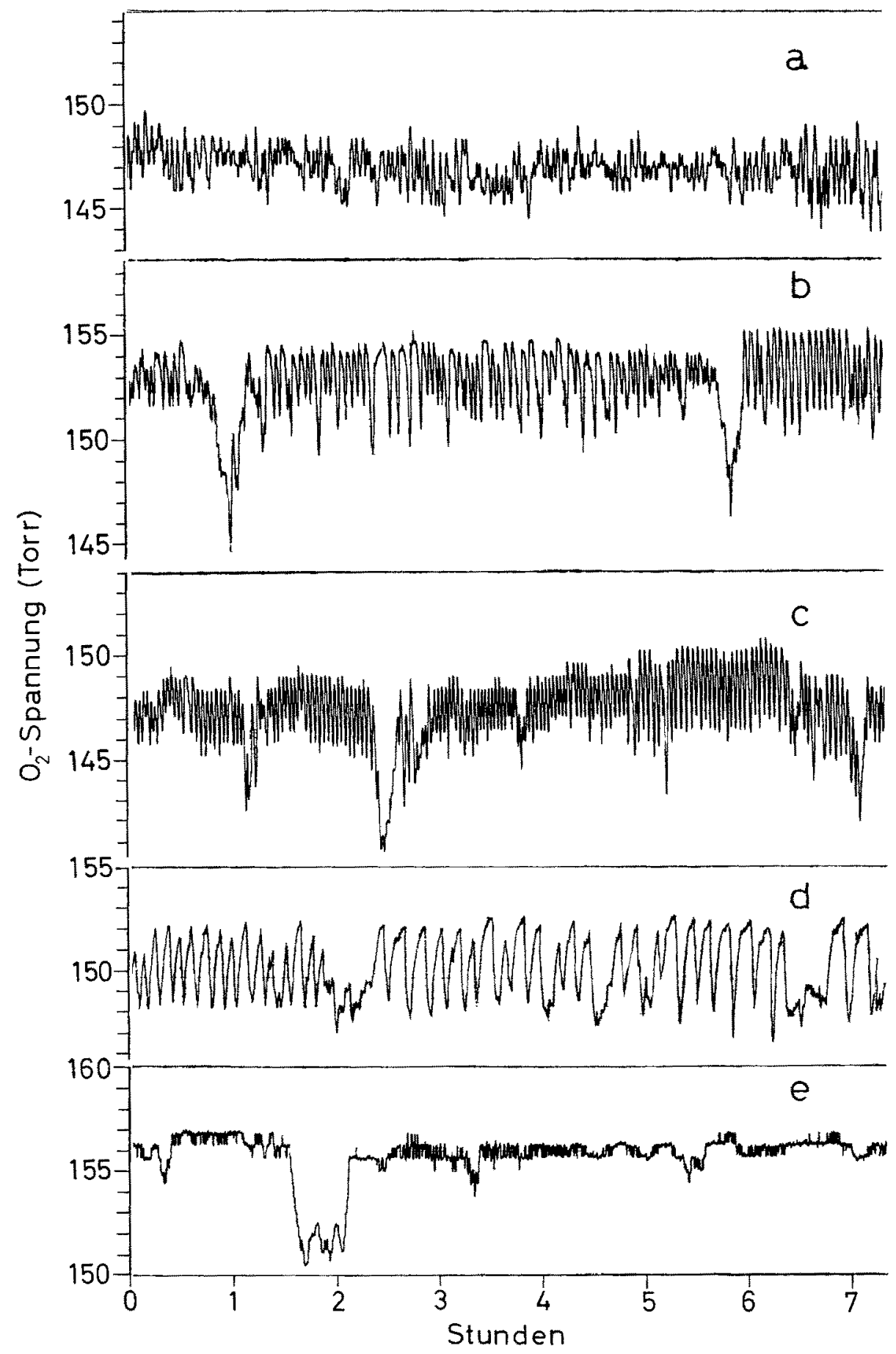


sich als abhängig von der Wasserdurchlaufmenge und der Individuengröße. Inwieweit die Ventilationsrhythmik durch weitere Faktoren, wie z.B. der Temperatur, modifiziert wird, ist im Rahmen dieser Arbeit nicht geprüft worden. Die Rate des Wasserdurchlaufs, die im Bereich zwischen 12 und $60 \mathrm{ml} / \mathrm{h}$ getestet wurde, beeinflußt die Amplitude dahingehend, daß deren Höhe mit zunehmenden Durchflußmengen abnimmt, ohne eine Veränderung der Frequenz aufeinanderfolgender Aktivitäts- und Ruhephasen der Pleopoden nach sich zu ziehen. Die Differenz der Sauerstoffspannung, die zwischen Beginn und Ende der Schlagaktivität erreicht wurde, betrug auch bei geringem Wasserdurchlauf im allgemeinen nicht mehr als 8 Torr, in der Regel ergaben sich weitaus geringere Werte. Es sei jedoch betont, daß diese Feststellungen nur einen geringen respiratorisch bedingten Abfall der Sauerstoffspannung zur Voraussetzung haben, der unter den gegebenen Versuchsbedingungen im allgemeinen weniger als $10 \%$ rom Sättigungswert betrug.

Der Einfluß der Individuengröße auf die Amplitudengröße dokumentiert sich darin, daß diese mit abnehmender Körpergröße kleiner wird. Zuden zeigen die Atmungskurven bei noch nicht geschlechtsreifen Tieren im allgemeinen eine weniger ausgeprägte rhythmische Schwingungsfolge. Die Amplitudenhöhe stellt auch bei völliger Ruhestellung keine unveränderliche Größe dar. Sie kann im Verlauf längerer Zeiträume größer oder kleiner werden. Ist letzteres der Fall, dann erhöhen sich die Frequenzen der Aktivitäts- bzw. der Ruhephasen der Pleopoden.

Die vorstehend beschriebenen Regelmäßigkeiten des Kurvenverlaufs konnten lediglich bei einzelnen Individuen von $G$. salinus, G. oceanicus und $G$. duebeni registriert werden; bei $G$. zaddachi traten sie nicht in so ausgeprägter Form zutage, und auch bei $G$. locusta wies das Kurvenbild im allgemeinen keine gleichmäßige Schwingungsfolge auf.

Vergleicht man die Registrierbeispiele der Abbildung 25, so wird deutlich, daß bei G. salinus die höchste Zahl alternierender Aktivitäts- und Ruheperioden pro Zeiteinheit zu verzeichnen ist; sie ist bei $G$. duebeni am niedrigsten, während $G$. oceanicus eine mittlere Stellung einnimt. Bei dem hier wiedergegebenen Beispiel für $G$, duebeni beträgt die Periodenlänge von einer Aktivitätsphase bis zur nächsten etwa 8-10 Minuten; als Extremwerte wurden bei dieser Art sogar 20-30 Minuten ermittelt, wobei sich die Ruhephase der Pleopoden zunehmend verlängerte.

Ober die Anzahl der Pleopodenschläge während der Aktivitätsphasen sind keine quantitativen Daten gewonnen worden. An Hand des Kurvenverlaufs und auf Grund visueller Beobachtungen ist jedoch festzustellen, daß die Anzahl der Pleopodenbewegungen pro Zeiteinheit bei $G$. duebeni relativ niedriger ist als bei $G$. salinus und G. oceanicus.

Aus den vorgeführten und anderen hier nicht dokumentierten Beispielen kann man indessen nur sehr bedingt artgebundene Unterschiede der Ventilationsrhythmik herauslesen, zumal die dargestellten Kurvenbilder - abgesehen von zahlreichen individuellen Abweichungen - erst nach längerem Hungerzustand, der mit einem Nachlassen der lokomotorischen Aktivität verbunden ist, zutage treten. Andererseits kann die bei $G$. duebeni verzeichnete relativ geringe Frequenz alternierender Bewegungs- und Ruhephasen der Pleopoden als ein arttypisches Merkmal gewertet werden, welches auf den verhältnismäßig niedrigen Sauerstoffbedarf dieser Art zurïckzuführen ist. 


\section{Einfluß des Häutungsgeschehens}

Der Ablauf der Wachstumsvorgänge vollzieht sich bei den Crustaceen in Häutungsschritten, die einer hormonalen Steuerung sowie dem Einfluß verschiedener exogener Faktoren unterliegen. Der Häutungszyklus ist mit zahlreichen Anderungen grundlegender, in Wechselwirkung stehender Stoffwechselvorgänge verknüpf, die u. a. den Wasserhaushalt, den Mineralstoffwechsel, den Umsatz von Reservestoffen und die Atmungsintensität betreffen.

Der Einfluß der Häutung auf den Atmungsstoffwechsel ist bisher vor allem an verschiedenen Decapoden untersucht worden, bei denen generell ein erhöhter Sauerstoffbedarf während des Abwurfes des alten Exoskeletts verzeichnet wurde (z. B. Scudamore 1947, Frost et al. 1951, Scheer \& Scheer 1954, Roberts 1957, HeineMANN 1964). Entsprechende Befunde liegen für den Leuchtkrebs Eupbausia pacifica (Paranjape 1967) und die Assel Porcellio scaber (WIeser 1965) vor. Der Anstieg des respiratorischen Stoffwechsels vor der Häutung beginnt bei Porcellio scaber mit der Einstellung der Nahrungsaufnahme. Der Sauerstoffbedarf erreicht zwei steile Maxima; das erste Maximum fällt mit der Ecdysis posterioris, das zweite mit der Ecdysis anterioris zusammen. Bei dem Cirripedier Balanus improvisus var. denticulata fanden Costlow \& Bookhour (1958) keinen Anstieg der Atmung, während BARnes \& BARNEs (1963) hingegen bei Balanus balanoides eine geringfügige Zunahme des Sauerstoffverbrauchs während der Häutung nachweisen konnten. Über die diesbezüglichen Verhältnisse bei Gammariden liegen - abgesehen von einer Untersuchung an $G$. duebeni über den Natriumtransport vor und nach der Häutung (LOCKWOOD \& ANDREws 1969) keine Angaben vor.

Im Rahmen der gegebenen meßtechnischen Möglichkeiten konnten die Veränderungen der Sauerstoffaufnahme, die sich während des Häutungsgeschehens abspielen,

Tabelle 2

Daten über die Veränderung der Atmungsintensität während der Häutung bei verschiedenen Gammarus-Arten $\left(15^{\circ} \mathrm{C}\right)$

\begin{tabular}{|c|c|c|c|c|c|c|}
\hline Species & Geschlecht & $\begin{array}{l}\text { Frisch- } \\
\text { gewicht } \\
\text { (mg) }\end{array}$ & $\begin{array}{l}\text { Salinität } \\
(\% \theta)\end{array}$ & $\begin{array}{c}\text { Anstieg des } \\
\mathrm{QO}_{2} \\
\text { vor der } \\
\text { Häutung } \\
\text { (Std) }\end{array}$ & $\begin{array}{l}\text { Abfall des } \\
\text { Q02 } \\
\text { nach der } \\
\text { Häutung } \\
\text { (Std) }\end{array}$ & $\begin{array}{c}\mathrm{QO}_{2} \\
\text { während der } \\
\text { Häutung }(\%) \\
\text { bezogen auf } \\
\text { Normalwerte } \\
(=100 \%)\end{array}$ \\
\hline G. locusta & $\begin{array}{l}0 \\
0 \\
+ \\
0\end{array}$ & $\begin{array}{l}71,0 \\
57,1 \\
12,7\end{array}$ & $\begin{array}{l}30 \\
30 \\
30\end{array}$ & $\begin{array}{r}12 \\
12 \\
5-7\end{array}$ & $\begin{array}{r}11-13 \\
\sim 12 \\
8\end{array}$ & $\begin{array}{l}310 \\
390 \\
230\end{array}$ \\
\hline G. oceanicus & $\hat{\delta}$ & 14,5 & 30 & $\sim 5$ & $10-12$ & 260 \\
\hline G. salinus & 8 & $\begin{array}{l}46,5 \\
27,4\end{array}$ & $\begin{array}{l}30 \\
30\end{array}$ & 6-7 & $\begin{array}{l}\sim 8 \\
\sim 10\end{array}$ & $\begin{array}{l}270 \\
240\end{array}$ \\
\hline G. zaddachi & $\delta$ & 113,2 & 10 & $?$ & 30 & 380 \\
\hline G. duebeni & $\begin{array}{l}0 \\
8 \\
0 \\
0\end{array}$ & $\begin{array}{l}67,6 \\
49,4 \\
34,8\end{array}$ & $\begin{array}{l}30 \\
10 \\
10\end{array}$ & $\begin{array}{r}4-5 \\
6 \\
10\end{array}$ & $\begin{array}{r}15 \\
14 \\
\sim 20\end{array}$ & $\begin{array}{l}220 \\
220 \\
310\end{array}$ \\
\hline
\end{tabular}


bei allen untersuchten fünf Gammarus-Arten kontinuierlich aufgezeichnet werden. Insgesamt wurden 10 Messungen an Tieren beiderlei Geschlechts ausgewertet.

Wie sich an allen fünf Arten übereinstimmend zeigte, geht auch bei den Gammariden dem Prozeß der Abtrennung der alten Cuticula von der Epidermis ein allmählicher Anstieg der Atmungsintensität voraus. Die Atmungskurven erreichen im Durchschnitt 5-12 Stunden nach Beginn des Anstiegs einen Gipfel, der mit dem eigentlichen

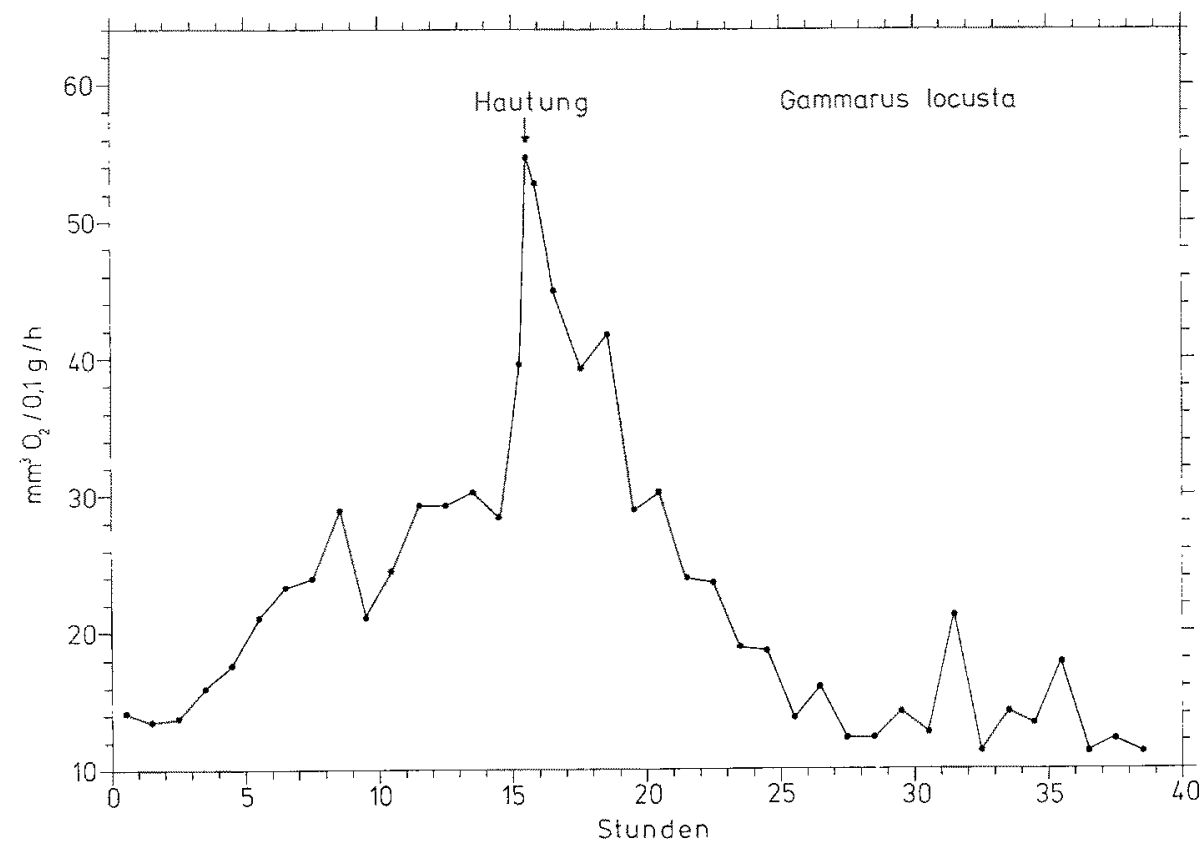

Abb. 26: Gammarus locusta $(9,30 \%)$. $\mathrm{O}_{2}$-Verbrauch (bei $\left.15^{\circ} \mathrm{C}\right)$ während des Häutungsvorganges

Häutungsakt zusammenfällt (Abb. 26, 27). Das Abwerfen des alten Exoskeletts geht sehr rasch vonstatten; dieser Vorgang dauert nicht länger als etwa eine Minute. Das Absprengen der Exuvie wird von einer starken motorischen Aktivität begleitet. In welchem $\mathrm{Maß}$ der gesteigerte Energieverbrauch durch die erhöhte Bewegungstätigkeit zu erklären ist und inwieweit darüber hinaus andere mit dem Häutungsgeschehen einhergehende Stoffwechselprozesse, wie z.B. die aktive Wasseraufnahme, den erhöhten Sauerstoffbedarf bedingen, ist nicht eindeutig zu beurteilen. Zwar ist der Atmungsanstieg vor einer Häutung stets mit einer Aktivitätszunahme verbunden, doch läßt sich an Hand des Kurvenverlaufes abschätzen, mit welcher Intensität die Krebse Bewegungen ausführen. Aus den vorliegenden Registrierungen ist jedoch zu erschließen, daß die Zunahme der Stoffwechselleistung nur zum Teil auf eine erhöhte Aktivität zurïckzuführen ist.

Die Stoffwechselsteigerung, die zum Zeitpunkt des Abwurfs des Exoskeletts erreicht wird, liegt zwischen dem 2,2- und 3,9fachen des vor bzw. nach der I-täutung er- 
reichten normalen Niveaus. Die geringste Steigerung konnte bei einem Exemplar von $G$. duebeni und die höchste bei Individuen von $G$. locusta und $G$. zaddachi verzeichnet werden (Tab. 2). Nachdem die Exuvie abgesprengt worden ist, fällt der $\mathrm{O}_{\mathrm{g}}$-Verbrauch zunächst rasch, dann, etwa 1-2 Stunden später, etwas langsamer ab. Der Abfall der Atmungskurven zeigt vielfach einen weniger steilen Verlauf als der Anstieg vor der Häutung, so daß sich unsymmetrische Kurvenbilder ergeben können. Im Verlauf von 8-20 Stunden, maximal 30 Stunden nach der Häutung, sind die Ausgangswerte für den Sauerstoffverbrauch wieder erreicht.

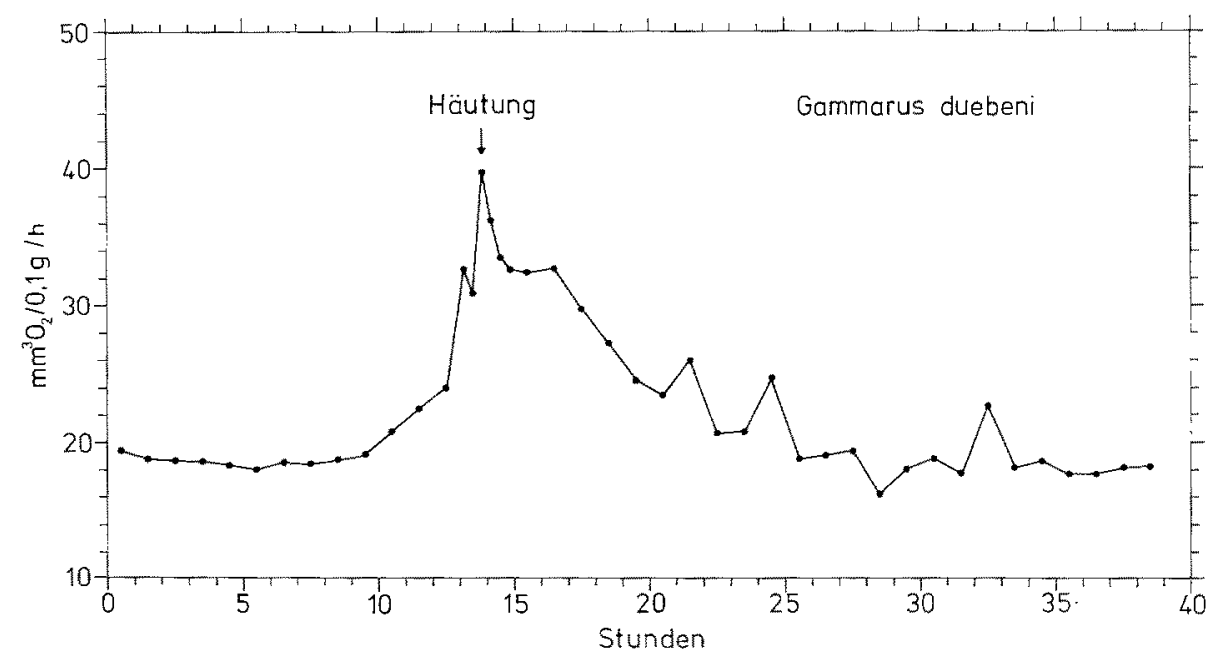

Abb. 27: Gammarus duebeni ( $\left(10 \%\right.$ ) $\mathrm{O}_{2}$-Verbrauch (bei $15^{\circ} \mathrm{C}$ ) während des Häutungsvorganges

Der zeitliche Ablauf der Stoffwechseländerungen vollzieht sich bei den einzelnen Arten in annähernd gleicher Weise, wenngleich eine gewisse Schwankungsbreite der ermittelten Werte festzustellen ist. Diese läßt eine mehr oder weniger deutliche Abhängigkeit von der Individuengröße erkennen. Die Veränderungen der Atmungsintensität pegeln sich bei kleineren Tieren im allgemeinen schneller auf einen Normalwert ein als bei größeren. Offensichtlich steht dieser Sachverhalt in ursächlicher Beziehung zur Häutungsfrequenz, die bei jungen Individuen unter gleichbleibenden Umweltbedingungen höher ist als bei adulten. Da sich im Laufe des Wachstums (mit Ausnahme der $q q$ während der Reproduktionsphase) die Häutungsintervalle zunehmend verlängern, erfahren auch diese Stoff wechseländerungen eine entsprechende zeitliche Verlängerung.

Wie aus Tabelle 2 hervorgeht, sind angesichts der Schwankungsbreite der Daten für den maximalen $\mathrm{O}_{2}$-Verbrauch während des Abwurfs des Exoskeletts keine ausgeprägten zwischenartlichen Unterschiede zu erkennen. Die niedrigsten Stoffwechselwerte wurden für $G$. duebeni und die höchsten für $G$. locusta ermittelt. Diese Befunde entsprechen dem unterschiedlichen Sauerstoffbedarf der einzelnen Arten, der - wie vorstehend ausgeführt wurde - bei $G$. duebeni die geringsten, bei $G$. locusta die höchsten Werte aufweist. 


\section{DISKUSSION}

Die folgenden Betrachtungen gelten der Erörterung einiger stoffwechselphysiologischer Fragestellungen, die aus den Befunden der vorliegenden Arbeit resultieren. Abschließend werden die Ergebnisse der Respirationsmessungen - soweit diese für ein kausales Verständnis der Umweltbeziehungen der untersuchten Gammarus-Arten Bedeutung erlangt haben - unter ökologischen Gesichtspunkten diskutiert.

\section{Physiologische Aspekte}

Die Untersuchungen über die Größenabhängigkeit des respiratorischen Stoffwechsels in Abhängigkeit von der Salinität des Außenmediums haben ergeben, daß - abgesehen von Gammarus locusta in der 30\%-Stufe - mit zunehmendem Körpergewicht eine relative Abnahme der Stoffwechselintensität zutage tritt. Diese Stoffwechselreduktion im Verlauf des Wachstums ist durch Werte charakterisiert, die zwischen einer Gewichts- und einer Oberflächenproportionalität oder sogar darunter liegen. Wie die Messungen in den beiden getesteten Salzgehaltsstufen gezeigt haben, sind die Regressionskoeffizienten für jede Art durch signifikant verschiedene Werte gekennzeichnet.

Eine Abhängigkeit dieses Koeffizienten von der Salinität des Außenmediums ist z. B. auch bei Artemia salina (Grcchrist 1956), Metapenaeus monoceros (RAo 1958), bei Hemigrapsus-Arten (DeHnel 1960) und Coropbium volutator (McLusKy 1969) festgestellt worden. Die vorliegenden Daten liefern somit einen weiteren Beleg für die nicht unerhebliche Variabilität des Regressionskoeffizienten und dessen Beeinflussung durch die Salzkonzentration des Außenmediums.

Zur Bedeutung der Größe des Regressionskoeffizienten sind in der stoffwechselphysiologischen Literatur zahlreiche Überlegungen angestellt worden. LEHMANN (1956) betrachtete den Regressionskoeffizienten als eine erblid festgelegte, arttypische Konstante, während v. BERTALANFFY (1957) diesen in Beziehung zu bestimmten systematischen Kategorien setzte. Hemmingsen (1960) kam zu der Auffassung, daß ein Exponent von 0,75 generell für poikilotherme Tiere Gültigkeit habe. Inzwischen sind jedoch zahlreiche Befunde erhoben worden, welche diese Auffassungen entkräfter bzw. widerlegt haben. Nicht nur der Faktor Salinität beeinflußt die Größe dieses Koeffizienten, sondern es besteht überdies eine Abhängigkeit von zahlreichen anderen Variablen, z. B. dem Aktivitätszustand (Wesemeier 1960), der Temperatur (Krüger 1964, BarNEs \& BARnes 1969), der Infektion durch Parasiten (Duerr 1967) und der Art des Atemmediums (NEwell et al. 1972). Auch jahreszeitliche und populationsbedingte Stoff wechselunterschiede (Frsf \& PREECE 1970) können sich in der Größe des Regressionskoeffizienten widerspiegeln. Die Ursachen für dessen Inkonstanz sind bislang unklar geblieben. Ohne die Diskussion der dargestellten Problematik an dieser Stelle zu vertiefen, ist daher der Ansicht KrüGERs (1964) zuzuscimmen, daß die beträchtliche Variabilität des Regressionskoeffizienten, welche hier nur durch einige Beispiele belegt worden ist, diesen in jeder Beziehung des Charakters einer grundlegenden Größe entkleidet.

Verschiedene Aspekte des respiratorischen Stoffwechsels sind bereits an einigen Vertretern der Gattung Gammarus untersucht worden (SCHäperclaus 1925, SChlie- 
Per 1931, Fox \& Simmonds 1933, LöWenstein 1935, Kinne 1952, Trotani 1954, Krog 1954, Suomalainen 1958, Lukacsovics 1958, Wautier \& Troiani 1960, Woynarovttch 1961, Ali \& Steele 1962, Halcrow \& Boyd 1967, Roux \& Roux 1967, Culver \& Poulson 1971, Roux 1972). An Hand der zahlreichen in der Literatur angegebenen Meßdaten wurde der Versuch unternommen, die Größen des Sauerstoffverbrauchs bei den einzelnen Species zu vergleichen, um den in dieser Arbeit untersuchten fünf Arten Bezugswerte gegenüberzustellen. Dabei wurde deutlich, daß ein Vergleich mit anderen Angaben über die Stoffwechselgröße der einzelnen GammarusArten nur bedingt möglich ist. Der Hauptgrund für diese einschränkende Feststellung ist, daß fast ausnahmslos nur Daten über die Atmungsgröße pro Gewichtseinheit vorliegen. Auf Grund der Stoffwechselreduktion im Verlauf des Wachstums, wie sie nach den gewonnenen experimentellen Erfahrungen bei den Gammariden vorherrschen dürfte, ist diese Form der Angabe der Stoffwechselintensität nicht ausreichend. Vielmehr ist die Ermittlung der allometrischen Parameter zur Charakterisierung der Beziehungen zwischen respiratorischem Stoffwechsel und Körpergewicht als Voraussetzung für interspezifische Vergleiche anzusehen. Ein derartiges Vorhaben wird überdies noch durch weitere Unsicherheiten belastet, die u. a. darin bestehen, daß den einzelnen Arbeiten verschiedene Untersuchungsmethoden zugrunde liegen, keine Einheitlichkeit der Bezugsgrößen für den $\mathrm{O}_{2}$-Verbrauch verwirklicht ist und darüber hinaus in einigen älteren Publikationen Fehldiagnosen der getesteten Arten nicht auszuschließen sind.

Auf die oben genannte Unzulänglichkeit, die Angabe der Stoffwechselintensität pro Gewichtseinheit ohne Berücksichtigung der Größenabhängigkeit, sind insbesondere die Diskrepanzen der eigenen Resultate zu den Angaben von Suomalainen (1958) zurüdkzuführen, die sich zudem nicht auf Einzelmessungen stützen. Er verzeichnete bei G. duebeni und $G$. oceanicus bei $15^{\circ} \mathrm{C}$ und $10 \%$ gleich hohe Stoffwechselwerte, während er bei G. zaddachi gegenüber diesen Arten einen um fast die Hälfte höheren Sauerstoffbedarf ermittelte. Bei $G$. oceanicus fand SuomalaINen einen erhöhten Qoz in $7 \%$ und $4 \%$, desgleichen bei G. zaddachi in $4 \%$. In $1 \%$ stellte er bei G. oceanicus einen starken, bei G.zaddachi einen schwachen Abfall fest, während er bei $G$. duebeni im Bereich zwischen $20 \%$ und 1\% keine wesentlichen Veränderungen der Atmungsintensität verzeichnete. KINNE (1952) fand hingegen bei männlichen Individuen von $G$. duebeni eine relative Zunahme des $\mathrm{O}_{2}$-Verbrauchs in $5 \%$ und einen starken Anstieg im Bereich von $2 \%$ bis zum Süßwasser, während er bei den $q$, gesamt höhere Werte ermittelt wurden, ein Maximum des $\mathrm{O}_{2}$-Verbrauchs in $5 \%$ mit einem schwachen Abfall in $2 \%$ und im Süßwasser registrierte. In Salzgehalten über $22 \%$ bzw. $30 \%$ ermittelte er bei 우 und $\hat{\delta} \hat{\delta}$ eine geringfügige Abnahme des Qo. Die von KINNE beobachteten geschlechtsspezifischen Unterschiede sind offensichtlich darauf zuriickzuführen, daß die gemessenen $q 9$ fast ausnahmslos Eier oder Junge im Marsupium trugen. Dieser Sachverhalt dürfte eine Beeinflussung der Meßwerte verursacht haben. KROG (1954) fand hingegen bei $G$. limnaeus keine geschlechtsbedingten Unterschiede, ein Resultat, das auch den eigenen Befunden entspricht.

Soweit die Literaturangaben einen interspezifischen Vergleich unter den oben angeführten Vorbehalten zulassen, ist die Schlußfolgerung zu ziehen, daß GammarusArten des Süßwassers eine höhere Stoffwechselintensität aufweisen als euryhaline Formen. Dies belegen die vergleichenden Untersuchungen von Fox \& Simmonds (1933) 
an G. locusta, G. marinus und G. pulex sowie von SuOMalainen (1958) an G. duebeni, G. zaddachi, G. oceanicus und G. pulex, die jeweils mit gleicher Methodik durchgeführt worden sind. Eine Bekräftigung erfährt diese Feststellung durch eine Gegenüberstellung der relativ hohen, auf das Trockengewicht und eine Temperatur von $15^{\circ} \mathrm{C}$ bezogenen Atmungswerte für die Süßwasserformen G. pulex, G. fossarum $\left(\sim 1200 \mathrm{~mm}^{3} \mathrm{O}_{2} / \mathrm{g} / \mathrm{h}\right)$ und $G$. lacustris $\left(\sim 1050-1300 \mathrm{~mm}^{3} \mathrm{O}_{2} / \mathrm{g} / \mathrm{h}\right.$ ) (Roux \& Roux 1967, Roux 1972) mit den Meßdaten für die hier untersuchten euryhalinen Arten. Unter Bezug auf das Trokkengewicht ergeben sich lediglich für $G$. locusta Werte $\left(\sim 900 \mathrm{~mm}^{3} \mathrm{O}_{g} / \mathrm{g} / \mathrm{h}\right.$ bei $30 \%$ \% $)$, die nur wenig unterhalb des Größenbereichs der limnischen Gammariden liegen, während die Angaben für die ebenfalls euryhalinen Species Marinogammarus (Gammarus) marinus und G. chevreuxi (Fox \& SIMMONDs 1933, Löwenstein 1935) mehr dem Sauerstoffbedarf von G. salinus und G. oceanicus zu entsprechen scheinen.

Die Stoffwechseländerungen nach einem Salinitätswechsel sind eng verknïpft mit osmo- und ionenregulatorischen Prozessen, die zur Einstellung eines neuen Konzentrationsniveaus der extrazellulären und intrazellulären Körperflüssigkeiten führen. Im folgenden werden daher einige Aspekte der osmotischen Anpassung bei Krebsen und deren Beziehung zum respiratorischen Stoffwechsel diskutiert.

Allen bisher untersuchten Gammarus-Arten, bei denen es sich sowohl um Meeresund Brackwasser- als auch um Süßwasserbewohner handelt, ist die Eigenschaft hyperosmorischer Regulation gemeinsam, doch bestehen in Abhängigkeit von der Bindung an die verschiedenen Lebensräume Unterschiede hinsichtlich des osmoregulatorischen Leistungsvermögens. Unter den in der vorliegenden Arbeit behandelten Arten ist lediglich die extrazelluläre anisosmotische Regulation von $G$. locusta, $G$. duebeni und $G$. oceanicus geprüft worden (vgl. BeAdle \& CRAGg 1940, KInNe 1952, WeRnTZ 1963).

Die osmotische Innenkonzentration zeichnet sich unterhalb von $30 \%$ bei $G$. oceanicus (Werntz 1963), 24\% bei G. locusta (BeAdle \& CRAGg 1940) und 22\% bei G. duebeni (KINNE 1952) durch eine zunehmend hypertonische Reaktion aus. Mit fortschreitender Verdünnung des Außenmediums fällt die osmotische Konzentration der Blutflüssigkeit nur geringfügig $a b$, wobei die osmoregulatorische Leistung, bezogen auf die Konzentrationsdifferen $z$ wischen Innen- und Außenmedium, ständig ansteigt. Sie erreicht bei $G$. duebeni und $G$. oceanicus in oligohalinen Stufen $(<5 \%$ ) ein Maximum und sinkt im unteren Grenzbereich der Salinitätstoleranz, in dem es schließlich zu einem Zusammenbruch der Regulationsmechanismen kommt, rasch ab. Oberhalb der genannten Brackwasserstufen und im Meerwasser liegt ein poikilosmotisches Verhalten vor. In diesem Bereich bestehen nahezu isosmotische Verhältnisse, wenngleich eine schwach hypertonische Reaktion der Blutflüssigkeit erhalten bleibt. Es ist anzunehmen, daß die Regulation der osmotischen Konzentration der Hämolymphe bei $G$. salinus und $G$. zaddachi in ähnlicher Weise erfolgt.

Im Rahmen der vorliegenden Untersuchungen gewinnt die Frage besonderes Interesse, mit welcher Geschwindigkeit sich die osmoregulatorischen Vorgänge auf extrazellulärer und intrazellulärer Ebene nach einem Salzgehaltssprung vollziehen. Über den zeitlichen Ablauf der osmotischen Anpassung liegen verschiedene Befunde an Crustaceen, vor allem an Decapoden, vor, die einige Auskünfte zu dieser Frage liefern.

Gross (1957) fand, daß die Osmolarität der Hämolymphe bei Pachygrapsus crassipes nach einem osmotischen Stress sowohl in hypertonischen als auch in hypotonischen 
Medien innerhalb von 24 Stunden (bei $16^{\circ} \mathrm{C}$ ) ein neues konstantes Niveau erreicht. Studien von DEHNEL (1962) an Hemigrapsus oregonensis und $H$. nudus ergaben, daß sich ein neuer "steady state“ der osmotischen Konzentration der Hämolymphe innerhalb von $24-48$ Stunden (bei $15^{\circ} \mathrm{C}$ ) nach einer Uberführung in verschiedene Salzgehaltsstufen einstellt. Die stärksten Veränderungen der osmotischen Werte erfolgen innerhalb der ersten drei Stunden. Die osmotische Anpassung vollzieht sich am langsamsten nach einem Wechsel in hyperhaline und oligohaline Konzentrationsstufen. Zu ähnlichen Befunden kamen SEgAL \& Burbanck (1963) an dem Isopoden Cyathura polita, der ebenso wie die Hemigrapsus-Arten eine hyperosmotische Regulation in Brackwassermedien aufweist. Bei einer Uberführung aus $8 \%$ in $1 \% 00,16 \%$ oder $24 \%$ waren nach 3 Stunden etwa gleichbleibende Werte der Osmolarität der Hämolymphe erreicht (bei $22^{\circ} \mathrm{C}$ ). Erfolgte ein Wechsel in höhere Salinitätsstufen (bis $48 \%$ ), so war der osmotische Ausgleich erst nach 24-48 Stunden beendet.

In einer Untersuchung über kinetische Aspekte der extrazellulären anisosmotischen und intrazellulären isosmotischen Regulation bei Carcinus maenas fanden SIERERs et al. (1972), daß der $\mathrm{O}_{2-}$ Verbrauch nach einem Salinitätssprung von $11 \%$ in $38 \%$ absinkt und innerhalb von 8-12 Stunden (bei $11^{\circ} \mathrm{C}$ ) einen neuen konstanten Wert erreicht. Die Konzentration der freien Aminosäuren und Proteine im Serum fällt ebenfalls innerhalb eines halben Tages auf ein dann gleichbleibendes Niveau ab. Die Osmolarität der Hämolymphe sowie die Konzentrationen von $\mathrm{Na}, \mathrm{K}, \mathrm{Ca}$ und $\mathrm{Mg}$ erfahren hingegen eine langsamere zeitlide Veränderung; erst nach 24 Stunden ist die Konzentrationserhöhung beendet. Auch die intrazelluläre Regulation ist innerhalb eines Tages vollzogen; lediglich niedermolekulare Neutralzucker erreichen erst nach einer ca. $10-$ tägigen Anpassungsdauer ein neues, und zwar beträchtlich erhöhtes Konzentrationsniveau.

Anpassungsversuche an Carcinus maenas aus Ostsee und Nordsee in $15 \%$ und $30 \%$ ergaben, daß die Stoffwechseladaptation von Kiemengewebe erst nach etwa 5 Tagen vollzogen ist (THEEDE 1964). Diese wie auch weitere Befunde von KING (1965) weisen darauf hin, daß sich isolierte Gewebe anders als Ganztiere nach einem osmotischen Stress verhalten können.

WEBER \& SPAARgaren (1970) fanden bei Crangon crangon, daß die osmotische Konzentration der Hämolymphe bei einem Wechsel von $30 \%$ in $15 \%$ nach 15 Stunden einen neuen stationären Wert erreicht (bei $15^{\circ} \mathrm{C}$ ). Die Untersuchung der isosmotischen intrazellulären Regulation an dem gleichen Objekt ergab einen Anstieg ninhydrinpositiver Substanzen in der Muskulatur nach einem Umsetzen von 17\% in 33\% (bei $5^{\circ}$ und $15^{\circ} \mathrm{C}$ ), wobei nach 24 Stunden ein neues gleichbleibendes Konzentrationsniveau erreicht war. Ein Salinitätssprung in umgekehrte Richtung beanspruchte bis zur Einstellung eines neuen Gleichgewichtszustandes etwa die gleiche Zeit (WEBER \& VAN MARREWIJK 1972). Die in geringer Konzentration vorhandenen ninhydrinpositiven Substanzen der Blutflüssigkeit fallen innerhalb weniger Stunden nach einer Überführung von $17 \%$ in $33 \%$ ab; bei einem Sprung von $33 \%$ in $17 \%$ erfolgt hingegen eine Konzentrationszunahme dieser Substanzen, die erst nach 3-5 Tagen bei großer individueller Schwankungsbreite ein neues stationäres Niveau erreichen.

Bei Palaemon serratus und Lysmata seticaudata wurde an Hand von Messungen der gesamten osmotischen Konzentration und der Elektrolytkonzentration der Hämo- 
lymphe festgestellt, daß nach einer Uberführung von $39 \%$ in $24 \%$ (bei $4^{\circ}$ und $22^{\circ} \mathrm{C}$ ) eine sehr rasche osmotische Anpassung erfolgt, wobei bereits nach etwa einer Stunde nahezu stationäre Werte erreicht werden (SPAARgaren 1972). Bei Lysmata seticaudata dauert dieser Vorgang nur geringfügig länger als bei Palaemon serratus. Unmittelbar nach dem Wechsel kommt es zu einer relativen Erhöhung der Konzentration an Nichtelektrolyten in der Hämolymphe. Während Lysmata seticaudata stark osmokonform reagiert, weisen Crangon crangon und Palaemon serratus in niederen Salinitäten eine Hyper- und in höheren Salinitäten eine Hyporegulation auf.

Auch bei dem Amphipoden Corophium volutator, einem hyperregulierenden Brackwasserbewohner, konnte bezüglich der Osmolarität der Blutflïsigkeit eine rasche osmotische Anpassung festgestellt werden, die nach einer Ubertragung von $3 \% 00$ in $10 \%$ innerhalb von 3 Stunden vollzogen ist (McLusky 1969).

Daß dieser Vorgang auch bei Gammariden innerhalb von einigen Stunden, allenfalls nach etwa einem Tag abgeschlossen sein dürfte, ist auch einigen Angaben von WERNTZ (1963) zu entnehmen. Er fand, daß bei G. oceanicus die osmotische Konzentration der Hämolymphe gleichbleibende Werte innerhalb von 12 Stunden nach einer sprunghaften Überführung von $32 \%$ in $3,5 \%$ erreicht (bei $16^{\circ}-19^{\circ} \mathrm{C}$ ). Bei $G$. fasciatus ist dies bereits innerhalb von $1 \frac{1}{2}$ Stunden nach einem Wechsel aus Süßwasser in Brackwasser von $21 \%$ der Fall.

Zahlreiche Untersuchungen über den Zusammenhang zwischen Atmungsintensität und Salzgehalt des Außenmediums haben deutlich werden lassen, daßs recht unterschiedliche Bezichungen vorliegen können. Folgende Reaktionen lassen sich bezüglich der Höhe des $\mathrm{O}_{2}$-Verbrauchs unterscheiden (vgl. KinNe 1971): (1) Zunahme in subnormalen und/oder Abnahme in supranormalen Salinitäten, (2) Zunahme in sub- und supranormalen Salinitäten, (3) Abnahme in sub- und supranormalen Salinitäten und (4) Fehlen erkennbarer Veränderungen. Die ersten beiden Gruppen umfassen im wesentlichen euryhaline Wirbellose, die dritte wird durch stenohaline Formen vertreten, während die vierte Gruppe durch holeuryhaline oder extrem euryhaline Arten repräsentiert wird. Da die untersuchten Gammarus-Arten auf Grund ihrer Stoffwedselreaktionen in die ersten beiden Gruppen einzureihen sind, soll auf die beiden folgenden Gruppen nicht näher eingegangen werden.

Beispiele für Reaktionen nach dem ersten Typ liefern Untersuchungen an den Crustaceen Carcinus maenas (Schlieper 1929), Uca spp. (Gross 1957) und Hemigrapsus oregonensis (DeHnel 1960). Dem 2. Typ können u. a. zugeordnet werden: Ocypode albicans (Flemister \& Fiemister 1951), Palacmonetes varians (LofTs 1956), Metapenaeus monoceros (RAo 1958) und Crangon vulgaris (HAGERMAN 1970).

Nach den vorliegenden Ergebnissen zeichnet sich bei euryhalinen Gammariden eine generelle Tendenz zur Erhöhung der Atmungsintensität als Folge einer Verringerung des Salzgehaltes im Bereich suboptimaler Konzentrationsstufen ab. In diesem Zusammenhang sei auch verwiesen auf ältere Befunde von SCHLIEPER (1931), der bei G. locusta eine Abnahme der Stoffwechselgröße um $18 \%$ nach Uberführung aus einem Medium von $16 \%$ in Seewasser von $32 \%$ feststellte sowie von LöwensteIN (1935), der bei $G$. chevreuxi gegenüber den in $32 \%$ erhaltenen Meßswerten in $8 \%$ einen um ca. 20\% verringerten Qog ermittelte. Jedoch, ohne Kenntnis der allometrischen Parameter, zumindest aber ohne Angabe der untersuchten Größenklassen, haben diese 
und andere Angaben über Anderungen des $\mathrm{O}_{2}$-Verbrauchs keinen zuverlässigen Aussagewert, wie die vorstehenden Ausführungen ïber die Beziehungen zwischen Atmungsstoffwechsel und Körpergewicht in Abhängigkeit vom Salzgehalt deutlich gemacht haben.

Wie aus den vorliegenden Untersuchungen hervorgeht, ist die Atmungsintensität der einzelnen Gammarus-Arten fast generell erhöht und die Salinitätsadaptation beansprucht einen längeren Zeitraum, wenn nach einem Wechsel aus einem konzentrierteren in ein verdünntes Medium eine aktive Salzaufnahme gegen ein Konzentrationsgefälle verstärkt einsetzt, um das Innenmedium hyperosmotisch zu halten. Die Frage, wodurch die Anderungen des $\mathrm{O}_{2}$-Bedarfs nach einer Herabsetzung oder Erhöhung des Salzgehaltes hervorgerufen werden, hat noch keine widerspruchsfreie Erklärung gefunden. SCHLIEPER (1929), der als erster bei einigen euryhalinen Tieren einen Stoffwechselanstieg als Folge einer reduzierten Salzkonzentration im Außenmedium feststellte, brachte diesen Befund in Beziehung zu der intensivierten osmoregulatorischen Arbeitsleistung und dem damit erhöten Energiebedarf. Diese Erklärung wurde bei entsprechenden Befunden über die Abhängigkeit der Atmungsintensität von der Salinität wiederholt herangezogen (z. B. Schwabe 1933, Flemister \& Flemister 1951). Sie mußte insofern zunächst als plausibel gelten, als viele euryhaline Tiere mit hyposmotischer Regulation in salzreichem Außenmedium den geringsten Sauerstoffbedarf aufweisen, wenn sie unter isosmotischen Bedingungen leben. Derartige Beziehungen sind z. B. bei Hemigrapsus oregonensis und $H$. nudus (DEHNEL 1960) sowie bei dem Flußkrebs Astacus astacus (PETERS 1935) nachgewiesen worden, der in einem isosmotischen Medium von $15 \%$ weniger Sauerstoff verbraucht als in Süßwasser.

Da der zusätzliche Energiebedarf, der für die Aufrechterhaltung osmo- und ionenregulatorischer Vorgänge erforderlich ist, auf Grund thermodynamischer Überlegungen (vgl. POTTS \& PARRY 1964) als zu gering angesehen werden muß, um die beobachteten Stoffwechseländerungen ausreichend erklären zu können, ist die Interpretation SCHLIEPERs infrage gestellt worden. Außerdem würde der beträchtliche Stoffwechselanstieg, der bei verschiedenen euryhalinen Evertebraten in Brackwassermedien gemessen wurde, eine sehr geringe Leistungsfähigkeit der beteiligten Ionentransportsysteme voraussetzen. Dem stehen zahlreiche Versuchsergebnisse an isolierten Geweben entgegen. Auch die Tatsache, daß bei manchen Arten keine meßbaren Stoffwechselunterschiede in verschiedenen Salinitätsstufen zutage treten oder gar eine Verringerung der Atmungsintensität in stärker ausgesüßten Medien verzeichnet worden ist, schließt - zumindest in diesen Fällen - die Deutung einer erhöhten Energieleistung durch osmo- und ionenregulatorische Prozesse aus. SCHLIEPER (1936) hat überdies die Veränderungen der Stoffwechselrate bei abnehmendem Salzgehalt mit einer erhöhten Hydratation der Gewebe und einer dadurch gesteigerten Enzymaktivität zu erklären versucht. KING (1965) zeigte bei verschiedenen marinen und Brackwasser-Arten, daß auch diese Erklärung keine allgemeine Gültigkeit beanspruchen kann.

Die Vorstellung, ein gesteigerter $\mathrm{O}_{2}$-Bedarf nach einem osmotischen Streß sei insbesondere auf eine Fluchtreaktion und erhöhte motorische Aktivität der Versuchstiere zurüdkzuführen (Gross 1957, MCFARLAND \& PrCKens 1965), kann auf Grund der früher genannten Argumente ebenfalls nicht als ausreichende Erklärung gelten. Wenngleich die Schockreaktion unmittelbar nach einem Salinitätssprung kurzzeitig zu ver- 
stärkter Bewegungstätigkeit bzw. zu erhöhter Spontanaktivität führen kann, so sprechen auch die unterschiedlichen Resultate über die Veränderungen des respiratorischen Stoffwechsels bei den einzelnen Gammarus-Arten gegen diese Interpretation.

Fragwürdig ist auch, inwieweit die Abhängigkeit der $\mathrm{O}_{2}$-Konzentration vom Salzgehalt bei gleichem $\mathrm{O}_{2}$-Partialdruck und die damit veränderten Diffusionsverhältnisse für die Größe des Atmungsstoffwechsels von Bedeutung sind, doch soll dieses Problem hier nicht näher erörtert werden.

Aus den vorstehenden Ausführungen und weiteren, nicht erwähnten experimentellen Befunden, die an anderen tierischen Organismen gewonnen wurden, geht hervor, daß die Beziehungen zwischen Atmungsintensität und Salinität noch keine befriedigende Deutung gefunden haben.

Für eine Bewertung des osmoregulatorischen Energieaufwandes ist es erforderlich, auch den Wirkungsgrad der zellulären Transportmechanismen zu berücksichtigen, worauf FLOREY (1970) hingewiesen hat. Rechnung $z u$ tragen ist für eine Klärung der in Rede stehenden Problematik insbesondere der Wirksamkeit und Geschwindigkeit des Ionentransports, der Permeabilität der Außen- und Zellmembranen für Elektrolyte und Wasser sowie den Mechanismen der intrazellulären isosmotischen Regulation. In diesem Zusammenhang werfen auch Untersuchungen über die ionale Regulation bei Gammariden ein Licht auf die Frage der Stoffwechselenergetik in Abhängigkeit vom Salzgehalt des Außenmediums. Sie haben zu der Erkenntnis geführt, daß marine Arten eine größere Permeabilität gegenüber Salzen und Wasser sowie eine intensivere Urinproduktion aufweisen als Brackwasser- und Süß\}wasserformen (vgl. SuTcliffe 1968). Zudem sind Brackwasserarten, wie $G$. duebeni und $G$. zaddachi, befähigt, in niedrigen Salzgehaltsstufen einen zur Blutkonzentration hyposmotischen Urin zu erzeugen (Lock wood 1961, SutCLIFfE 1967a, 1968), wodurch der Wirkungsgrad der Elektrolytregulation erhöht wird.

\section{Ơkologische Aspekte}

Abschließend sollen die physiologischen Befunde der vorliegenden Arbeit unter ökologischen Gesichtspunkten betrachter und zu den Umweltansprüchen der einzelnen Gammarus-Arten in Beziehung gesetzt werden. Damit soll ein Versuch unternommen werden, ihre ökologische Differenzierung von der Stoffwechselleistung, dem Adaptationsvermögen und der Toleranz insbesondere gegenüber dem Faktor Salzgehalt zu begründen. Es sei allerdings vorausgeschickt, daß es vorerst nicht möglich ist, eine umfassende ökophysiologische Charakteristik dieser Artengruppe zu geben, da weitere funktionelle Merkmale und regulative Eigenschaften unter vergleichenden Gesichtspunkten experimentell geprüft werden müssen, um zu Fragen der Lebensraumbevorzugung, der geographischen Verbreitung, des Konkurrenzvermögens und anderen Problemen ausführlich Stellung nehmen zu können.

Ausgangspunkt dieser Erörterung soll ein kurzer Uberblick über die Umweltansprüche unter besonderer Berücksichtigung der Salinitätstoleranz der einzelnen Arten sein, über die zahlreiche Einzelarbeiten Auskunft geben (u. a. Spooner 1947, SEgERStråle 1947, 1959, Kinne 1954, 1959, den Hartog 1964, Movaghar 1964, Stock 1967, Dennert et al. 1969, Pinkster et al. 1970). 
Unter den behandelten fünf Species ist G. locusta eine mehr marine Form, die im vegetationsreichen, flachen Litoralbereich des gemäßigten östlichen atlantischen Raumes lebt. Ihr Vorkommen schließt sich südlich an das von $G$. oceanicus an. In Uberlappungsgebieten des Vorkommens beider Arten, wie z. B. in der Ostsee, werden nahezu die gleichen Areale besiedelt. G. oceanicus ist eine arktisch boreale Form des atlantischen Gebiets und bevorzugt das küstennahe flache Wasser, erträgt aber eine stärkere Aussïßung als $G$. locusta. G. salinus lebt in brackigen Gewässern der verschiedensten Typen, in denen erhebliche Salzgehaltsfluktuationen auftreten können, doch kommt die Art auch in rein marinen Gebieten vor. G. zaddachi ist ebenso wie G. salinus eine stark euryhaline Species. Sie dringt weiter in ausgesüßtes Wasser vor als letztere und meidet Gewässer des euhalinen Bereichs. Im oberen Teil von Flußmündungsgebieten wird $G$. salinus im allgemeinen durch $G$. zaddachi ersetzt, wo diese Art sogar Süßwasserzonen erreicht.

G. duebeni schließlich ist eine stark euryhaline und eurytherme Brackwasserform, welche die größte ökologische Potenz unter den behandelten Gammariden besitzt. Sie weist eine weite Verbreitung an den nordatlantischen Küsten auf und bewohnt eine Vielzahl verschiedener Lebensräume. $G$. duebeni ist ein charakteristischer Vertreter der "rockpool“-Fauna, besiedelt brackige Tümpel, Kanäle, Teiche, Randgebiet von Ǎstuarien und sogar hyperhaline Gewässer. Im freien Meer tritt diese Form jedoch nur ausnahmsweise auf. Darüber hinaus vermag $G$. duebeni auch in Süßwasserbiotopen zu existieren, wobei ihr Vorkommen nicht nur auf den küstennahen Bereich beschränkt ist, sondern in Irland und der Bretagne auch im küstenfernen Süßwasser mit einem relativ niedrigen NaCl-Gehalt anzutreffen ist. SuTCLIFFE \& SHAw (1968) zeigten an Hand der unterschiedlichen Fähigkeit zur Natriumregulation, daß die irische Süßwasserpopulation eine eigene physiologische Rasse gegenüber der Brackwasserform darstellt, wenngleich SUTCLIFFE (1971) Zweifel anmeldet, ob tatsächlich genotypisch verankerte Merkmale vorliegen, die es gerechtfertigt erscheinen lassen, von zwei physiologischen Rassen zu sprechen. Stock \& Pinkster (1970) fanden jedoch auch morphologische Besonderheiten und trennten die Brackwasserform $G$. duebeni duebeni von der Süßwasserform $G$. duebeni celticus als Subspecies voneinander $a b$.

Aus den vorstehenden Angaben über die Habitatpräferenz und Verbreitung geht hervor, daß die einzelnen Arten unterschiedliche ökologische Nischen besiedelt haben, die von der Tolerenz gegenüber dem Faktor Salzgehalt entscheidend bestimmt werden. In Abhängigkeit von den speziellen Gegebenheiten eines Biotops können sich deren Lebensräume allerdings auch überschneiden. Während $G$. locusta meistens allein auftritt - abgesehen von gelegentlicher Vergesellschafung mit $G$. oceanicus und $G$. salinus - kann sich die Verbreitung von G. oceanicus, G. salinus und G. zaddachi gebietsweise, wie im Ostseeraum, überlappen. In abgeschlossenen brackigen Gewässern ist auch eine Koexistenz von G. salinus, G. zaddachi und G. duebeni möglich; in Astuarien weicht allerdings $G$. duebeni der Konkurrenz mit diesen Arten aus und besiedelt Teile des Eu- und Supralitorals, während G. salinus und G. zaddachi erst im unteren Eulitoral und Sublitoral auftreten (DEN HARTOG 1964). Die beiden letztgenannten Arten kommen häufig sympatrisch vor, während $G$. duebeni offensichtlich auf Grund seines geringeren Konkurrenzvermögens, aber zufolge seiner größeren Toleranz gegenüber abiotischen Umweltfaktoren in Biotope abgedrängt wird, in denen die anderen Gammarus- 
Arten nicht zu existieren vermögen (vgl. KINNE 1959). Da jedoch das interspezifische Konkurrenzvermögen nicht allein von der physiologischen Leistung einer Art her erklärt werden kann, sollen die verschiedenen Aspekte dieses Fragenkomplexes nicht weiter zur Debatte stehen.

Setzt man die unterschiedlichen Stoffwechselgrößen der einzelnen euryhalinen Gammariden in Beziehung zu den von ihnen bevorzugten Lebensräumen, so wird verständlich, daß G. locusta als Art mit dem relativ höchsten Sauerstoffbedarf hauptsächlich im sauerstoffreichen, freien Wasser verbreitet ist, während $G$. duebeni als die Form mit der geringsten Atmungsintensität in Biotopen mit extremen Umweltbedingungen noch Lebenschancen findet. Die anderen drei Arten nehmen dagegen eine intermediäre und untereinander nicht so deutlich abgegrenzte Position ein, wobei sich allerdings $G$. oceanicus von $G$. salinus und $G$. zaddachi deutlicher abhebt als die beiden letztgenannten Arten voneinander.

Der Fähigkeit von G. duebeni, einen plötzlichen Salzgehaltswechsel ohne nachhaltige Anderungen der Stoffwechselintensität zu kompensieren, ist eine besondere adaptive Bedeutung zuzumessen. Diese Eigenschaft ist im Lichte des Vorkommens dieser Art in Gebieten mit besonders starken Salinitätsschwankungen zu sehen. In bezug auf die physiologische Fähigkeit zur Salzgehaltsanpassung erweist sich G. locusta wiederum als das andere Extrem. Aus der erheblichen Steigerung der Atmungsintensität nach einem Wechsel aus einem konzentrierten in ein verdünntes Medium ist abzulesen, daß die Stoffwechselökonomie dieser Art durch einen derartigen Salinitätsstreß in nachhaltiger Weise belastet wird. Dieser Sachverhalt liefert eine Erklärung dafür, weshalb G. locusta nicht in poikilohaline Astuare vordringt, sondern homoiohaline Gebiete bevorzugt. Diese Species lebt daher vorwiegend im euhalinen Bereich; sie vermag nur in einem relativ stabilen Milieu, wie der Ostsee, wo aperiodische Salinitätsfluktuationen weitgehend fehlen, in salzarme Zonen vorzustoßen.

Die anderen drei Arten zeigen bezüglich der Reaktionen auf einen Salzgehaltswechsel ein ähnliches physiologisches Verhalten und nehmen auch in dieser Hinsicht eine Mittelstellung ein. Insgesamt scheint das Kompensationsvermögen von G. zaddachi etwas besser als das von $G$. salinus ausgebildet zu sein, wenn sich auch die stoffwechselphysiologischen Unterschiede zwischen diesen beiden Geschwisterarten als sehr gering erwiesen haben. Dieses Resultat steht in Einklang mit anderen Befunden über die Ahnlichkeit funktioneller Merkmale beider Species, wie Untersuchungen über die Wachstumsintensität, Häutungsfolge, Herzfrequenz und Dauer der Embryonalentwicklung (KINNE 1961) sowie über die Strahlenresistenz (HoppenHeIt 1969) gezeigt haben. Wenngleich gewisse Unterschiede der ökologischen Ansprüche zwischen G. salinus und G. zaddachi verzeichnet werden können, so spricht doch ihre große strukturelle Ahnlichkeit, besonders der Jungtiere (vgl. Dennert et al. 1969), für die von Kinne (1961) geäußerte Annahme, daß sie zwei verhältnismäßig junge Species verkörpern, die offensichtlich erst relativ spät ihre genetische Selbständigkeit erlangt haben. 


\section{ZUSAMMENFASSUNG}

1. Der respiratorische Stoffwechsel der euryhalinen Amphipoden Gammarus locusta (L.), G. oceanicus Segerstråle, G. salinus Spooner, G. zaddachi Sexton und G. duebeni LILljEвoRg wurde in einer Durchflußapparatur auf polarographischem. Weg bei einer Temperatur von $15^{\circ} \mathrm{C}$ untersucht.

2. Bei allen fünf Arten wurden die Beziehungen zwischen Sauerstoffverbrauch $(y)$ und Körpergewicht $(x)$ in Abhängigkeit vom Salzgehalt (30\% und 10\%) geprïf und die Parameter der allometrischen Funktion $y=a \cdot x^{b}$ ermittelt (vgl. Tab. 1).

3. Der Regressionskoeffizient $b$, der die Größenabhängigkeit des Stoffwechsels kennzeichnet, weist artspezifische Unterschiede auf und ist abhängig vom Salzgehalt. Dieser zeichnet sich - mit Ausnahme von $G$. duebeni-bei einer Salinität von 30\% durch höhere Werte aus als bei $10 \%$ und ist in allen Fällen signifikant verschieden. Die Größenabhängigkeit des Stoffwechsels liegt im Bereich zwischen einer Gewichts- und einer Oberflächenproportionalität bzw. sogar darunter $(b=\sim 1-0,6)$.

4. Ein interspezifischer Vergleich des Faktors $a$, der die aus der Gesamtheit der Meßwerte berechnete Atemgröße von der Gewichtseinheit charakterisiert, ergibt, daß die Stoffwechselintensität in der Reihenfolge von G. locusta über G. oceanicus, G. salinus, G. zaddacbi bis zu G. duebeni fortschreitend abnimmt. Der durchschnittliche $\mathrm{O}_{2}$-Bedarf von Flohkrebsen mit einem Lebendgewicht von $0,1 \mathrm{~g}$ reicht bei $30 \%$ von $17,1 \mathrm{~mm}^{3} / \mathrm{h}$ ( $G$. locusta) bis zu $7,1 \mathrm{~mm}^{3} / \mathrm{h}$ (G. duebeni).

5. Die Veränderungen des $\mathrm{O}_{2}$-Verbrauchs nach einem sprunghaften Salinitätswechsel und der zeitliche Ablauf der Salzgehaltsanpassung wurden unter vergleichenden Gesichtspunkten untersucht. In Abhängigkeit von der Salinitätstoleranz der einzelnen Arten erfolgte eine Überführung von $10 \%$ in $30 \%$, von $30 \%$ in $45 \%$, von $30 \%$ in $10 \%$ und von $10 \%$ in $3 \%$.

6. Bei einem Wechsel aus verdünnten in konzentriertere Medien geht der Adaptationsprozeß wesentlich rascher vonstatten und ist mit geringeren Anderungen der Atmungsintensität verknüpt als bei Uberführungen in umgekehrte Richtung. Die Anpassungszeiten bis zum Erreichen eines neuen, gleichbleibenden Stoffwechselniveaus liegen $z$ wischen 3 und ungefähr 30 Stunden. $G$. duebeni verfügt über ein besseres Kompensationsvermögen als die anderen Arten, unter denen G. locusta die relativ geringste Regulationskapazität aufweist.

7. Bei Nahrungsentzug sinkt die Stoffwedhselrate. Messungen an $G$. oceanicus haben ergeben, daß die Atmungsintensität nach 20-24 Stunden gegenüber den Ausgangswerten um ca. $15 \%$ abfällt und sich auch innerhalb der folgenden 5 Tage nur unwesentlich verringert.

8. Der Aktivitätsstoffwechsel adulter Flohkrebse beträgt etwa das $2^{1 / 2}-3$ fache des Ruheumsatzes. Unter Grundumsatzbedingungen kann eine ausgeprägte Rhythmik der Ventilationsbewegungen der Pleopoden zutage treten.

9. Während der Häutung nimmt die $\mathrm{O}_{2}$-Aufnahme um das $2,2-$ bis 3,9 fache des mittleren Normalverbrauchs zu. Bei $G$. locusta wurden die höchsten, bei $G$. duebeni die niedrigsten Stoffwechselsteigerungen verzeichnet.

10. Verschiedene stoffwechselphysiologische Aspekte, insbesondere das Problem der Salzgehaltsanpassung und der damit verbundenen osmo- und ionenregulatorischen 
Prozesse, werden diskutiert. Die Stoffwechselleistungen der einzelnen GammarusArten werden verglichen und zu ihren Umweltansprïchen in Beziehung gesetzt.

Danksagungen. Herr Prof. Dr. F. KRüGER gestattete mir, die rechnerischen Auswertungen an einem Wang Mini-Computer vorzunehmen, der ihm als Leihgabe von der Deutschen Forschungsgemeinschaft zur Verfügung gestellt wurde. Die Kollegen Dr. M. Hoppenhert und Dr. D. SrEBERS förderten die Fertigstellung der Arbeit durch kritische Diskussionen. Fräulein M. MüHLENKamp assistierte bei der Durchführung der Experimente und deren Auswertung. Herr J. Marschall übernahm die Anfertigung der Zeichnungen. Allen genannten Mitarbeitern der Biologischen Anstalt Helgoland bin ich für ihre Hilfe sehr zu Dank verpflichtet.

\section{ZITIERTE LITERATUR}

Alr, M. A. \& STEELE, V. J., 1962. Metabolic rates of the amphipod Gammarus oceanicus (Arthropoda, Crustacea, Gammaridae) from two latitudes, at various light intensities and temperatures in the laboratory. J. zool. Soc. India 14, 4-11.

BARNES, H. \& BARNES, M., 1963. The relation of water uptake and oxygen consumption of the body tissues to the molting cycle in Balanus balanoides (L.). Crustaceana 6, 62-68.

- - 1969. Seasonal changes in the acutely determined oxygen consumption and effect of temperature for three common cirripedes, Balanus balanoides (L.), B. balanus (L.) and Chthamalus stellatus (PonI). J. exp. mar. Biol. Ecol. 4, 36-50.

BeAdle, L. C. \& CRAGG, J. B., 1940. Studies on adaptation in Gammarus spp. I. Regulation of blood and tissues and the problem of adaptation to fresh water. J. exp. Biol. 17, 153-163.

Bertalanffy, L. von, 1957. Quantitative laws in metabolism and growth. Q. Rev. Biol. 32, $217-231$

BuLNHEIM, H.-P., 1969. Zur Analyse geschlechtsbestimmender Faktoren bei Gammarus duebeni (Crustacea, Amphipoda). Zool. Anz. (Suppl.) 32, 244-260.

- 1971. Entwicklung, Obertragung und Parasit-Wirt-Beziehungen von Thelobania herediteria sp. n. (Protozoa, Microsporidia). Z. Parasitkde 35, 241-262.

- 1972. On sex-determining factors in some euryhaline Gammarus species. Proc. 5th Europ. Symp. mar. Biol.; Piccin, Padova, 115-130.

Costrow, J. D., Jr. \& Bookнout, C. G., 1958. Molting and respiration in Balanus improvisus var. denticulata Broch. Physiol. Zool. 31, 271-280.

Culver, D. C. \& Poulson, T. L., 1971. Oxygen consumption and activity in closely related amphipod populations from cave and surface habitats. Am. Mid1. Nat. 85, 74-84.

DEHNEL, P. A., 1960. Effect of temperature and salinity on the oxygen consumption of two intertidal crabs. Biol. Bull. mar. biol. Lab., Woods Hole 118, 215-249.

- 1962. Aspects of osmoregulation in two species of intertidal crabs. Biol. Bull. mar. biol. Lab., Woods Hole 122, 208-227.

Dennert, H. G., Dennert, A. L., Kant, P., Pinkster, S. \& Stock, J. H., 1969. Upstream and downstream migrations in relation to the reproductive cycle and to environmental factors in the amphipod, Gammarus zaddachi. Bijdr. Dierk. 39, 11-43.

DuERR, F. G., 1967. Changes in the size-metabolic rate relationship of Lymnaea stagnalis appressa SAY produced by digenetic trematode parasitism. Comp. Biochem. Physiol. 20, 391-398.

Eucken, A. \& Wicke, E., 1958. Grundriß der physikalischen Chemie. Geest \& Portig, Leipzig, $740 \mathrm{pp}$.

Fincham, A. A., 1972. Rhythmic swimming and rheotropism in the amphipod Marinogammarus marinus (LEACH). J. exp. mar. Biol. Ecol. 8, 19-26.

FisH, J. D. \& PREECE, G. S., 1970. The ecophysiological complex of Bathyporeid pilose and B. pelagica (Crustacea: Amphipoda). I. Respiration rates. Mar. Biol. 5, 22-28. 
Flfmister, L. J. \& Fitemtster, S. C., 1951. Chloride ion regulation and oxygen consumption in the crab Ocypode albicans (Bosq.). Biol. Bull. mar. biol. Lab., Woods Hole 101, 259-273.

FloRey, E., 1970. Lehrbuch der Tierphysiologie. Thieme, Stuttgart, 574 pp.

Forsman, B., 1951. Studies on Gammarus duebeni Linl], with notes on some rockpool organisms in Sweden. Zool. Bidr. Upps. 29, 215-237.

Fox, H. M. \& Simmonds, B. G., 1933. Metabolic rates of aquatic arthropods from different habitats. ]. exp. Biol. 10, 67-74.

Frost, R., SAloum, R. \& Kleinhorz, L. H., 1951. Effect of sinus gland and eyestalk removal on oxygen consumption of Astacus. Anat. Rec. 111, 270.

Gamble, J. C., 1970. Effect of low dissolved oxygen concentrations on the ventilation rhythm of three tubicolous crustaceans, with special reference to the phenomenon of intermittent ventilation. Mar. Biol. 6, 121-127.

Gilchrist, B. M., 1956. The oxygen consumption of Artemia salina (L.) in different salinities. Hydrobiologia 8, 54-65.

Gleichmann, U. \& Lübbers, D. W., 1960. Die Messungen des Sauerstoffdruckes in Gasen und Flüssigkeiten mit der Pt-Elektrode unter besonderer Berüdksidhtigung der Messung im Blut. Pflügers Arch. ges. Physiol. 271, 431-455.

GreEN, E. J. \& CARRITT, D. E., 1967. New tables for oxygen saturation of seawater. J. mar. Res. 25, 140-147.

Gross, W. J., 1957. An analysis of response to osmotic stress in selected decapod Crustacea. Biol. Bull. mar. biol. Lab., Woods Hole 112, 43-62.

Hagerman, L., 1970. The oxygen consumption of Crangon vulgaris (Fabricius) (Crustacea, Natantia) in relation to salinity. Ophelia 7, 283-292.

HALCROW, K. \& BOYD, C. M., 1967. The oxygen consumption and swimming activity of the amphipod Gammarus oceanicus at different temperatures. Comp. Biochem. Physiol. 23, 233-242.

Hartog, C. DEN, 1964. The amphipods of the deltaic region of the rivers Rhine, Meuse and Scheldt in relation to the hydrography of the area. Part III. The Gammaridae. Neth. J. Sea Res. 2, 407-457.

Heinemann, F., 1964. Der Gewebestoffwechsel einheimischer Dekapoden und seine Bedeutung für ihre Biologie und Okologie. Zool. Jb. (Abr. allg. Zool. Physiol. Tiere) 71, 89-116.

Hemmingsen, A. M., 1960: Energy metabolism as related to body size and respiratory surfaces, and its evolution. Rep. Steno meml Hosp. 9 (2), 1-110.

HoppenHeIT, M., 1969. Strahlenbiologische Untersuchungen an Gammariden (Crustacea, Amphipoda). Helgoländer wiss. Meeresunters. 19, 163-204.

Hynes, H. B. N., 1954. The ecology of Gammarus duebeni LiLljeBorg and its occurrence in fresh water in western Britain. J. Anim. Ecol, 23, 38-84.

JANSSON, B.-O. \& KällANDER, C., 1968. On the diunal activity of some littoral peracarid crustaceans in the Baltic Sea. J. exp. mar. Biol. Ecol. 2, 24-36.

JAŻDŻEwski, K., 1970. Gammarus inaequicauda STock in the Baltic Sea (Amphipoda, Gammaridea). Crustaceana 19, 216-217.

KING, E., 1965. The oxygen consumption of intact crabs and excised gills as a function of decreased salinity. Comp. Biochem. Physiol. 15, 93-102.

Kinne, O., 1952. Zur Biologie und Physiologie von Gammarus duebeni LrLl. V: Untersuchungen über Blutkonzentration, Herzfrequenz und Atmung. Kieler Meeresforsch. 9, 134-150.

- 1954. Die Gammarus-Arten der Kieler Bucht. Zool. Jb. (Abt. Syst. Okol. Geogr. Tiere) 82, 405-425.

- 1959. Ecological data on the amphipod Gammarus duebeni. A monograph. Veröff. Inst. Meeresforsch. Bremerh. 6, 177-202.

- 1961. Growth, molting frequency, heart beat, number of eggs, and incubation time in Gammarus zaddachi exposed to different environments. Crustaceana 2, 26-36.

- 1964. Non-genetic adaptation to temperature and salinity. Helgoländer wiss. Meeresunters. 9, 433-458. 
- 1971. Salinity: Animals - Invertebrates. In: Marine Ecology, Ed. by O. KINNE. WileyInterscience, London, 1 (2), 821-995.

KRoG, J., 1954. The influence of seasonal environmental changes upon the metabolism, lethal temperature and rate of heart beat of Gammarus limnaeus (SMTrH) taken from an Alaskan lake. Biol. Bull. mar. biol. Lab., Woods Hole 107, 397-410.

KRÜGER, F, 1964. Versuche ïber die Abhängigkeit der Atmung von Arenicola marina (Annelides Polychaeta) von Größe und Temperatur. Helgoländer wiss. Meeresunters. 10, 38-63.

Lehmann, G., 1956. Das Gesetz der Stoffwechselreduktion und seine Bedeutung. In: Handbuch der Zoologie. Hrsg. von W. Kükenthal \& T. Krumbach. De Gruyter, Berlin, 8, $4(5), 1-32$.

LockwOod, A. P. M., 1961. The urine of Gammarus duebeni and G. pulex. J. exp. Biol, 38, 647-658.

- 1964. Activation of the sodium uptake system at high blood concentrations in the amphipod Gammarus duebeni. J. exp. Biol. 41, 447-458.

- 1965. The relative losses of sodium in the urine and across the body surface in the amphipod, Gammarus duebeni. J. exp. Biol. 42, 59-69.

- 1970. The involvement of sodium transport in the volume regulation of the amphipod crustacean, Gammarus duebeni. J. exp. Biol. 53, 737-751.

- \& ANDrEws, W. R. H., 1969. Active transport and sodium fluxes at moult in the amphipod, Gammarus duebeni. J. exp. Biol. 51, 591-605.

Löwenstern, O., 1935. The respiratory rate of Gammarus chevrewxi in relation to differences in salinity. J. exp. Biol. 12, 217-221.

LORTS, B., 1956. The effects of salinity changes on the respiratory rate of the prawn, Palaemonetes varians (LEACH). J. exp. Biol. 33, 730-736.

LüBbers, D. W. \& Windisch, E., 1963. Die Messung hoher Sauerstoffdrucke in kleinen Gasoder Flüssigkeitsmengen mit der Pt-Elektrode. Pflïgers Arch, ges. Physiol. 276, 429-434.

LuKacsovics, F., 1958. Vergleichende Untersuchungen über den Sauerstoffverbrauch von Amphipoden aus stehenden und fließenden Gewässern. Annls Inst. biol. Tihany 25, 57-67.

MCFARLAND, W. N. \& Pickens, P. E., 1965: The effects of season, temperature and salinity on standard and active oxygen consumption of the grass shrimp, Palaemonetes vulgaris (SAY). Can. J. Zool. 43, 571-585.

McLuskY, D. S., 1969. The oxygen consumption of Corophium volutator in relation to salinity. Comp. Biochem. Physiol, 29, 743-753.

Movaghar, C.-A., 1964. Verbreitung und OKologie der Amphipoden im Elbe-Aestuar. Arch. Hydrobiol. (Suppl.) 29, 97-179.

Newell, R. C., Ahsanullah, M. \& Pye, V. I., 1972. Aerial and aquatic respiration in the shore crab Carcinus maenas (L.). Comp. Biochem. Physiol. 43 A, 239-252.

OpITz, E. \& Bartezs, H., 1955. Gasanalyse. In: Handbuch der physiologisch- und pathologisch-chemischen Analyse. Hrsg. von E. F. Hoppe-Seyler \& H. Thier felder. Springer, Berlin, 2, 183-311.

Paranjape, M. A., 1967. Molting and respiration of euphausiids. J. Fish. Res. Bd Can. 24, $1229-1240$.

Petres, H., 1935: Uber den Einfluß des Salzgehaltes im Außenmedium auf den Bau und die Funktion der Exkretionsorgane dekapoder Crustaceen. Z. Morph. Okol. Tiere 30, 355-381.

Pinkster, S., Denneri, A. L., Stock, B. \& Stock, J. H., 1970. The problem of European freshwater populations of Gammarus duebeni LILLJEBORG, 1852. Bijdr. Dierk. 40, 116-147.

PotTs, W. T. W. \& PARRY, G., 1964. Osmotic and ionic regulation in animals. Pergamon Press, Oxford, 423 pp.

Prosser, C. L., 1958. The nature of physiological adaptation. In: Physiological adaptation. Ed. by C. L. Prosser. Am. Physiol. Soc., Washington, D.C., 167-180.

RaO, K. P., 1958. Oxygen consumption as a function of size and salinity in Metapenaeust monoceros FAB. from marine and brackish-water environments. J. exp. Biol. 35, 307-313.

RiNG, K., Schlecht, S., EschweILER, W. \& Kutscher, J., 1969. Eine Elektrode zur kontinuierlichen Messung des Gelöstsauerstoffs $\left(p \mathrm{O}_{2}\right)$ in Fermenterkulturen. Arch. Mikrobiol. $65,48-60$. 
Roberts, J., 1957. Thermal acclimation of metabolism in the crab Pacbygrapsus crassipes Randall. I. The influence of body size, starvation, and molting. Physiol. Zool. 30, 232-242.

Roux, C., 1972. Les variations de la courbe métabolisme/température de Gammarus lacustris G. O. Sars (Crustacé, Amphipode) sous l'influence de divers facteurs écologiques. Crustaceana (Suppl.) 3, 287-296.

- \& Roux, A.-L., 1967. Température et métabolisme respiratoire d’espèces sympatriques de Gammares du groupe pulex (Crustacés Amphipodes). Annls Limnol. 3, 3-16.

SACHS, L., 1972. Statistische Auswertungsmethoden. Springer, Heidelberg, 545 pp.

SCHÄPERCLAUS, W., 1925. V. Untersuchungen über den Stoffwechsel, insbesondere die Atmung niederer Wassertiere. Z. Fisch. 23, 167-280.

Scheer, B. T. \& ScherR, M. A. R., 1954. The hormonal control of metabolism in crustaceans. VIII. Oxygen consumption in Leander serratus. Pubbl. Staz. zool. Napoli 25, 419-426.

SCHLIEPER, C., 1929. Über die Einwirkung niederer Salzkonzentrationen auf marine Organismen. Z. vergl. Physiol. 9, 478-514.

- 1931. Uber das Eindringen mariner Tiere in das Süßwasser. Biol. Zbl. 51, 26-37.

- 1936. Die Abhängigkeit der Atmungsintensität der Organismen vom Wassergehalt und kolloidalen Zustand des Protoplasmas. Biol, Zbl. 56, 87-94.

SchWABE, E., 1933. Uther die Osmoregulation verschiedener Krebse (Malacostracen). Z. vergl. Physiol. 19, 183-236.

SCUdAMORE, H. H., 1947. The influence of the sinus glands upon molting and associated changes in the crayfish. Physiol. Zool. 20, 187-208.

SEGal, E. \& Burbanck, W. D., 1963. Effects of salinity and temperature on osmoregulation in two latitudinally separated populations of an estuarine isopod, Cyathura polita (Strmpson). Physiol. Zool. 36, 250-263.

SEGERSTRÅLE, S., 1947. New observations on the distribution and morphology of the amphipod, Gammarus zaddacbi SEXTON, with notes on related species. J. mar. biol. Ass. U.K. 27, 219-244.

- 1959. Synopsis of data on the crustaceans Gammarus locusta, Gammarus oceanicus, Pontoporeia affinis, and Corophium volutator (Amphipoda Gammaridea). Commentat, biol. 20, $1-23$.

SExton, E. W., 1912. Some brackish-water Amphipoda from the mouths of the Weser and the Elbe, and from the Baltic. Proc. zool. Soc. Lond. 1912, 656-665.

Siebers, D., Lucu, C., Sperling, K.-R. \& Ererlein, K., 1972. Kinetics of osmoregulation in the crab Carcinus maenas. Mar. Biol. 17, 291-303.

SpaArgaren, D. H., 1972. Osmoregulation in the prawns Palaemon serratus and Lysmata seticaudata from the Bay of Naples. Neth. J. Sea Res. 5, 416-439.

Spooner, G. M., 1947. The distribution of Gammarus species in estuaries. Part I. J. mar. biol. Ass. U.K. 27, 1-52.

- 1951. On Gammarus zaddachi oceanicus Segerstråle. J. mar. biol. Ass. U.K. 30, 129-147.

STоск, J. H., 1967. A revision of the European species of the Gammarus locusta-group (Crustacea, Amphipoda). Zool. Verh., Leiden 90, 3-56.

- Nijssen, H. \& Kant, P., 1966. La répartition écologique des Amphipodes de la famille des Gammaridae dans la Slack et son estuaire. Bull. zool. Mus. Univ. Amsterdam 1, 19-30.

- \& Pinkster, S, 1970. Irish and French freshwater populations of Gammarus duebeni subspecifically different from brackish water populations. Nature, Lond. 228, 874-875.

Suomalainen, P., 1958. Der Sauerstoffyerbrauch finnischer Gammarus-Arten. Verh. int. Verein. theor. angew. Limnol. 13, 873-878.

Sutcliffe, D. W., 1967a. Sodium regulation in the amphipod Gammarus duebeni from brackish-water and fresh-water localities in Britain. J. exp. Biol. 46, 529-550.

- 1967b. Sodium regulation in the fresh-water amphipod, Gammarus pulex (L.). J. exp. Biol. 46, 499-518.

- 1968. Sodium regulation and adaptation to fresh water in gammarid crustaceans. J. exp. Biol. 48, 359-380. 
- 1971a. Sodium influx and loss in freshwater and brackish-water populations of the amphipod Gammarus duebeni LiLlJEBorg. J. exp. Biol. 54, 255-268.

- 1971b. Regulation of water and some ions in gammarids (Amphipoda). II. Gammarus pulex (L.). J. exp. Biol. 55, 345-355.

- 1971c. Regulation of water and some ions in gammarids (Amphipoda). III. Three euryhaline species. J. exp. Biol. 55, 357-369.

- \& SHaw, J., 1967. The sodium balance mechanism in the fresh-water amphipod, Gammarus lacustris Sars. J. exp. Biol. 46, 519-528.

- -, 1968. Sodium regulation in the amphipod Gammarus duebeni LiluyEBorg from freshwater localities in Ireland. J. exp. Biol. 48, 339-358.

Theede, H., 1964. Physiologische Unterschiede bei der Strandkrabbe Carcinides maenas L. aus der Nord- und Ostsee. Kieler Meeresforsch. 20, 179-191.

Trotanr, D., 1954. La consommation d'oxygène de quelques Gammaridae. C. r. hebd. Séanc. Acad. Sci., Paris 239, 1540-1542.

Wälshe-Maetz, B. M., 1956. Contrôle respiratoire et métabolisme chez les Crustacés. Vie Milieu 7, 523-543.

WEBER, R. E. \& MARREWIJK, W. J. A. VAN, 1972. Free amino acids in the shrimp Crangon crangon and their osmoregulatory significance. Neth. J. Sea Res. 5, 391-415.

- \& SpaArgaren, D. H., 1970. On the influence of temperature on the osmoregulation of Crangon crangon and its significance under estuarine conditions. Neth. J. Sea Res. 5, $108-120$.

Wautier, J. \& Trotanr, D., 1960. Contribution à l'étude du métabolisme respiratoire de quelques Gammaridae. Ann. Stat. Centr. Hydrobiol. 8, 9-49.

WERNTZ, H. O., 1963. Osmotic regulation in marine and fresh-water gammarids (Amphipoda). Biol. Bull, mar. biol. Lab., Woods Hole 124, 225-239.

WESEMEIER, H., 1960. Untersuchungen über Stoff wechselreduktionen. Z. vergl. Physiol. 43, $1-28$.

Wieser, W., 1965. Uber die Häutung von Porcellio scaber LATr. Zool. Anz. (Suppl.) 28, $178-195$.

Wolvekamp, H. P. \& Waterman, T. H., 1960. Respiration. In: Physiology of Crustacea. Ed. by T. H. Waterman. Acad. Press, New York, 1, 35-100.

WoYNarovich, E., 1961. Sauerstoffverbrauch einiger Wassertiere bei verschiedenen Temperaturen. Verh. int. Verein. theor. angew. Limnol. 14, 1014-1018.

Anschrift des Autors: Dr. H.-P. Bulnheim

Biologische Anstalt Helgoland

(Zentrale)

2 Hamburg 50

Palmaille 9

Bundesrepublik Deutschland 